University of Rhode Island

DigitalCommons@URI

Open Access Dissertations

1982

\title{
AN INVESTIGATION OF SOME FACTORS CONTROLLING SOLUTE TRANSPORT ACROSS LIQUID MEMBRANES
}

Andrea Panaggio

University of Rhode Island

Follow this and additional works at: https://digitalcommons.uri.edu/oa_diss

\section{Recommended Citation}

Panaggio, Andrea, "AN INVESTIGATION OF SOME FACTORS CONTROLLING SOLUTE TRANSPORT ACROSS LIQUID MEMBRANES" (1982). Open Access Dissertations. Paper 161.

https://digitalcommons.uri.edu/oa_diss/161

This Dissertation is brought to you for free and open access by DigitalCommons@URI. It has been accepted for inclusion in Open Access Dissertations by an authorized administrator of DigitalCommons@URI. For more information, please contact digitalcommons-group@uri.edu. 
AN INVESTIGATION OF SOME FACTORS CONTROLLING

SOLUTE TRANSPORT ACROSS LIQUID MEMBRANES

BY

ANDREA PANAGGIO

A DISSERTATION SUBMIITED IN PARTIAL FULFILLMENT OF THE REQUIREMENTS FOR THE DEGREE OF DOCTOR OF PHILOSOPHY

IN

PHARMACEUTICAL SCIENCES

UNIVERSITY OF RHODE ISLAND 1982 
DOCTOR OF PHILOSOPHY DISSERTATION

OF

ANDREA PANAGGIO

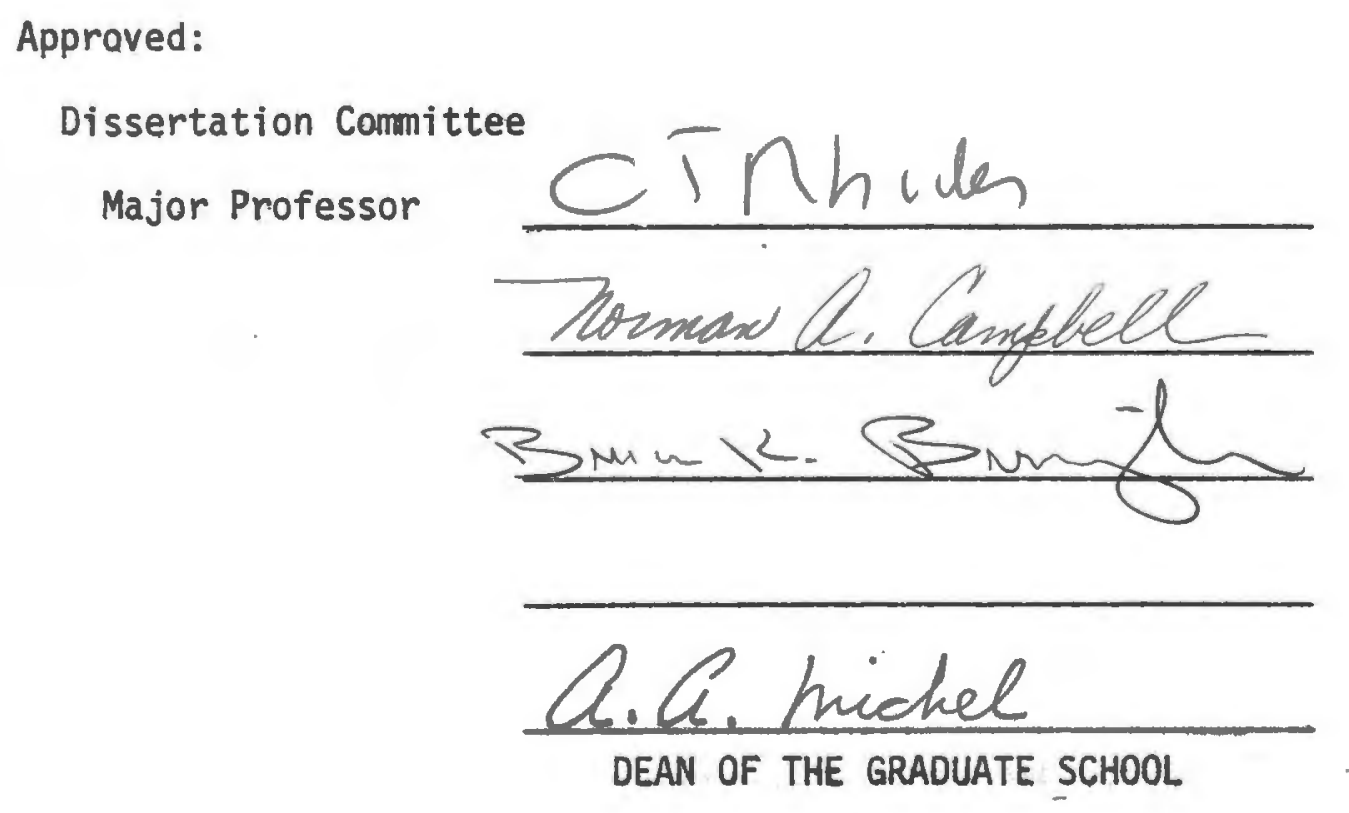

UNIVERSITY OF RHODE ISLAND

1982 


\section{DEDICATION}

To my parents for their patience and support. 


\section{ABSTRACT}

Accurate, precise, sensitive and reproducibie experimental protocols using high pressure liquid chromatographic assay tecnniques (HPLC) have been developed to study some fundamental factors controlling the transport of solutes across liquid membranes. A simple model, previously developed by Rhodes and co-workers, used to describe the kinetics of solute transport across liquid membranes was evaluated and some formulation aspects of emulsions for use as liquid membranes were studied.

The removal of solutes from an external aqueous phase by a liquid membrane was found to be influenced by a number of factors including initial solute concentration, $\mathrm{pH}$ of the external aqueous phase, and temperature of the system. As the initial concentration of solute increased, the apparent transport rate constants decreased. This was observed for both single and multicomponent systems. Increasing the $\mathrm{pH}$ of the external aqueous phase resulted in reduced transport rate constants for salicylic acid. This is in agreement with the pHpartition theory. An attempt was made to predict the uptake of salicylic acid as a function of $\mathrm{pH}$ using a Computer simulation Modeling Program. Lack of quantitative agreement between experimental and predicted data is attributed to the complexity of the systems and insufficiency of the model. Salicylic acid uptake increased as a function of temperature in apparent agreement with the Arrhenius 
equation. Similar'y, the uptake of phenobarbita? by a liquid membrane system appeares to obey the Arrhenius relationship until a "critical" temperature or temperature range was reached (about $43^{\circ} \mathrm{C}$ ). Above the critical temperature, the transport rates of phenobarbital decreased as temperature was increased. Increasing the viscosity of the liquid membrane at the critical temperature did not help to improve transport at this temperature range.

Alterations in the physical properties of liquid membranes resulted in changes in the rate of solute uptake. Increasing viscosity and oil/ water ratio both resulted in reduced transport rate constants for the uptake of solutes. These effects can be readily interpreted using classical diffusion theory. Liquid membranes which were frozen and thawed were satisfactorily used for drug removal indicating the surprising robustness of these systems.

Studies reported in this thesis indicate that previous use of liquid membranes for solute transport does not materially affect their further use as sinks. These systems also demonstrated the ability to remove simultaneously two solutes from a multicomponent system at rates which were of the same magnitude as that measured in one solute systems.

Method of manufacture and appropriate surfactant blends were determined to be key factors in the development of emulsions for use as liquid membranes formulated using only Generally Regarded As Safe components (GRAS). Liquid membrane systems prepared by the investigator using only GRAS components would need substantial further development work before commercialization could be effected; however, they do appear to merit additional studies for a number of possible pharmaceutical uses. 


\section{ACKNOWLEDGMENTS}

The author wishes to express her most sincere thanks and appreciation to Dr. Christopher T. Rhodes for his enthusiasm, interest, guidance, support, and patience throughout this project. The suggestions and assistance provided by the faculty members of the College of Pharmacy, University of Rhode Island, are grätefully acknowledged, especially committee members Dr. Norman A. Campbe11, for his ir:terest and encouragement and Dr. Bruce K. Birmingham for his contributions.

The author also wishes to acknowledge in a special way Dr. Joan M. Lausier, honorary committee member, whose interest, encouragement, opinions, and editing were greatly appreciated.

Much thanks and appreciation are extended to Dr. John M. Frankenfeld of Exxon Research Engineering Company for providing the author with liquid membrane, and to Sylvia Stoner for her patience in typing this manuscript. 


\section{TABLE OF CONTENTS}

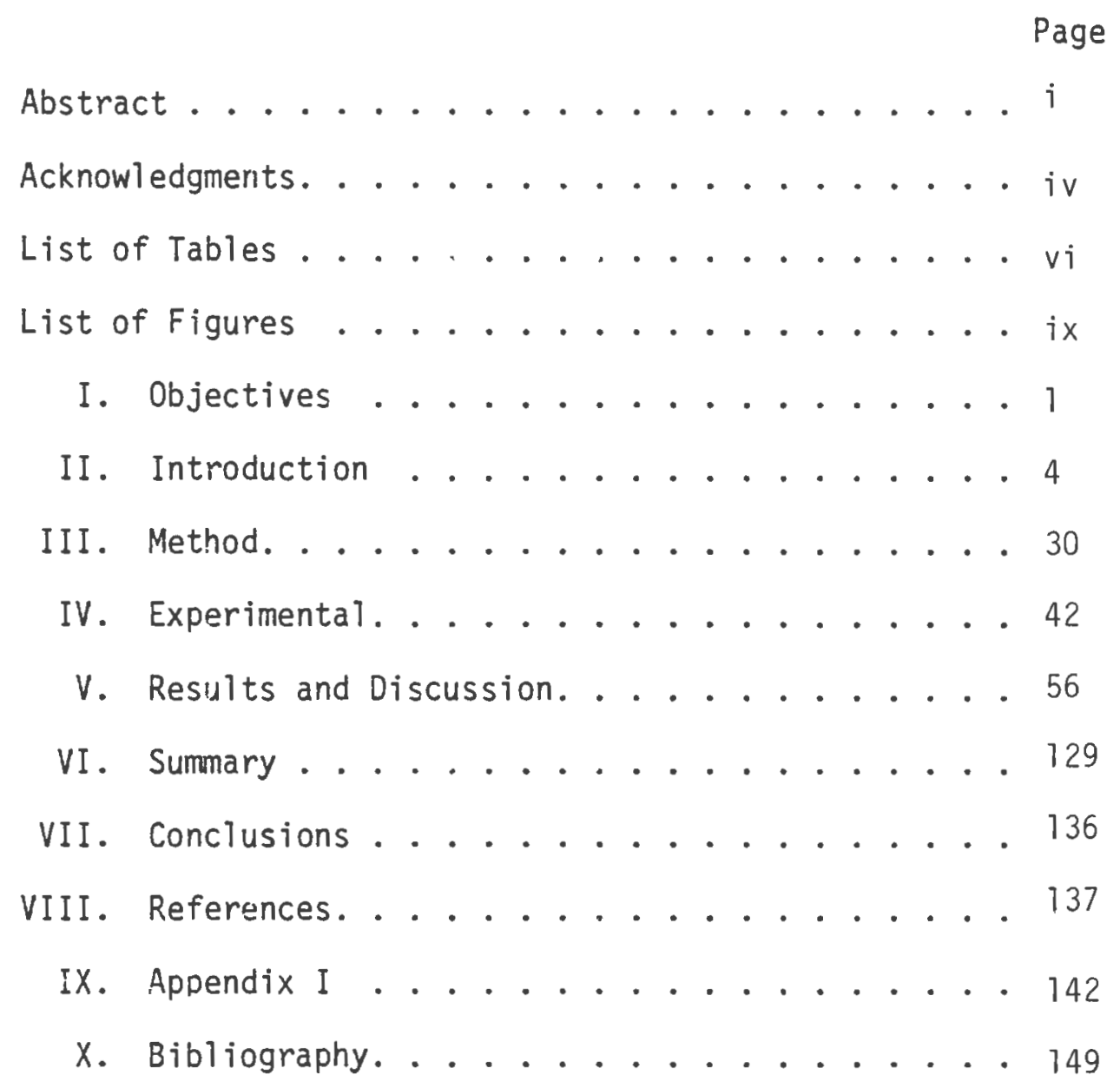




\section{LIST OF TABLES}

Page

I. Formula for Water-in-0i1-in-Water Emulsion (19). . . 38

II. Order of Subsequent Solute Uptake. . . . . . . . . 49

III. Co-Uptake of Solutes with Different Initial Concentrations ............ . . 49

IV. Co-Uptake of Solutes with Equimolar Initial Concentrations........... 50

V. Preliminary Formulations and Formulations of Emulsions Prepared Using the HLB Approach . . . 52

VI. Emulsions Prepared as Variations of the Davis Formula (19)........... . 55

VII. Comparison of Apparent $\beta$ Values from One and Two Compartment Model Fits .......... 59

VIII. Comparison of Detected Drug in the Donor Phase Using Two Analytical Methods .......... 62

IX. Comparative Sensitivity of UV Spectrophotometry

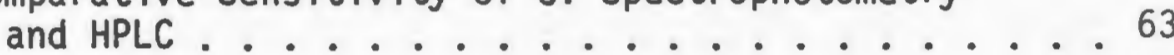

X. Accuracy and Precision of HPLC Technique . . . . . 65

XI. Comparison of Percent Acetylsalicylic Acid $1.0 \mathrm{~g} / 1$ Remaining in External Donor Phase After Treatment with Liquid Membrane at Various Times in Six Replicate Experiments . . . . 69

XII. Comparison of Percent Acetyl salicylic Acid $0.5 \mathrm{~g} / 1$ Remaining in External Donor Phase After Treatment with Liquid Membrane at Various Times in Five Replicate Experiments. . . . . 70

XIII. Apparent $\beta$ Rate Constants for Each Replicate Run of Acetylsalicylic Acid $1.0 \mathrm{~g} / 1$ Uptake. . . . . 74

XIV. Apparent $\beta$ Rate Constants for Each Replicate Run of Acetylsalicylic Acid $0.5 \mathrm{~g} / 1$ Uptake . . . . 75 


\section{LIST OF TABLES (Continued)}

Page

$X V$. Mean Apparent $\beta$ Rate Constants for Uptake of Various Mclar Concentrations of Salicylic Acid....... 75

XVI. Mean Apparent $\beta$ Rate Constants for Uptake of Salicylic Acid $1.0 \mathrm{~g} / 1$ by Liquid Membranes with Various $0 i 1 /$ Water Ratios............. 79

XVII. Mean Apparent $\beta$ Rate Constants for the Uptake of Acetylsalicylic Acid $1.0 \mathrm{~g} / 1$ as a Function of Donor Phase pH.............. 82

XVIII. Mean Apparent $\beta$ Rate Constants for the Uptake of Salicylic Acid $1.0 \mathrm{~g} / 1$ as a Function of $\mathrm{pH} . . . . .884$

XIX. Mean Apparent $\beta$ Rate Constants for the Uptake of Salicylic Acid $1.0 \mathrm{~g} / 1$ as a Function of Liquid Membrane Viscosity . . . . . . . . . . 87

$X X$. Mean Apparent $\beta$ Rate Constants for the Uptake of Salicylic Acid $1.0 \mathrm{~g} / 1$ as a Function of

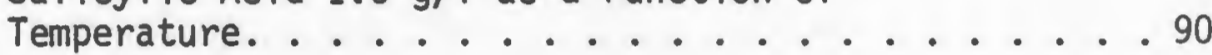

XXI. Mean Rate Constant for the Uptake of Phenobarbital $0.6 \mathrm{~g} / \mathrm{l}$ as a Function of Temperature................ 95

XXII. Mean Rate Constants for the Uptake of Phenobarbital $0.6 \mathrm{~g} / 1$ as a Function of Viscosity at a Critical

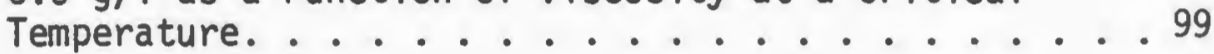

XXIII. Estimated Mean Percent of Drug Remaining in the External Aqueous Phase Following Exposure to Liquid Membrane for 120 Minutes................. 102

XXIV. Mean Apparent $\beta$ Rate Constants for the Uptake of Salicylic Acid $1.0 \mathrm{~g} / 1$ Following Phenobarbital Uptake ................... 108

XXV. Mean Apparent Rate Constants for the Co-Uptake of Drug I in a Multicomponent System with Drug II When Initial Molar Concentrations are Different. . . 112

XXVI. Mean Percent of Drug I Remaining in the External Aqueous Phase at 120 Hinutes After Co-iptake with Drug II................. ...113 


\section{LIST OF TABLES (Continued)}

XXVII. Mean Apparent B Rate Constants for the Co-Uptake of Solutes in Equimolar Initial Concentrations in a Multicomponent System and Mean Percent Remaining in the External Aqueous Phase at 120 Minutes . . . . . 114

XXVIII. Mean Apparent $\beta$ Rate Constants for the Co-Uptake of Drugs as a Function of Liquid Membrane Oil/Water

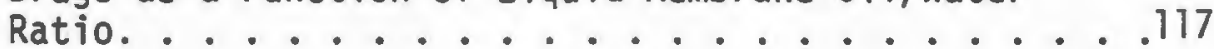

XXIX. A Comparison of the Apparent $B$ Rate Constants for the Uptake of Salicylic Acid $1.0 \mathrm{~g} / 1$ Using a Freeze/ Thaw Stressed Liquid Membrane Versus the Mean Apparent $\beta$ Rate Constants for the Uptake of Salicylic Acid $1.0 \mathrm{~g} / 1$ Under Ideal Conditions. . . . 122

XXX. Visual Analysis, Determination of Emulsion Type, and Evaluation of Potential to Form a Liquid Membrane for Those Emulsions Prepared Using the HLB Approach. .123

$X X X I$. Determination of Viscosity and Characterization of Flow for Those Emulsions Prepared Using the HLB Approach ................. . . . . 25

XXXII. Percent Salicylic Acid Remaining in the External Aqueous Phase with Time After Exposure to Emulsions Manufactured Using the HLB Approach. . . . . . . . 126 
LIST OF FIGURES

Page

1. Removal of Ammonia From Waste Water Using A Liquid

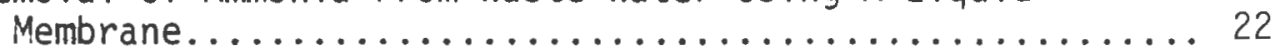

2. Kinetic Model Developed to Rationalize Transport of

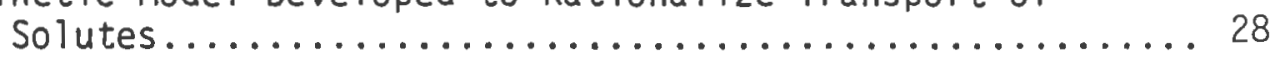

3. Experimental Sequence for Liquid Membrane Reuse......... 46

4. Experimemntal Sequence for Subsequent Uptake of Solutes... 48

5. Typical HPLC Chromatogram for Acetylsalicylic Acid and

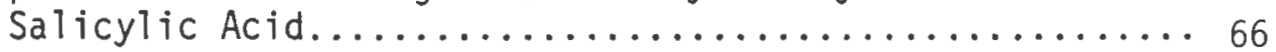

6. Typical HPLC Chromatogram for Phenobarbital.......... 67

7. Acetylsalicylic Acid $1.0 \mathrm{~g} / 1$ Removal As A Function of Time -- Six Replicate Experiments................

8. Acetylsalicylic Acid $0.5 \mathrm{~g} / 1$ Removal As A Function of Time -- Five Replicate Experiments............... 71

9. Mean Apparent $\beta$ Rate Constants As A Function of Initial Salicylic Acid Concentration................... 72

10. Salicylic Acid $1.0 \mathrm{~g} / 1$ Removal As A Function of Time Using Liquid Membranes with Different 0i1/Water Ratios.. 76

11. Mean Apparent $\beta$ Rate Constants for Salicylic Acid Removal As A Function of Liquid Membrane Oil/Water Ratio....... 77

12. Mean Apparent $\beta$ Rate Constants for Acetylsalicylic Acid Removal As A Function of External Aqueous Phase pH..... 80

13. Salicylic Acid $1.0 \mathrm{~g} / 1$ Removal As A Function of Time Using External Aqueous Phases with Different pHs..... 81

14. Mean Apparent $\beta$ Rate Constants for Salicylic Acid $1.0 \mathrm{~g} / 1$ Removal As A Function of External Aqueous Phase pH..... 85

15. Mean Apparent $\beta$ Rate Constants for Salicylic Acid $1.0 \mathrm{~g} / 1$ Removal As A Function of Liquid Membrane Viscosity..... 86 
LIST OF FIGURES (Continued)

Fage

16. Salicylic Acid $1.0 \mathrm{~g} / 1$ Removal As A Function of Time at Various Temperatures............................

17. Percent of Salicylic Acid in External Aqueous Phase As $A$

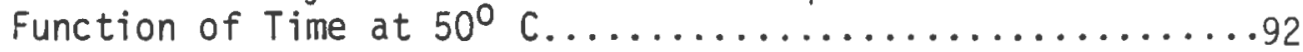

18. Log of Mean Apparent $\beta$ Rate Constants for Salicylic Acid Removal As A Function of Reciprocal Absolute Temperature...93

19. Phenobarbital $0.6 \mathrm{~g} / 1$ Removal As A Function of Time at Various Temperatures............................96

20. Log of Mean a Rate Constants for Phenobarbital $0.6 \mathrm{~g} / 1$ Removal As A Function of Reciprocal Absolute Temperature...97

21. Log of Mean B Rate Constants for Phenobarbital $0.6 \mathrm{~g} / 1$ Removal As A Function of Reciprocal Absolute Temperature...98

22. Mean Rate Constants for Phenobarbital $0.6 \mathrm{~g} / 1$ Removal Using Liquid Membranes with Different Viscosities at the

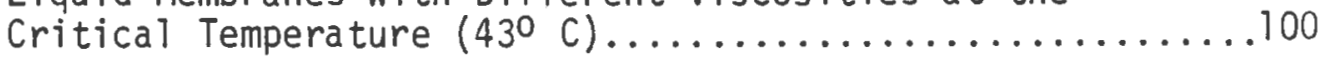

23. Subsequent Uptake of Phenobarbital $0.6 \mathrm{~g} / 1$ As A Function of Time Following Salicylic Acid $1.0 \mathrm{~g} / 1$ Removal at $50^{\circ}$ C..104

24. Subsequent Uptake of Salicylic Acid $1.0 \mathrm{~g} / 1$ As A Function of Time Following Phenobarbital $0.6 \mathrm{~g} / 1$ Removal at $37.5^{\circ} \mathrm{C} .105$

25. Subsequent Uptake of Salicylic Acid $1.0 \mathrm{~g} / 1$ As A Function of Time Following Phenobarbital $0.6 \mathrm{~g} / 1$ Removal at $45^{\circ} \mathrm{C} .{ }^{106}$

26. Concentration of Salicylic Acid in External Aqueous Phase As A Function of Time During Subsequent Uptake of

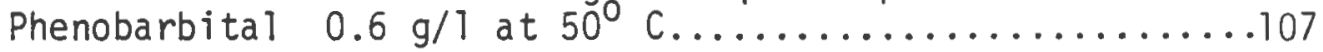

27. Concentration of Phenobarbital in External Aqueous Phase As A Function of Time During Subsequent Uptake of

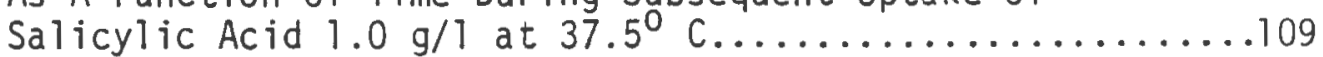

28. Mean Apparent $\beta$ Rate Constants for Phenobarbital $0.6 \mathrm{~g} / 1$ Removal in a Multicomponent System As A Function of Liquid Membrane 0il/Water Ratio........................118

29. Salicylic Acid $1.0 \mathrm{~g} / 1$ Removal As A Function of Time Using Frozen/Thawed Liquid Membranes..................... 120 


\section{LIST OF FIGURES (Continued)}

30. Beer's Plot for Acetylsalicylic Acid Using UV

Spectrophotometry.......................... 143

31. Beer's Plot for Salicylic Acid Using UV Spectrophotometry...144

32. Beer's Plot for Phenobarbital Using UV Spectrophotometry.....145

33. Beer's Plot for Acetylsalicylic Acid Using HPLC............. 146

34. Beer's Plot for Salicylic Acid Using HPLC............... 147

35. Beer's Plot for Phenobarbital Using HPLC............... 148 


\section{OBJECTIVES}

The recent development of liquid membrane systems has prompted studies exploring their usefulness $(3-16)$. These systems, which may be either water-in-oil-in-water $(w / 0 / w)$ or $0 i l$-in-water-in-0i\} (o/w/o) type emulsions (10), have been investigated for use in areas such as blood oxygenation $(3,4)$, encapsulation of enzymes $(5,6)$, the purification of waste water $(11-14)$, the separation of hydrocarbons $(2,7,11)$, and the removal of toxic substances from the human body $(8,9)$. An area of major interest is the potential use of liquid membrane systems in cases of drug overdose $(15,16)$. Studies have demonstrated the rapid uptake of phenobarbital and aspirin from either $\mathrm{pH} 2$ or 7 buffer solutions (15).

As evidenced by the literature, extensive work has been done in the area of liquid membrane application. Although the effect of some of the physical and chemical properties of liquid membrane systems on drug transport have been studied (15), only recently has work been initiated in the area of development of kinetic models to rationalize the transport of solutes across liquid membranes. Yang and Rhodes investigated the formulation variables of liquid membranes on transport (17), while Chilamkurti and Rhodes studied the effect of molecular structure on transport across liquid membranes (18). Some preliminary work was done by Yang and Rhodes on the effect of electrolytes on the transport of water through the liquid membranes (17). 
In their work, Yang and Rhodes were able to determine the macro rate constants ( $\alpha$ and $\beta$ ) for the systems studied, but they were unable to determine the micro rate constants. For some systems Chilamkurti and Rhodes were able to establish micro rate constants (18), while in other systems their attempts were unsuccessful.

All of the work reported by Rhodes and his co-workers concerned systems in which the internal aqueous phase of a liquid membrane functioned as a sink, capturing solute which crossed the liquid membrane from the external donor phase. There are a limited number of reports in the literature on the formulation of multiple emulsions functioning as reservoirs for drug delivery and the difficulties encountered in their development (19-22). The choice of oil and emulsifying agents are of particular importance when the stability and in vivo use of these emulsions is considered. The nature of the internal aqueous phase is another potential source of emulsion instability if the proper emulsifying agents and additives are not included in the formulation. A delicate balance of all system components is required for the successful formulation of liquid membranes.

The purpose of this project was to develop a precise and reproducible protocol for studying the kinetics of solute transport across liquid membranes and to use this protocol to study some fundamental factors controlling liquid membrane solute transport. This project was developed also to evaluate a simple model designed to rationalize some aspects of the kinetics of liquid membrane transport 
and to investigate the formulation of liquid membranes for possible in vivo use for drug uptake and drug delivery. 


\section{INTRODUCTION}

Three areas are considered here. The first and second deal with the general aspects of the kinetics of drug transport and emulsion technology, thereby providing background information for discussions of 1 iquid membranes.

A. Principles of Drug Transport

1. Transport Processes

"A membrane transport system is created where there is passage of a solute across a membrane" (23). This passage may be active, passive, or facilitated. Active transport is a process which requires energy to allow movement of a solute against a concentration or activity gradient. Facilitated transport makes use of additives(i.e. carrier) to improve the rate of solute transport over the rate of transport expected from passive diffusion $(11,12,14)$. Most drugs seem to be transported by passive diffusion.

Passive transport, or free diffusion, may be described as the random movement of liquid or solute molecules from a solution of high concentration into a pure solvent until equilibrium is reached. The driving force in this transport is the concentration gradient $(23,24)$. Considering passive transport thermodynamically, this process is driven entropically. The system undergoes an overall decrease in free energy due to an increase in entropy in accordance with the 
following equation:

$$
\Delta G=\Delta H-T \Delta S+\sum \mu_{i} d n_{i} \quad \text { Equa:ion (i) }
$$

Where: $\Delta G=$ change in free energy,

$$
\begin{aligned}
\Delta H & =\text { change in enthalpy, } \\
T & =\text { absolute temperature }\left({ }^{O} K\right), \\
\Delta S & =\text { change in entropy, } \\
\mu & =\text { chemical potential of a comconent }, \\
n & =\text { component. }
\end{aligned}
$$

Passive diffusion may be described by Fick's first law (23), which states:

$$
d q / d t=-D A(d c / d x) \text { Equation (2) }
$$

Where: $\quad d q / d t=$ rate of solute transfer (number of moles of solute crossing the membrane per unit of time),

$D=$ diffusion coefficient,

$A=$ area of membrane available for diffusion, $\mathrm{dc} / \mathrm{dx}=$ concentration gradient/thickness of membrane.

A number of factors influence the passive diffusion of a drug across a membrane. These include the partition coefficient, pKa and molecular weight of the drug, and the $\mathrm{pH}$ of the medium.

The partition coefficient, the ratio of distribution of solute between two immiscible liquids, is expressed as follows:

$$
k=C_{1} / C_{2} \quad \text { Equation (3) }
$$

Where $C_{1}$ and $C_{2}$ are the equilibrium concentrations of solute in liquid 1 (nonaqueous) and liquid 2 (aqueous) and $k$ is the partition coefficient. The rate of solute transport is directly porportional to its partition coefficient for a particular system.

Most drugs are weak acids or weak bases which exist as both ionized and unionized species in solution. The extent of ionization, 
which depends in the pka of the solute and the pir of the solution: may be calculated using the Henderson-Hasselsach equation (24):

$$
p H=p K a+\log (\text { salt/acid) Equation (4) }
$$

Where: $\mathrm{pH}=$ reciprocal $\mathrm{log}$ of the hydrogen ion concentration of tive solution $\left(\log 1 /\left[\mathrm{H}^{+}\right]\right)$,

$$
\begin{aligned}
& \text { pKa }=\text { dissociation constant of the solute, } \\
& (\text { salt/acid })=\text { molar concentration of ionized species/molar }
\end{aligned}
$$

concentration of unionized species.

Since the unionized species has a greater partition coefficient than the ionized species, it would be expected that as the fraction of unionized solute increases, the rate of solute transport increases. Acidic drugs are transported most easily from solutions with a low $\mathrm{pH}$ since the drug does not ionize to any great extent. As the $\mathrm{pH}$ of the solution increases, the extent of ionization increases, thereby reducing the percent of unionized drug available to transfer across a membrane. Conversely, basic drugs are transported best from solutions with a high $\mathrm{pH}$. As the $\mathrm{pH}$ of the solution increases, the extent of ionization decreases and the percent of drug available for transport increases. The pH-partition theory as it applies to the absorption of drugs in the stomach and small intestines. has been studied in both humans (26) and animals $(27-30)$.

\section{Kinetics of Transport}

The amount of solute transported from one compartment to another per unit of time, or the rate of solute transfer, may be expressed using the specific rate constant, $k$, for that process. A reaction may proceed by zero, first, or second order kinetics with $k$ calculated accordingly. 
Whereas for zero-order kinetics the rate at which the reaction proceeds is independent of solute concentration, the rate of a firstorder reaction is directly proportional to concentration, as expressed by the following equation:

$$
d x / d t=-k C \quad \text { Equation (5) }
$$

Where: $d x / d t=$ rate of transfer,

$$
k=\text { first-order rate constant, }
$$$$
C=\text { transferable concentration. }
$$

By rearranging Equation 5 and integrating between time 0 and time $t$, the following equation is obtained:

$$
\log C_{t}=\log C_{0}-(k t / 2.303) \quad \text { Equation (6) }
$$

Where: $c_{0}=$ concentration at time 0 ,

$$
\begin{aligned}
& c_{t}=\text { concentration at time } t, \\
& k=\text { first-order rate constant, } \\
& t=\text { time. }
\end{aligned}
$$

By plotting $\log C$ against time, a straight line is obtained, the slope of which is k. Equation (6) permits the calculation of concentration at any time, $t$, when $k$ is known.

The effect of temperature on the rate of a reaction may be described by the Arrhenius equation (25);

$$
k=A e^{-E_{a} / R T} \quad \text { Equation (7) }
$$

Where: $k=$ specific rate constant,

$$
A=\text { frequency factor (frequency of collisions between }
$$
molecules),

$$
E_{a}=\text { energy of activation (minimum kinetic energy a molecule }
$$
must possess in order to undergo a reaction), 


$$
\begin{aligned}
& R=\text { gas constant }\left(1.987 \mathrm{cal} / \mathrm{mole}^{\circ} \mathrm{K} \text { or } 8.314 \text { Joul } \mathrm{e} / \mathrm{mol} \mathrm{e}^{\circ} \mathrm{K}\right), \\
& T=\text { absolute temperature }\left({ }^{\circ} \mathrm{K}\right) .
\end{aligned}
$$

By plotting the $\log$ of $k$ against $1 / T$, a straight line with a negative slope is obtained which indicates that with a rise in temperature, the rate of a reaction increases. As a general rule, the rate of a reaction may increase by a factor of 2-3 with every $10^{\circ}$ rise in temperature. The slope of the 1 ine $\left(E_{a} / 2.303 R\right)$ may be used to calculate the energy of activation $\left(E_{a}\right)$ for the system. $E_{a}$ may be calculated also using the following equation:

$$
\log \left(k_{1} / k_{2}\right)=E_{a} / 2.303 R\left[\left(T_{2}-T_{1}\right) / T_{1} T_{2}\right] \text { Equation (8) }
$$

Where: $k_{1}=$ rate constant for reaction at temperature $T_{1}\left({ }^{\circ} \mathrm{K}\right)$, $k_{2}=$ rate constant for reaction at temperature $T_{2}\left({ }^{\circ} \mathrm{K}\right)$. Most pharmaceutical reactions have an energy of activation of $8-20 \mathrm{kcal} / \mathrm{mole}$.

Although the Arrhenius equation is useful in predicting shelf-life from accelerated stability testing, there are some situations for which the equation is not valid. The slope may change at high temperatures or over long periods of time because of physical alterations of a dose form, redistribution and/or evaporation of moisture from a dose form or container, secondary degradative pathways, or activation of ingredients which will enhance the degradation of a product (24). At low temperatures accelerated decomposition due to dehydration of the system by freezing or due to contamination by microorganisms may result in a change of slope (25). 
B. Emulsion Tecrnolsgy

1. Definiticn of Emulsions

"An emulsion is a thermodynamical ly unstabie system consisting of at least two immiscible liquic prases, one which is dispersed as globules in the other licuid phase" (25). The two immiscible phases of an emulsion consist of a polar liquid such as water and a nonpolar liquid such as oil. These systems may be classified according to which phase is dispersed or internal in the continuous or external phase. If the aqueous phase is dispersed in the oil phase, the emulsion is classified as a water-in-oil (w/o) type. Alternatively, in cases where the oil phase is dispersed throughout a continuous aqueous phase, the emulsion is an oil-in-water $(0 / w)$ type. Complex or multiple emulsions may be formed by dispersing an emulsion in another liquid which becomes the final external phase. In this way, a w/o emulsion dispersed in an aqueous phase forms a water-inoil-in-water $(w / O / w)$ multiple emulsion. If an $0 / w$ emulsion is dispersed in a oil phase, an oil-in-water-inoil (o/w/o) emulsion results. Generally, the particle size diameter of the dispersed phase of a two phase emulsion may range from 0.01 to $100 \mu \mathrm{m}$ with the majority of them being 0.1 to $10 \mu \mathrm{m}$. 
2. Consiaration of tne Hydrophilic-Lipophilis Balance (HLB) Approach to Emulsion Formulation

In order to render àn emulsion stable, another component must be added to the mixture of immiscible liquids. Surfaceactive agents are employed to stabilize emulsions through their ability to act at the interface or at the point where the two 1 iquid meet. At the interface, surface-active agents are adsorbed and ". . . lower the surface free energy associated with the dispersed phase making the emulsion energetically more stable" (31). Details of the theory of interfacial phenomena have been discussed extensively with regard to their theoretical and practical aspects in emulsion technology, and they have been the subject of books and review articles in colloid chemistry (32-36).

Surface-active agents may be classified as anionic, cationic, nonionic, and ampholytic. Naturally occurring substances such as acacia, sterols, and phospholipids are used widely as surface-active agents. In pharmaceutical technology frequently employed classes of nonionic surfaceactive agents include Spans and Tweens, with Myrjs and Bryjs used to a lesser extent. Spans are sorbitan esters; Myrjs and Tweens are polyoxyethylene sorbitans. 
Surface-active agents may be classitieut accsoring to the ratio of their hydrophilic and lipophilic criaracteristics. In pharmaceutical preparations, this ratio, known as the hydrophilic-lipophilic balance (HLB), is a number between 1 and 18 . Those materials with HLB values below 9 are considered lipophilic in character; whereas those with HLB values above 11 are hydrophilic. Intermediate substances fall into the range of 9 to 11. Those emulsifying agents in the range of 3 to 6 tend to produce $w / 0$ emulsions and those in the range of 8 to 18 produce $0 / w$ emulsions. Since Spans are lipophilic in nature, they have low HLB values. By contrast, Tweens and Myrjs possess hydrophilic characteristics and therefore have high HLB values.

The HLB approach in emulsion formulation aids in the choice of emulsifiers for a particular system. By determining the required HLB of the components or combination of components in an emulsion and matching it to a single emulsifying agent or blend of emulsifying agents with the same HLB, a suitable formulation may be developed (31). When a blend of emulsifying agents is desired, the ratio of emulsifiers required to achieve a particular HLB may be determined by the following equation:

$$
\begin{array}{ll}
\% A=100\left(X-H L B_{B}\right) /\left(H L B_{A}-H L B_{B}\right) & \text { Equation }(9) \\
\% B=100-\% A & \text { Equation }(10)
\end{array}
$$


Where $A$ and $B$ ire the surface-active agents composing the blend and $X$ equals the required H'B.

An important consideration when choosing a blend of surfactants at a required HLB is the chemical type of each emulsifying agent. The success of a formulation depends upon the fatty acid ester and the extent of esterification of the emulsifier (31). Achieving correct emulsion type is of great importance in emulsion formulation. One of the major factors governing emulsion type is the ratio of solubility of the surface-active agent in the oil and aqueous phases. In general, the phase in which the emulsifying agent is most soluble becomes the external phase. An emulsifying agent which readily disperses in the oil phase will be expected to produce a w/o emulsion.

The procedures involved in the use of the HLB approach in emulsion formulation have been described in detail in The HLB System, A TimeSaving Guide to Emulsifier Selection by the Atlas Chemical Industries, Inc. (31). Further consideration pertaining to the chemistry of emulsifying agents and the theories of emulsification have been discussed thoroughily by a number of authors $(25,32-34)$.

3. Preparation of Emulsions

The details of emulsion preparation must be planned carefully in advance of the manufacturing process in order to achieve a stable product. The components of a pharmaceutical emulsion must be selected with regard for patient safety and for efficiency $(33,37)$. Addition order and temperature of the components as well as the manufacturing process will determine the final characteristics of the system $(33,38-41)$. 
Emulsions may be prepared by either the inversion or noninversion technique. The noninversion technique involves dissolving the emulsifier in the aqueous phase and subsequently adding the oil, thereby producing an $0 / w$ emulsion. The process may be extended by continued addition of oil until an inversion point is reached and the emulsion becomes $w / 0$. Another noninversion process involves dissolving the emulsifying agent in the oil phase and adding it to the aqueous phase with an $0 / w$ emulsion resulting. Dispersing the emulsifying agent in the $0 i l$ and then adding the aqueous phase produces a.w/o emulsion. Continued addition of water to this system results in an inversion and an $0 / \mathrm{w}$ emulsion (33).

The emulsification process may be accomplished spontaneously (42), by simple stirring, homogenization, colloid milling, or ultrasonic vibrations (33). In research and small scale production, simple stirring or shaking methods are employed frequently. Blenders, turbine mixers, mortar and pestles, and closed containers may be used. For scale-up operations and in industrial manufacturing, homogenizers are used. Adjustments in a formulation are often required in the scale-up production of an emulsion. An emulsion made by stirring or shaking may be a noticeably different product when made by homogenization. Homogenized products usually have a smailer overall particle size diameter. The particle size and particle size distribution of an emulsion are important in predicting the stability of the system. In general, an emulsion with a smaller mean particle size will exhibit greater physical stability than those with a larger mean particle size. 
Both the quality ar: ouartity of the oil and emu? sifying agents will influence the stabiity of the final emulsion. The concentration and type of emulsifying agent have been shown to have an effect on the particle size distribution of an emulsion (43). Pharmaceutical emulsions intended for cral and parenteral use must be formulated with nontoxic, nonirritating components which are generally regarded as safe (GRAS). Minerai oil, soybean oil, many Spans, Tweens, Myrjs, and phospholipids are examples of components which may be contained in products intended for human use.

In some instances it may be advantageous to include additional agents such as stabilizers, thickening agents, antioxidents, and preservatives in a formulation to insure stability of the finished product. Thickening agents and stabilizers may have particular importance when the aqueous phase contains ions. The viscosity of an emulsion may be regulated by the addition of substances to either the internal or external phase. Whereas the addition of a miscible liquid to the external phase will decrease the viscosity, the incorporation of soluble materials into that phase will increase the viscosity of the emulsion. A more viscous emulsion results when the ratio of internal to external phase is increased.

Instability of an emulsion may be observed as creaming, cracking or breaking, or phase inversion. Due to the formation of floccules in the dispersed phase, creaming, the separation of an emulsion into two phases, occurs. The emulsion may be restored to its original form by gentle shaking. Creaming may be explained using Stokes' law (Equation 11) (32). 


$$
v=\frac{2 r^{2}\left(\rho-\rho_{0}\right) g}{9_{r_{0}}} \quad \text { Equation (ii) }
$$

Where: $v=$ sedimentation of spherical particles,

$r=$ radius of particles,

$\rho=$ density of the internal phase,

$\rho_{0}=$ density of the external phase,

$g$ = acceleration due to gravity,

$\eta_{0}=$ viscosity of the dispersion medium.

Since the radius term in the equation is squared, particle size has the greatest effect on the rate of creaming. A smaller particle size results in a slower rate of creaming. With reference to particle size distribution, Stokes' law assumes that the particles are spherical and uniform in shape. Deviations from this ideal condition affect the creaming of a system. Differences between the density of the internal and external phases will influence the rate and direction of particle settling. If the density of the internal phase is less than that of the external phase, a negative value for velocity is obtained. This indicates an upward settling or creaming of the particles. A positive velocity suggests a downward settling. If the emulsion viscosity is increased, the rate of settling will be slower. These aspects concerning Stokes' law are discussed in detail by a number of authors $(25,32-36)$.

Irreversible separation of an emulsion into two distinct phases is referred to as breaking or cracking. Particles of the dispersed phase coalesce as a result of destruction of the emulsifier film surrounding 
these particles (37). Vigorous agitation will not restore the system to its former state. When an emulsion has cracked, it is no longer pharmaceutically useful.

An unstable emulsion may be observed when phase inversion or the conversion of a system from one emulsion type to another occurs. Factors affecting phase inversion include the phase volume ratio of the system, $\mathrm{pH}$, temperature, the emulsifying agents, and the addition of other materials to the system. This irversion may render an undesirable product in terms of palatability and drug release rate.

4. Evaluation of Emulsions

Emulsions may be evaluated in terms of flow (viscosity), appearance (color, phase separation), particle size, and emulsion type.

In pharmaceutical formulations the flow of a product is important when considered in terms of administration and storage. It must pour easily for oral use, flow freely through tubing or a syringe for parenteral use, and spread easily for topical use. These properties should not change with time. The flow properties of an emulsion may be characterized through viscosity determinations. Viscosity readings may be made using any one of a number of instruments including two common ones, the Ostwald and Brookfield viscometers. Becher, in Emulsion Theory and Practice (33), explains the uses of the various viscometers as well as the theory and determination procedures for surface and interfacial viscosity.

Determination of emulsion type may be made by either the phase dilution, conductivity, or dye solubility methods (33). The phase 
dilution method is explained in Section III of this paper. The conductivity method is based upon the ability of the external phase to conduct an electric current. Whereas the external oil phase of an w/o emulsion will not conduct electricity, the external aqueous phase of an oíw emulsion will conduct electricity. Considering the dye solubility method, a water soluble dye will diffuse through the external aqueous phase of an $0 / w$ emulsion and color the system. A w/o emulsion will not be colored when a water soluble dye is added to the system.

Methods of particle size determination have been investigated and reviewed extensively by a number of authors, including $(33,36,37$, 42, 44-47). Although time consuming, microscopic determination of particle size using an ocular micrometer is a reliable method. Photomicroscopy offers the advantage of obtaining a permanent record. Other techniques employed in particle size analysis of emulsions include sedimentation, light scattering and transmission $(33,44,45)$ and the use of the Coulter Counter $(44,45,47,48)$.

The use of accelerated aging studies and factors designed to impose a stress on an emulsion have been considered extensively with regard to stability $(33,36,37,49-54)$. The use of heat, cyclic temperatures, freezing/thawing $(37,46)$, centrifugation $(46)$, and the addition of differing quantities of various electrolytes $(36,54)$ have all been studied to determine their effects on the stability of emulsions. Heat and cyclic temperature treatments impose some of the greatest stress on an emulsion system. 


\section{Pharmaceutical Uses of Emulsions}

Emulsions find uses in a number of different areas including the paint, agricultural, food, and pharmaceutical industries. Emulsions used pharmaceutically may be administered orally, topically, or parenterally. Topically applied emulsions in the form of creams or lotions serve as vehicles for medicaments or as cosmetic bases. Parenteral lipid emulsions are used in long term total parenteral nutrition (TPN) therapy. Orally administered emulsions are used to improve the palatability of oily bases for medicaments, for nutritional purposes such as dietary sources of fats, or to administer fat soluble vitamins. Other oral emulsions are used as laxatives or as radioopaque agents for diagnostic purposes. An area of recent interest is the oral use of multiple emulsions in pharmaceutics for both drug delivery and drug uptake (15-18). These emulsion systems are referred to as liquid membranes.

\section{Liquid Membranes}

1. Definition and Overview

Liquid membranes, formed by the dispersion of a two-phased emulsion in a third continuous liquid phase, were developed by $\mathrm{Li}$ at Exxon Research and Engineering Company in $1968(1,2)$. In these complex emulsion systems, the encapsulated or internal phase and the continuous external phase are miscible, but they are separated by a thin liquid film which is miscible with neither of these phases (14). This liquid film is the liquid membrane. 
There are two major types of liquid membrane systems. A water-inoil-in-water (w/o/w) system is formed by dispersing a w/o emulsion in a continuous aqueous phase. The dispersion of an $0 / w$ emulsion in an oil yields an oil-in-water-in-oil (o/w/o) liquid membrane system. $W / 0 / W$ systems have received more attention in terms of their potential applications, especially in pharmaceutics. When an emulsion is dispersed by agitation in a continuous phase, it breaks up into stable globule usually 0.2 to $2 \mathrm{~mm}$ in diameter. Each globule encapsulates aqueous phase droplets of 1 to $10 \mu \mathrm{m}$ in diameter. The formulation of the primary emulsion is important to the overall stability of the liquid membrane system $(19-21,55)$.

Considering the formulation of a w/o/w system, a w/o emulsion is formulated with the proper specifications. The internal aqueous phase may function as a sink to receive materials from the external aqueous phase or as a reservoir to release a substance into the external aqueous phase. The composition of the internal aqueous phase depends upon which of these functions it will assume. In either case the nature of the phase will contribute to the challenge of preparing a stable emulsion. In the selection of the oil phase the intended purpose of the emulsion must be considered. If the emulsion is for oral or parenteral use, the oil must fall with the GRAS specifications.

In order to maintain the overall stability of the liquid membrane system, surfactants, stabilizers, and viscosity-inducing agents may be added to either the primary emulsion or the continuous phase of the system. The size of the dispersed globules formed depends on the 
nature and concentration of the surfactants in the emulsion as well as on the viscosity and method of mixing (14). This, in turn, will determine the surface area available for the transport of solute either into or out of the internal aqueous phase. Additives to enhance the solubility and permeation rates of solutes through facilitated transport $(11,12)$ may be incorporated into the formulation also. Formulation factors pertaining to liquid membrane systems have been investigated in both the chemical $(2,13,14)$ and pharmaceutical industries (17).

2. Basic Separation Mechanisms Used with Liquid Membranes

Separation mechanisms as they apply to liquid membranes have been discussed by Frankenfeld, Cahn, and Li' (14) and are described below.

\section{a. Selective Permeation}

This simple mechanism, which was described by $L i$ in reference to the separation of hydrocarbons (2), is dependent only upon the selectivity of the liquid membrane to allow specific materials to pass through it.

b. Chemical Reaction Inside Droplet

This mechanism is based upon the diffusion of an unionized species with significant oil solubility (2) from an area of high concentration (external aqueous phase) through the liquid membrane and into the internal aqueous phase which contains a trapping agent. This process has been described by Matulevicius and Li (11) as a type of facilitated transport through maximization of the concentration gradient. The unionized species, through a chemical reaction with the contents of 
the internal phase, is converted to its ionized form, a form which does not readily transport, and is trapped within the internal phase. The concentration of transportable species is maintained at zero, thus creating a favorable concentration gradient. Acidic materials may be trapped by an encapsulated aqueous base. Conversely, a basic solute may be trapped by an encapsulated aqueous acid. Substances such as phenol (12), and phenobarbital and acetylsalicylic acid $(15,16)$ have been trapped by this method.

The removal of ammonia from waste water is a classic example used to illustrate this separation mechanism as depicted in Figure 1. Ammonia $\left(\mathrm{NH}_{3}\right)$, in a pH 9 external aqueous phase, exists predominantly in its unionized, lipophilic form. This species easily transfers from the external aqueous phase, through the liquid membrane, and into the internal aqueous acid phase where upon contact it is ionized to an oil insoluble ammonium ion $\left(\mathrm{NH}_{4}{ }^{+}\right)(13)$.

In addition to acidic or basic solutions, plasma proteins, activated charcoal, and specific antibodies have been proposed as possible trapping agents.

\section{c. Carrier in Membrane Phase or Facilitated Transport}

In the previous example, the oil solubility of the solute was an important factor in its transport through the liquid membrane. In order to assist in the transport of a solute through a liquid membrane by improving its solubility in the oil phase, a carrier may be used. The carrier, which is incorporated into the external aqueous phase, reversibly binds with the solute to form a complex capable of 
mosenumponsons $\mathrm{O}$

Hydroptiobsc-llydroph1lic

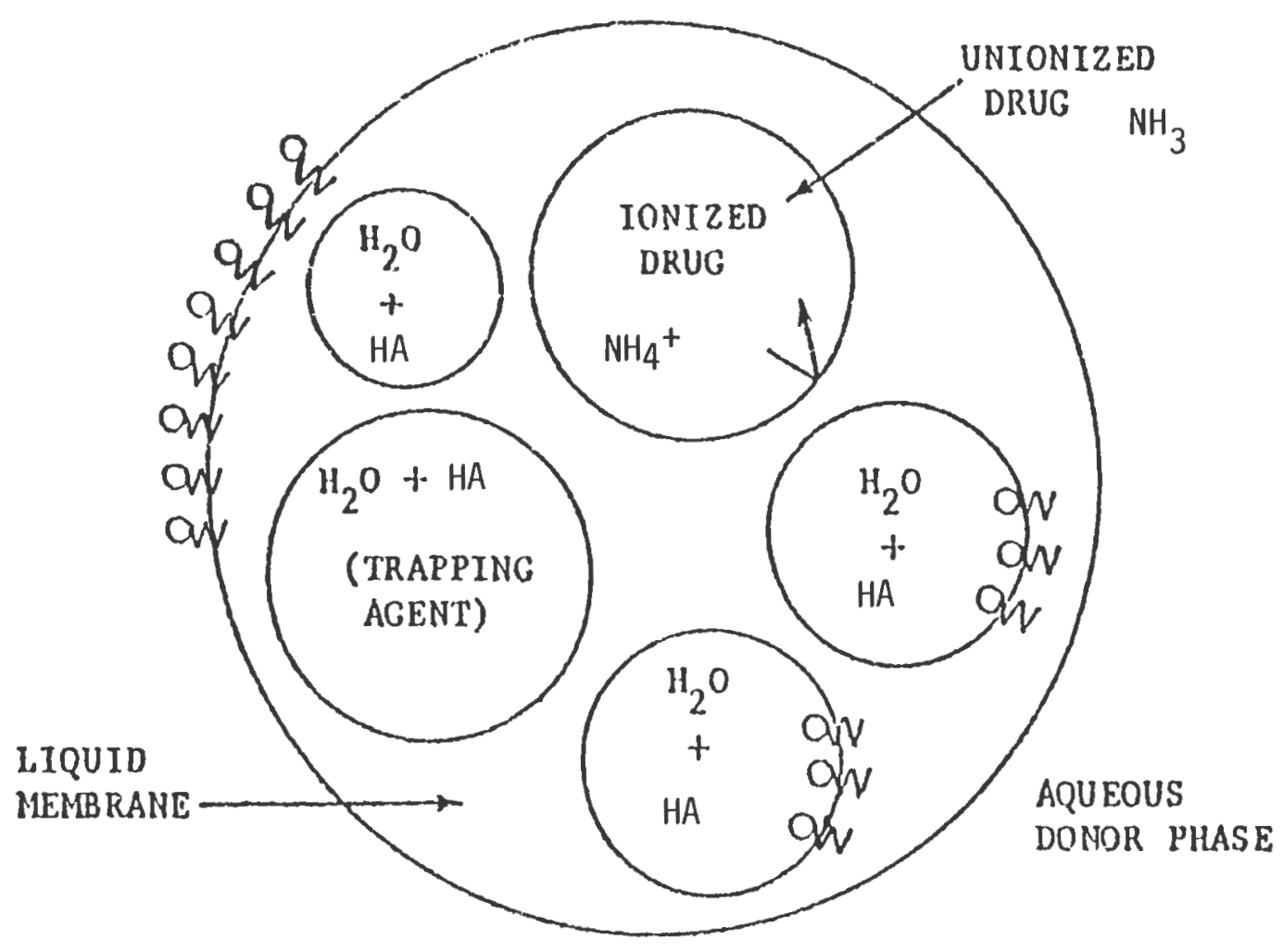

Fig. I Removal of Ammonia From Waste Water Using A Liquid Membrane 
diffusing through the liquid membrane. Once inside the internal aqueous phase, a "stripping" agent removes the solute from the carrier. Used in the transport of heavy metal ions (i.e. $\mathrm{Hg}^{+2}, \mathrm{Cr}^{+6}, \mathrm{Cd}^{+8}$, $\left.\mathrm{Cu}^{+2}\right)(13,14)$, this method is limited by the extent of suitable carriers (14). Carriers must be soluble in the membrane and compatible with the surfactants in a system (11).

d. Adsorption of Water-Insoluble Particles on Membrane Surface Absence of reports in the literature suggest that little work has been done in the area of adsorption of water-insoluble particles on the membrane surface as a mechanism for achieving separation (14).

\section{Applications of Liquid Membranes}

a. General Applications

Since the initial development of liquid membranes, they have been tested for a number of potential uses. In the area of waste water purification, liquid membranes have been studied with regard to their ability to reduce and separate nitrates and nitrites by encapsulated enzymes $(6,13)$, the extraction of heavy metals from waste water $(11,13,14)$, and the separation of phenols from waste water (12).

Liquid membranes are capable of separating hydrocarbons $(2,7,11)$ and have exhibited promise as a potential way of oxygenating blood by a less traumatic, more efficient means $(3,4)$. Research has been directed toward developing a liquid membrane which will serve as an adjunct to kidney dialysis through the removal of uremic toxins $(8,9)$. Enzyme encapsulation by 1 iquid membranes as a means of protecting enzymes from destructive materials or to inmobilize them also appear 
feasibie $(5,6,10)$. Liquid membranes have also been proposed for use in the pharmaceutical industry.

b. Pharmaceutical Applications

At the present time, reported studies in the literature pertaining to the use of liquid membranes in pharmaceutics are sparse. Liquid membranes have been proposed for use as sinks to trap drugs in the treatment of emergency drug overdose $(15,16)$ and for in vivo drug delivery systems $(19-21,55)$. The effect of formulation variables and molecular structure on the transport of drugs across liquid membranes al so have been investigated $(17,18)$.

The major emphasis of the work involving the use of liquid membranes as recipient sinks describes their proposed use in the emergency treatment of drug overdose $(15,16)$. Liquid membranes possess several distinct advantages over the usual methods of treating drug overdose.

The liquid membranes may be administered easily and in a single dose. Since they have the consistency and appearance of a milk shake and may be flavored, minimal patient resistance would be anticipated (i0). Using a stomach tube, the system may be administered even if the patient is unconscious (15).

The drug classes investigated in the emergency treatment of drug overdose were barbiturates and salicylates. Both of these classes have a high potential for being present in a drug overdose situation since both are easily accessible. Barbituric acid and its derivatives account for an estimated ten percent of poisoning deaths per year in 
the United States with approximate' $y 15$ percent of these deaths as suicides (56). Although the use of child-procf safety caps on aspirin containers has resulted in a decrease in aspirin poisoning deaths in children, accidental ingestion of this drug still occurs. This accounts for approximately 1.5 percent of the total accidental deaths due to drugs and medications in children five years of age and younger (56). At the present time there are no reports in the literature pertaining to the emergency treatment of drug overdose with liquid membranes and other classes of drugs.

The results of the in vitro work to evaluate the potential usefulness of liquid membranes for the rapid removal of drug from the gastrointestinal tract showed that $95 \%$ of the phenobarbital present in the external aqueous phase was removed within 5 minutes and essentially complete removal occurred in 10 minutes. The rate of acetylsalicylic acid uptake was slightly faster. The rate of uptake followed first order kinetics (16).

The rate of drug uptake by liquid membranes was observed to be influenced by variables introduced into the system. The viscosity of the liquid membrane proved to be a very important variable. As the viscosity of the membrane decreased, the rate of drug removal increased at the expense of the membrane integrity. Membranes composed of lower viscosity oil phases ruptured and leaked. It was observed that at higher temperatures the rate of uptake increased (16), and increasing the $\mathrm{pH}$ of the external aqueous phase slowed the rate but did not affect the completeness of drug removal (15). The presence of bile salts in the external aqueous phase had an adverse effect on 
drug removai (:5), and the ratio of liquid membrane to external acues:a phase was noted as an important variable influensing the rate of crug transport (1E).

As previousiy mentioned, the manufacture of a stable liquid membrane is a cnal'enging task. This is especially true for those liquid membrane systems proposed for use in pharmaceutics. For example, buffer solution trapping agents add electrolytes to this sensitive system which may be a source of instability (20). In order to insure a stable emulsion which will function as a liquid membrane, an optimum ratio of oil to surfactant must be determined. For pharmaceutical use, both of these components must be regarded as safe (GRAS).

More extensive studies on the effect of formulation variables on the transport of solutes across liquid membranes were conducted by Yang and Rhodes (17). Using acetylsalicylic acid and phenobarbital as model drugs, they evaluated the effect of liquid membrane oil to water ratio, the size the internal aqueous phase droplets, liquid membrane viscosity, and internal aqueous phase $\mathrm{pH}$ on solute transport. Confirming the results of earlier work, they found that the lower the membrane viscosity, the faster the rate of drug removal. Faster drug removal was observed also with membranes having smaller internal phase droplets. Increasing the $\mathrm{pH}$ of the internal aqueous phase resulted in more efficient acetylsalicylic acid removal from the external aqueous phase. 
Formulation variables have been considered by other investigators in attempts to formulate systems suitable for drug delivery. In general, it is agreed that the concentration and nature of the surfactants $(20,21,55)$, the incorporation of other additives into the formulation (19), and the composition of the internal aqueous phase greatly influence the successful manufacture of the finished product.

The effect of molecular structure on the transport of solutes across liquid membranes was investigated by Chilamkurti and Rhodes (18). The authors were able to reiate differences in rates of solute transport to molecular structure, to show that some ionic species are capable of transporting across the membrane, and to demonstrate the effect of solute ionization on transport.

The development of a two compartment kinetic model to rationalize the transport of solute from an external aqueous phase across a liquid membrane to an internal aqueous phase resulted from the work by Yang and Rhodes (17). The following equation describes the model

$$
c_{e} \frac{k_{12}}{k_{21}} c_{L M} \frac{k_{23}}{k_{32}} c_{i} \quad \text { Equation (12) }
$$

Where: $c_{e}=$ concentration of solute in external aqueous phase, $C_{L M}=$ concentration of solute in liquid membrane, $c_{i}=$ concentration of solute in internal aqueous phase, $k_{12}, k_{21}, k_{23}, k_{32}=$ first order micro rate constants.

Figure 2 depicts the scheme of transport using Equation (12).

The concentration of drug in the external aqueous phase at any time, $t$, may be determined by the following equation: 


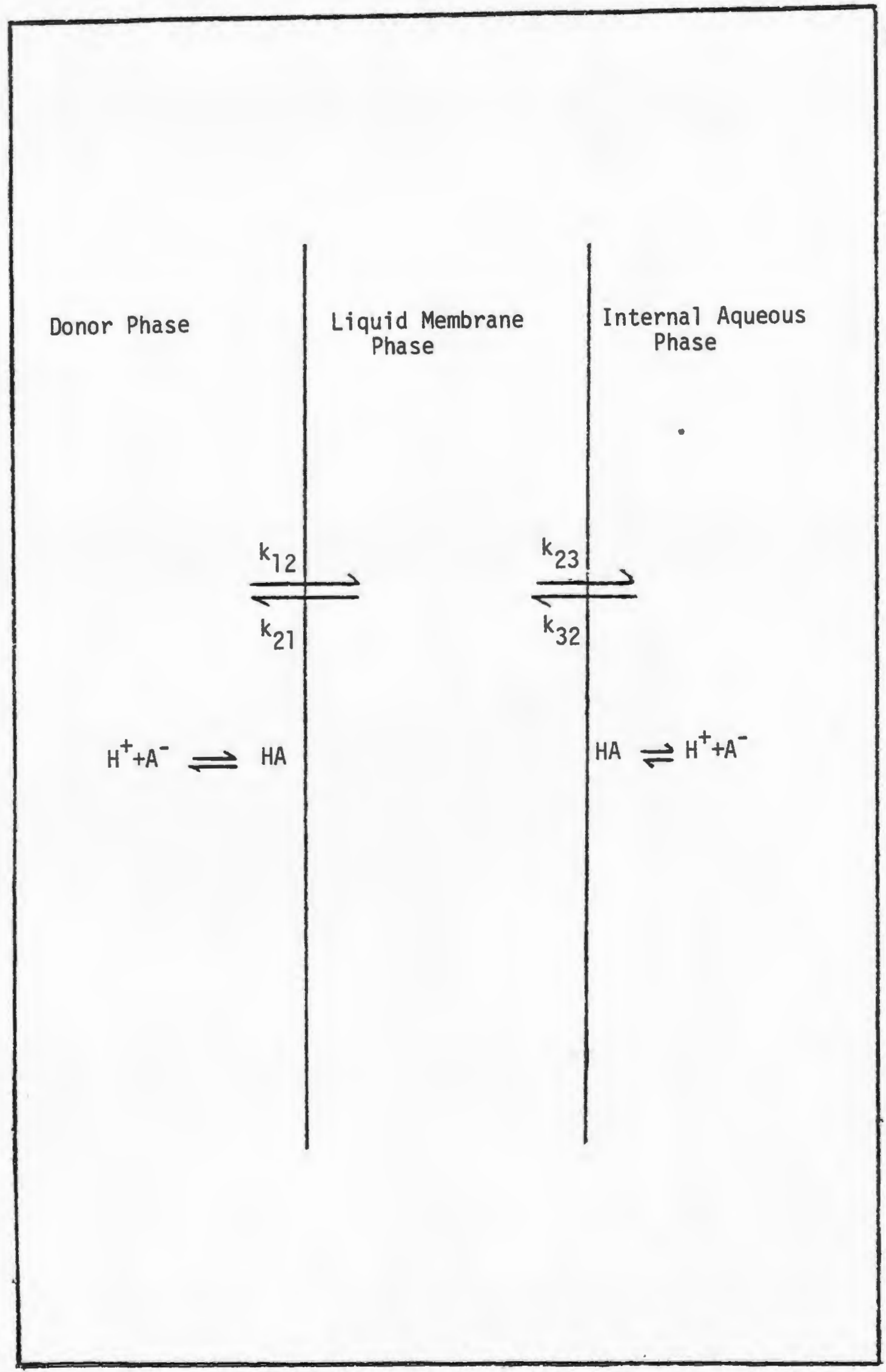

Fig. 2 Kinetic Model Developed to Rationalize Transport of Solutes 


$$
C_{e}^{t}=A e^{-x t}+B e^{-B t}+C_{e}^{s} \text { Equation }
$$

Where: $c_{e}^{t}=$ concentration of solute in the external aqueous phase at any time, $t$,

$A$ and $B=$ pre-exponential terms containing the micro rate constants,

$\alpha$ and $\beta=$ first order (macro) rate constants, $t=$ time, $c_{e}^{s}=$ concentration of solute in the external aqueous phase at steady state.

Although Yang and Rhodes were not able to determine the micro-rate constants for the solute uptake process, Chilamkurti and Rhodes (18) were able, at least for some systems, to determine these rate constants. For salicylic acid, they determined the uptake process to be monoexponential, that is, having a single rate expression, since they found $k_{12}$ is larger than $k_{21}, k_{23}$, and $k_{32}$. They found that acetylsalicylic acid uptake is biexponential since they determined $k_{12}$ is smaller than both $k_{21}$ and $k_{23}$. In this case both the a and $\beta$ rate constants were observed. It is possible that the application of a more sensitive assay technique (i.e. high pressure liquid chromatography) may serve to define these processes more fully. 
III. METHOD

A. Materials

1. Chemicals

Acetic Acid, Glacial Reagent A.C.S. (1ot \# 705283, lot \# 712081) 1

Acetonitrile $\left(\right.$ lot \# 121602) ${ }^{2}$

Acetylsalicylic Acid (lot \# KC040577) 3

Aluminum Monostearate

Boric Acid, crystal (lot \# C0075) 4

Cetyl Alcohol N.F. (1ot \#B11030023) ${ }^{5}$

Hydrochloric Acid (lot \# KMBV) ${ }^{6}$

Methanol HPLC Grade (lot \# UN1230) ${ }^{1}$

Methanol (1ot \#AH749) ${ }^{7}$

Methylcellulose U.S.P. $\left(\right.$ lot \# C706594) ${ }^{8}$

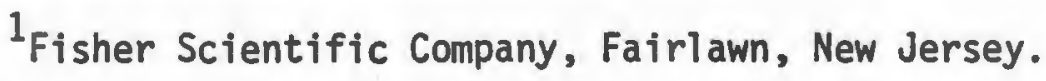

2 Waters Associates, Milford, Massachusetts.

${ }^{3}$ Aldrich Chemical Company, Inc., Milwaukee, Wisconsin.

${ }^{4}$ Allied Chemical, Morristown, New Jersey.

${ }^{5}$ Ruger Chemical Company, Inc., Irvington, New Jersey.

${ }^{6}$ Mall inckrodt Chemical Works, New York, New York.

7 Burdick \& Johnson Laboratories, Inc., Muskegon, Michigan.

${ }^{8}$ Amend Drug and Chemical Company, Irvington, New Jersey. 
Mineral $0 i 1$ U.S.P. $(10 t \# 119-12)^{1}$.

Myrj $\star 52(10 t \# 260)^{2}$

Phenobarbital U.S.P. powder (1 ot \# 6588, control MPY) ${ }^{3}$

Phosphoric Acid (1ot \# YLP) ${ }^{3}$

Potassium Chloride U.S.P. powder (1ot \# 950373) ${ }^{4}$

Potassium Biphthalate

Potassium Phosphate Monobasic, crystal (lot \# TPJ) ${ }^{3}$

Salicylic Acid (1ot \# DC 041987) 5

Sodium Hydroxide U.S.P. pellets (lot \# 66222425$)^{6}$

Span **60 (1ot \#65576) ${ }^{7}$

Span 80, sorbitan monooleate $\left(\right.$ lot \# 1477) ${ }^{7}$

Tween $* * * 60\left(1\right.$ ot \# 1153) ${ }^{7}$

Tween 80 , polysorbate 80, U.S.P. $(\text { lot \# } 1580)^{2}$

*Myrj: poloxyethylene ester

**Span: sorbitan ester

***Tween: polyoxyethylene sorbitan

1 Pennsyivania Refining Company, Butler, Pennsyivania.

${ }^{2}$ Ruger Chemical Company, Inc., Irvington, New Jersey.

3 Mallinckrodt Chemical Works, New York, New York.

4J. T. Baker Chemical Company, Phillipsburg, New Jersey.

${ }^{5}$ Aldrich Chemical Company, Inc., Mitwaukee, Wisconsin.

${ }^{6}$ Amend Drug and Chemical Company, Inc., Irvington, New Jersey.

${ }^{7}$ Atlas Chemical Industries, Wilmington, Delaware. 
2. Liquid Membranes ${ }^{1}$ (Designated by L.M.)

The 1 iquid membranes were composed of an internal aqueous phase of pH 10 buffer and an external oil phase. The oil phase was a mixture of straight and branched chain alkyls and polyamino surfactants.

L.M. 573-119A

L.M. 573-119B

L.M. $573-120 \mathrm{~A}$

L.M. 573-119A off spec

L.M. 573-120-1, 21.6 (centipoise) (CDS)

L.M. 573-120-2, $9.9 \mathrm{cps}$

L.M. $573-120-3,12.8 \mathrm{cps}$

L.M. 573-121-1, volume ratio oil/water 2:1

L.M. 573-121-2, volume ratio oil/water 3:1

L.M. 573-121-3, volume ratio oil/water 2:3

L.M. 573-121-4, volume ratio oil/water $1: 2$

3. 0 il Phase ${ }^{1}$

B. Supplies and Equipment

Mettler H8 Balance; Mettler Type H 16 Balance, Mettler Instrument Company, Hightstown, New Jersey.

Photoreflectance Tachometer, model 1030, Pioneer Electric and Research Corporation, Forest Park, Illinois. Motor Generator Monomatic, Electro Craft Corporation, Hopkins, Minnesota.

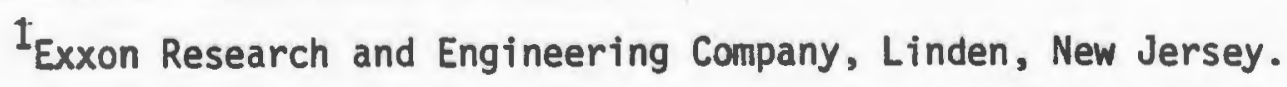


Constant Speed and Torque Control Unit, Cole-Parmer Instrument Company, Chicago, Illinois.

Hewlett-Packard Calculator, 9810A, model 10, and Plotter (9862 A), Hewlett-Packard Calculators Division, Loveland, Colorado. Ovens, model LEFL-75, Despatch Oven Company, Minneapolis, Minnesota. Lauder Cooler IC-6, Brinkman Instruments, Westbury, New York. Beckman Expandomatic S5-2 pH meter, Beckman Instruments, Inc., Fullerton, California. Homogenizer Cylindrical Reaction Flask Body, $2000 \mathrm{ml}$, Lab Glass, Inc., Vineland, New Jersey. Microscope, Baush and Lomb. UV-VIS Spectrophotometer, Perkin-Elmer, Hitachi 200, Perkin Elmer, Norwalk, Connecticut. Porta-Temp with Stir Pump, Precision Scientific Company, Chicago, Illinois.

Solvent Delivery System, model M6000A, Waters Associates, Milford, Massachusetts. WISP 710B, Waters Associates, Milford, Massachusetts. uBondapak $C_{18}$ (reversed phase) column, Waters Associates, Milford, Massachusetts.

Fixed Wavelength Detector, model 440, Waters Associates, Milford, Massachusetts. 
Chart Strip Recorder, Cole-Parmer Instrument Company, Chicago, Illinois.

Millipore Vacuum Pump, Millipore Corporation, Bedford, Massachusetts.

Millipore Filter Holder, Millipore Corporation, Bedford, Massachusetts.

Glassware and common laboratory equipment as available in the College of Pharmacy.

C. Procedures

1. Preparation of Donor Phase Solutions

Standard donor phase solutions were prepared by dissolving drug in a $200 \mathrm{ml}$ volumetric flask with either a buffer solution or hydrochloric acid $(0.1,0.01$, or $0.001 \mathrm{~N})$. Hydrochloric acid (pH 2), Acid Phthalate ( $\mathrm{pH} 3.5$ ), Phosphate ( $\mathrm{pH} \mathrm{6.0)}$, and Alkaline Borate (pH 10) buffer solutions were prepared in accordance with USP XX. (57).

2. Sampling Method

A $2000 \mathrm{ml}$ round bottom flask with baffled sides was mounted on a ring stand with a circular brace and chain clamp. The unit was positioned in a water bath which was thermostatically controlied using a Porta-Temp to maintain temperatures of $25^{\circ} \mathrm{C}$ and above, or an immersion cooler to maintain temperatures in the range of $4-24^{\circ} \mathrm{C}$. A mechanically driven stirrer was introduced into the beaker and was operated at $250 \mathrm{rpm}$ lising a constant speed and torque control unit. The donor soiution was poured into the flask and allowed to temperature equilibrate. An equal volume of liquid membrane, temperature 
adjusted by storage at a specific temperature as required for at least 24 hours, was poured into the fiask containing the donor solution to form a liquid membrane system (LMS). At predetermined time intervals samples of the LMS were drawn from the flask using a $25 \mathrm{ml}$ glass buret at a fixed position. The samples were filtered using Whatman No. 42 filter paper lining a glass filter and a vacuum pump for suction. The sample collection began at 10 seconds before the designated time to allow 5 seconds for sample withdrawal and 5 seconds for filtration. The sample was filtered for an additional 5 seconds after the designated time, thereby making the midpoint of the filtration the theoretical sampling time. The samples were assayed by either UV spectrophotometric or high pressure liquid chromatographic determinations.

\section{Sample Assay}

a. U.V. Spectrophotometric Determination

A calibration curve was generated for each drug assay spectrophotometrically. Dilutions were prepared from a standard drug solution and the absorbance of each dilution was determined at the wavelength of maximum absorptivity for that drug. The absorbance values of salicylic acid samples were read at $236 \mathrm{~nm}$, acetylsalicylic acid at $228 \mathrm{~nm}$, and phenobarbital at $255 \mathrm{~nm}$. Dilutions of salicylic and acetylsalicylic acid were made using the same solvent as the donor phase, whereas phenobarbital samples were diluted with IN sodium hydroxide to insure maximum absorptivity (58). 
A Beer's plot was generated for each drug by plotting the absorbance of each sample dilution against the known concentration of the dilution. Beer's law states:

$$
A=a b C \quad \text { Equation (14) }
$$

Where: $A=$ absorbance,

$a$ = absorptivity,

$b=$ sample path length,

$C=$ concentration.

Applying Beer's law, the slope of the straight line obtained by the absorbance versus concentration plot is equivalent to the term $a b$ in Equation (14).

By rearranging Equation (14) to

$$
C=A / \text { slope Equation (15) }
$$

the concentration of an unknown sample may be calculated.

b. High Pressure Liquid Chromatographic Determination (HPLC)

A calibration curve was generated for each drug assayed by high pressure liquid chromatography (HPLC). The HPLC system included a Waters Intelligence Sample Processor (WISP) unit which was progranmed to inject automatically a range of sample volumes from one standard solution into the system for assay. For each drug, a series of dilutions from a standard solution was made also and the absorbance of each sample was determined. A Beer's plot was obtained for each drug by plotting the absorbance of each sample volume or sample dilution against its known concentration. Based on the principles described above in section $3 \mathrm{a}$, these plots were used to determine unknown concentrations of solutes. 
The HPLC system used in these experiments consisted of a soivent delivery system, the WISP unit for automatic and precise sample injection, and a fixed wavelength detector with interchangeable lamps. The separation was performed on a $3.9 \mathrm{~mm}$ (id) $\times 30 \mathrm{~cm}$ $\mu$ Bondapak $C_{18}$ (reversed phase) column. The chromatographic peaks were recorded using a chart recorder.

The mobile phase employed in the analysis of salicylic acid and acetyisalicylic acid consisted of acetic acid $1 \%$ :methanol $(40: 60)$ with the following chromatographic conditions: flow rate $-1.5 \mathrm{ml} / \mathrm{min}$.; detector wavelength - $280 \mathrm{~nm}$; injection volume 25 or $50 \mu \mathrm{l}(59)$.

To assay phenobarbital, the following chromatographic conditions were employed $(60)$ : flow rate $-2.0 \mathrm{ml} / \mathrm{min}$.; detector wavelength $254 \mathrm{~nm}$; injection volume $-100 \mu \mathrm{r}$. The mobile phase consisted of double distilled water:acetonitrile:phosphate buffer $\left(80 \mu 1 \mathrm{M} \mathrm{KH}_{2} \mathrm{PO}_{4}\right.$; $14 \mu 1 \mathrm{H}_{3} \mathrm{PO}_{4} ; 500 \mathrm{ml}$ double distilled water) (11:19:70).

4. Preparation of Emulsions

a. Using the HLB Approach

Sixty milliliter quantities of $50 \%$ water-in-mineral oil emulsions were prepared using blends of emulsifying agents having a HLB of 6.0 the HLB of mineral oil. The ratio of emulsifiers required to achieve this HLB was determined using Equations ( 9 ) and (10).

The emulsions were prepared by adding $33.3 \mathrm{ml}$ of mineral oil to the emulsifier blend and heating to $72^{\circ} \mathrm{C}$. The required quantity of aqueous phase, also heated to $72^{\circ} \mathrm{C}$, was poured into a clear $120 \mathrm{ml}$ 
bottle containing the heated oil/surfactant mixture. The total preparation was hand shaken for 2 mirutes and stored at room temperature.

In order to scale-up the quantity of emulsion prepared, the same procedure was followed using a homogenizer instead of the bottle for mixing. The total preparation was homogenized for 1.5 minutes.

b. Using the Davis Approach

Sixty milliliter quantities of water-in-mineral oil emulsions (50\%) were prepared based on a formula developed by Davis (19) (see Table I). The required quantities of ingredients comprising the oil phase were heated to $72^{\circ} \mathrm{C}$, as was the aqueous phase. The two phases were hand shaken in a clear $120 \mathrm{ml}$ bottle for 2 minutes and stored at room temperature.

In order to scale-up the quantity of emulsion prepared, the same procedure was followed except a homogenizer was used for 1.5 minutes instead of the bottle for mixing.

TABLE I

FORMULA FOR WATER-IN-OIL-IN-WATER EMULSIONS (19)

\begin{tabular}{lc}
\hline 0il Phase & Aqueous Phase (Internal) \\
\hline $50 \%$ Mineral $0 i 1$ & Methocel $4000^{*}$ \\
$10 \%$ Span 80 & \\
$2 \%$ Tween 80 & \\
$10 \%$ Cety] Alcohol & \\
$10 \%$ Aluminum Tristearate & \\
\hline
\end{tabular}

*Percent not specified 
5. Analysis of Emulsions

a. Visual

After preparation, emulsions were analyzed visually in terms of color and physicai stability. Observations were made immediately and 24 hours after manufacture. The emulsions were classified according to color from white to shades of white to gray, with white indicating the better emulsions. The emulsions were inspected for phase separation as an indication of physical stability.

Although it is appreciated that these visual observations are inherently subjective in nature, these evaluation methods are accepted both academically and industrially and the researcher has used these techniques to evaluate emulsions in previous research experiments.

b. Determination of Emulsion Type

Emulsion type was determined immediately and 24 hours after preparation using an aqueous dilution test. A drop of emulsion was introduced into a beaker containing $\mathrm{pH} 2$ buffer. If the drop of emulsion readily dispersed upon contact with the buffer solution, the emulsion was considered to be oil-in-water; whereas if the droplet remained in a spherical form, the emulsion was considered water-in-oil.

c. Evaluation of Potential to Form a Liquid Membrane System

The potential of the w/o emulsions to form a liquid memorane system (w/o/w emulsion) was evaluated immediately and 24 hours after preparation. An aqueous dispersion test was used to make this evaluation. Several militiliters of emulsion were poured into a beaker containing $\mathrm{pH} 2$ buffer. The buffer was stirred using a magnetic stirrer. If the 
emulsion broke up into stable, intact drops which dispersed throughout the buffer solution and could be separated from the buffer solution upon filtration, the emulsion was considered to have good potential for forming a liquid membrane system. The emulsion was considered unsuitable for forming a liquid membrane system if one of the following occurred: the emulsion dispersed readily as evidenced by the formation of a cloudy external aqueous phase which could not be separated upon filtration, or if the emulsion underwent phase inversion and mixed with the buffer.

d. Rheological Determination and Characterization of Flow

For those emulsions which could flow through an Ostwald viscometer, viscosity measurements were made. This was accomplished by determining the time required for a volume of emulsion to flow through the capillary tube of an Ostwald viscometer, size 350 , and eniploying the following equation:

$$
\eta u=n k\left(d_{u} t_{u} / d_{k} t_{k}\right) \quad \text { Equation (16) }
$$

Where: $d_{u}=$ the density of the emulsion,

$$
\begin{aligned}
d_{k}= & \text { the density of water, } \\
t_{u}= & \text { the time required for the volume of emulsion to flow } \\
& \text { through the tube, } \\
t_{k}= & \text { the time required for the volume of water to flow through } \\
& \text { the tube, } \\
n_{u}= & \text { the viscosity of the emulsion, } \\
n_{k}= & \text { the viscosity of water. }
\end{aligned}
$$


For those emulsions which has poor flow, the ease of shaking and pourability served as indicators of viscosity. Emulsions were characterized by ease of shaking and pourability and rated on a basis of 1 to 5 with the following key:

$$
\begin{aligned}
& 1=\text { very good } \\
& 2=\text { good } \\
& 3=\text { average } \\
& 4=\text { difficult } \\
& 5=\text { poor } .
\end{aligned}
$$




\section{EXPERIMENTAL}

The sampling method and assay techniques as described in Section III were employed to study the kinetics of solute transfer in liquid membranes under the various conditions listed in this section. Al1 experiments were carried out at $25^{\circ} \mathrm{C}$ for 120 minutes unless otherwise indicated.

A. Effect of Initial Donor Phase Concentration on Acetylsalicylic Acid Uptake

The effect of varying initial donor phase concentration on the rate of solute uptake was studied using acetylsalicylic acid in concentrations of $1.0 \mathrm{~g} / 1$ and $0.5 \mathrm{~g} / 1$ in $0.1 \mathrm{~N} \mathrm{HCl} \mathrm{(pH} \mathrm{1)} \mathrm{and} \mathrm{L.M.} \mathrm{573-119} \mathrm{B.}$ Collected samples of filtrate were subjected to UV spectrophotometric analysis. Six replicate runs for acetylsalicylic acid $1.0 \mathrm{~g} / 1$ and five replicate runs of the drug at $0.5 \mathrm{~g} / 1$ were conducted, thereby allowing evaluation of the reproducibility of the sampling technique.

B. Effect of Donor Phase Molar Concentration on Salicylic Acid Uptake The effect of varying the initial molar concentration of solute on the rate of solute uptake was investigated using various molar concentrations of salicylic acid in pH 2 buffer and L.M. 573-120 A. Two replicate runs were performed at the following concentrations: $2.5 \mathrm{mM}, 4.1 \mathrm{mM}, 7.2 \mathrm{mM}$. A single run was performed at a concentration of $5.6 \mathrm{mM}$. Each run was 10 minutes in length and the filtrate was assayed by HPLC. 
C. Effect of Liauid Membrane Viscosity on Salicylic Acid Uptake The effect of liquid membrane viscosity on the rate of uptake of salicylic acid $1.0 \mathrm{~g} / 1$ in $\mathrm{pH} 2$ buffer was investigated using the following liquid membranes: L.M. 573-119 B (16.7 cps), L.M. 573-119 A (3.0 cps), L.M. 573-120-1 (21.6 cps), L.M. 573-120-2 (9.9 cps), 573-120-3 (12.8 cps).

Two replicate runs were completed with sample collection each minute for 10 minutes and subsequent HPLC analysis for each liquid membrane except L.M. 573-119 B. For this membrane, samples were collected for 120 minutes with subsequent UV spectrophotometric analysis.

D. Effect of Liquid Membrane 0i1/Water Ratio on Salicylic Acid Uptake The effect of liquid membrane oil/water ratio on the rate of uptake of salicylic acid $1.0 \mathrm{~g} / 1$ in $\mathrm{pH} 2$ buffer was investigated using the following liquid membranes:

Liquid Membrane

L.M. 573-120 A

L.M. $573-121-1$

L.M. $573-121-2$

L.M. $573-121-3$

L.M. $573-121-4$
0i1/Water Ratio

$1: 2$

Two replicate runs were performed using each liquid membrane with sample collection every minute for 10 minutes and subsequent HPLC analysis. 
E. Effect of Donor Phase pH on Solute Iptake

1. Acetylsalicylic Acid

Two replicate runs were performed to determine the effect of donor phase $\mathrm{pH}$ on the rate of uptake of acetylsalicylic acid $1.0 \mathrm{~g} / 1$ using L.M. 573-119 B. Three different pH donor solutions were investigated: $\mathrm{pH} 1(0.1 \mathrm{~N} \mathrm{HCl}), \mathrm{pH} 2(0.01 \mathrm{~N} \mathrm{HCl})$, and $\mathrm{pH} 3(0.001 \mathrm{~N} \mathrm{HCl})$. The $\mathrm{pH}$ of the donor phase solution was measured at the onset $(t=0)$ and the end ( $t=120$ minutes) of each run. The filtrate was analyzed using the UV spectrophotometer.

2. Salicylic Acid

Using L.M. 573-120 A Off Spec, two replicate runs were performed to determine the effect of donor phase $\mathrm{pH}$ on the rate of salicylic acid $1.0 \mathrm{~g} / 1$ uptake. Buffer solutions of $\mathrm{pH} 1, \mathrm{pH} 2, \mathrm{pH} 3.5$, and $\mathrm{pH} 6.0$ were used as donor solutions with the $\mathrm{pH}$ measured at the beginning and end of each run ( $t=0$ and $t=120$ minutes). Collected samples of filtrate were subjected to HPLC analysis.

F. Effect of Temperature on Solute IJptake

1. Salicylic Acid

The effect of temperature on the rate of uptake of salicylic acid $1.0 \mathrm{~g} / 1$ in $0.1 \mathrm{~N} \mathrm{HCl}$ donor solution was investigated using L.M. 573-119 A. The temperatures studied were $4^{\circ}, 16^{\circ}, 28^{\circ}, 37.5^{\circ}$, and $50^{\circ} \mathrm{C}$. Two replicate runs were performed at each temperature and samples collected were assayed by HPLC. 


\section{Phenobarbital}

Using L.M. 573-119 A, the effect of temperature on the rate of uptake of phenobarbital $0.6 \mathrm{~g} / 1$ in $\mathrm{pH} 2$ buffer was studied at $4^{\circ}, 20^{\circ}$, $37.5^{\circ}, 41^{\circ}, 42^{\circ}, 43^{\circ}$, and $45^{\circ} \mathrm{C}$. Two replicate runs were performed at each temperature with an additional two runs performed at $43^{\circ} \mathrm{C}$. Samples were collected and assayed by HPLC.

G. Effect of Liquid Membrane Viscosity on Phenobarbital Uptake at a Critical Temperature $-43^{\circ} \mathrm{C}$

The effect of liquid membrane viscosity on the rate of uptake of phenobarbital $0.6 \mathrm{~g} / \mathrm{l}$ in $\mathrm{pH} 2$ buffer at $43^{\circ} \mathrm{C}$ was investigated. Two replicate runs were performed using each of the following liquid membranes: L.M. 573-120-1, L.M. 573-120-2, L.M. 573-120-3. Samples collected were assayed by HPLC.

H. Evaluation of Liquid Membrane Reuse

1. Transport of Trapped Solute

Figure 3 depicts the experimental sequence used to investigate the integrity of liquid membranes for reuse and their ability to release trapped drug using L.M. 573-120 A. Two replicate uptake runs were performed using each of the three investigational drugs - phenobarbital $0.6 \mathrm{~g} / 1$ in $\mathrm{pH} 2$ buffer, salicylic acid $1.0 \mathrm{~g} / 1$, and acetylsalicylic acid $1.0 \mathrm{~g} / 1$ each in $0.01 \mathrm{~N} \mathrm{HCl}$. A drug free $\mathrm{pH} 2$ buffer donor solution served as a control. At the end of the 120 minute sampling period, the remaining liquid membrane system (external donor phase/liquid membrane mixture), designated LMS I, was collected, measured, and mixed in a beaker until further use. The glassware used in the initial uptake run was washed and dried. 


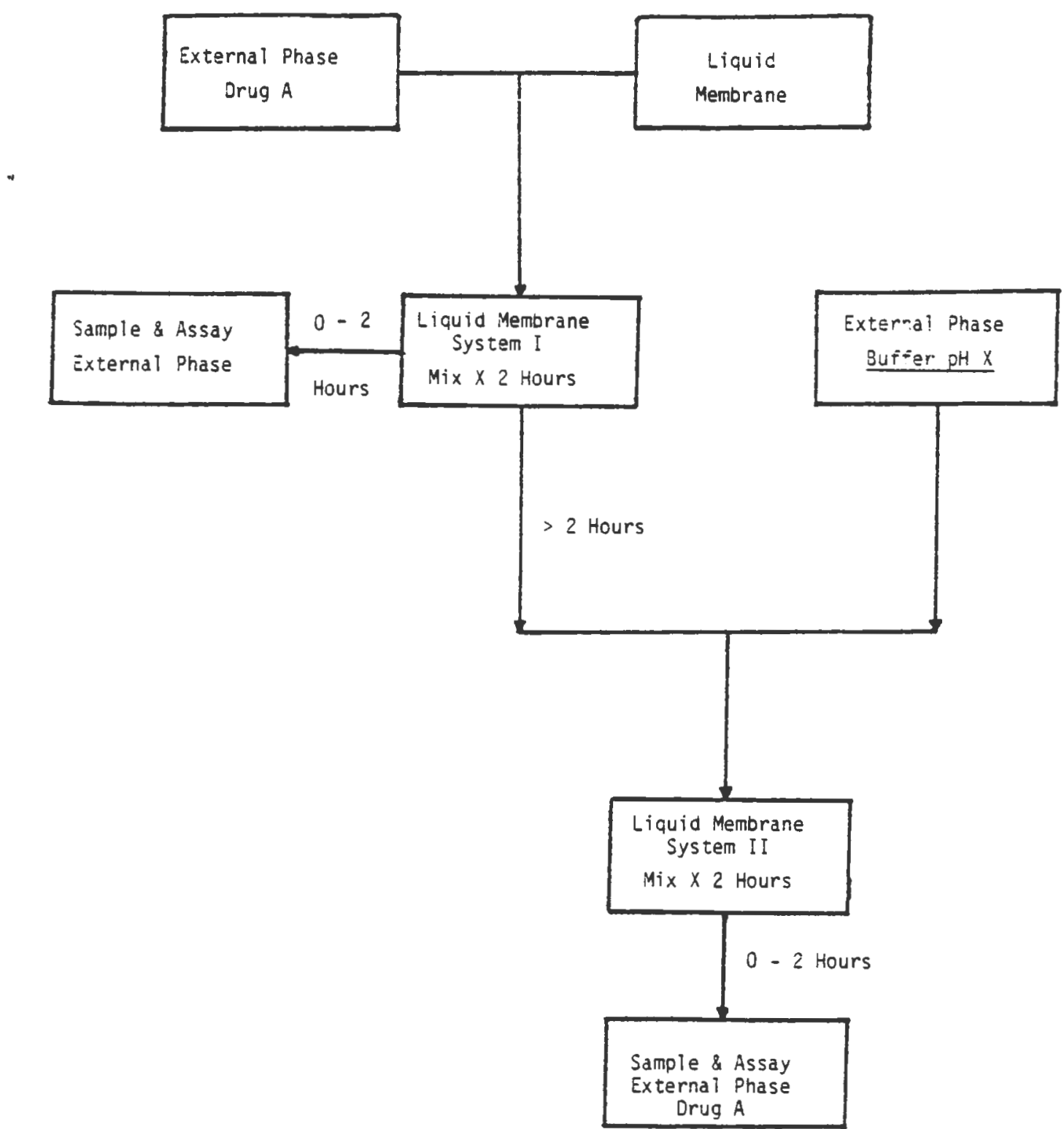

Fig. 3 Experimental Sequence for Liquid Membrane Reuse 
A drig free $\mathrm{pH} 10$ buffer solution was used as the external aqueous phase for the second part of the experiment. A drug free $\mathrm{pH} 2$ buffer solution was used also for the second portion of one phenobarbital experiment. LMS I was mixed with the $\mathrm{pH} 2$ or $\mathrm{pH} 10$ buffer to form LMS II and the experiment proceeded according to the standard sampling method for 120 minutes. Collected samples were assayed using the UV spectrophotorneter to determine if the drug had remained trapped within or if it had transported out of the membrane.

2. Evaluation of Subsequent Solute Uptake

The experimental scheme depicted in Figure 4, was devised in order to investigate the ability of liquid membranes to be reused for the purpose of subsequent solute uptake. Using L.M. 573-119 A, an uptake experiment using either salicylic acid $1.0 \mathrm{~g} / 1$ in $0.1 \mathrm{~N} \mathrm{HCl}$ or phenobarbital $0.6 \mathrm{~g} / 1$ in $\mathrm{pH} 2$ buffer was conducted for 120 minutes with HPLC sample analysis. The liquid membrane system remaining at the end of the run (LMS I) was collected, measured, and mixed in a beaker until further use. The glassware used in the initial uptake run was washed and dried.

A pH 2 buffer solution containing either salicylic acid $1.0 \mathrm{~g} / 1$ or phenobarbital $1.2 \mathrm{~g} / 1$ was used as the external aqueous phase for the second part of the experiment. Samples collected from LMS II for 120 minutes were assayed for both drugs. Table II lists the order of drug uptake and the temperature at which the experiment was run. 


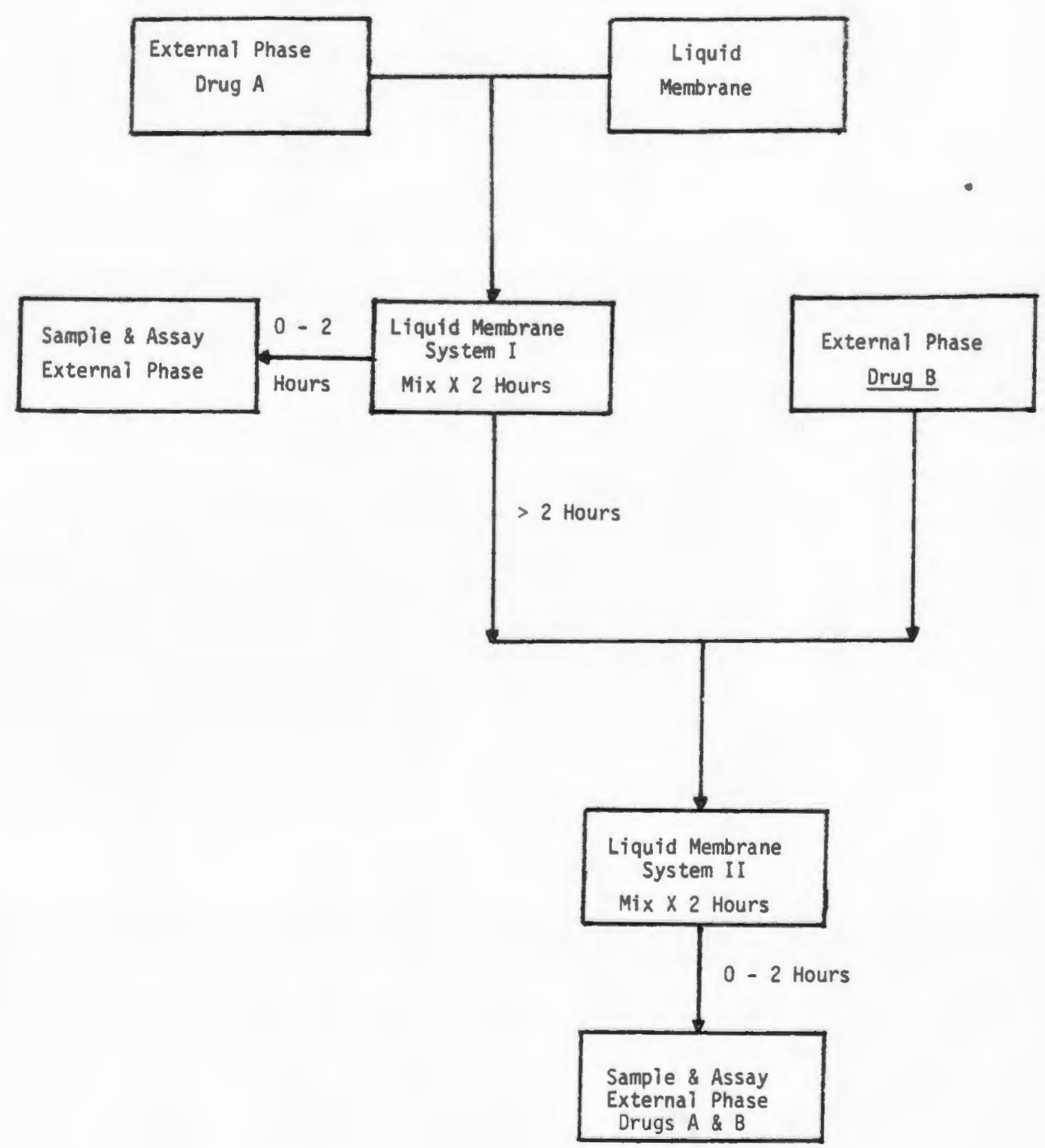

Fig. 4 Experimental Sequence for Subsequent Uptake of Solutes 
TABLE II

ORDER OF SUBSEQUENT SOLUTE UPTAKE

\begin{tabular}{lcc}
\hline \hline Initial Solute & Subsequent Solute & Temperature ${ }^{\circ} \mathrm{C}$ \\
\hline Salicylic Acid & Phenobarbital & 50 \\
Phenobarbital & Salicylic Acid & 37.5 \\
Phenobarbital & Salicylic Acid & 45 \\
\hline
\end{tabular}

I. Evaluation of Co-Uptake of Solutes from One Donor Solution

1. Co-Uptake of Solutes with Different Initial Molar Concentrations

Two replicate runs were conducted to determine the effect of the presence of one solute on the rate of uptake of another solute when the initial concentrations of each solute were different. Table III lists the combinations of solutes and their initial concentrations in pH 2 buffer. L.M. 573-120 A was used in these experiments. Samples collected were assayed using HPLC.

TABLE III

CO-UPTAKE OF SOLUTES WITH DIFFERENT INITIAL CONCENTRATIONS

\begin{tabular}{clc}
\hline \hline External Aqueous Phase & \multicolumn{1}{c}{ Solutes } & Molar Concentration (mM) \\
\hline 1 & Salicylic Acid & 7.2 \\
& Acetylsalicylic Acid & 5.6 \\
2 & Salicylic Acid & 7.2 \\
& Phenobarbital & 2.5 \\
3 & Acetylsalicylic Acid & 5.6 \\
& Phenobarbital & 2.5 \\
\hline
\end{tabular}


2. Co-Uptake of Solutes with Equimolar Initial Concentrations

Two replicate runs were conducted to determine the effect of the presence of one solute on the rate of uptake of another when their initial concentrations were equimolar. Table IV lists the combinations of solutes and their initial concentrations in pH 2 buffer. L.M. 573$120 \mathrm{~A}$ was used in these experiments. Samples collected were assayed using HPLC.

TABLE IV

CO-UPTAKE OF SOLUTES WITH EQUIMOLAR INITIAL CONCENTRATIONS

\begin{tabular}{|c|c|c|c|}
\hline External & Aquecus Phase & Solutes' & Molar Concentration (mM) \\
\hline & 1 & $\begin{array}{l}\text { Salicylic Acid } \\
\text { Acetylsalicylic Acid }\end{array}$ & 5.6 \\
\hline & 2 & $\begin{array}{l}\text { Salicylic Acid } \\
\text { Phenobarbital }\end{array}$ & 2.5 \\
\hline
\end{tabular}

J. Effect of Liquid Membrane 0il/Water Ratio on the Co-Uptake of Sointes

Two replicate runs were performed to study the effect of liquid membrane $0 i l /$ water on the co-uptake of solutes having different initial molar concentrations. The solutes and their molar concentrations were phenobarbital $0.6 \mathrm{~g} / 1(2.5 \mathrm{mM})$ and salicylic acid $1.0 \mathrm{~g} / 1(7.2 \mathrm{mM})$. The samples collected were assayed using HPLC. The liquid membranes used were: L.M. 573-120 A, L.M. 573-121-1, L.M. 573-121-2, L.M. 573$121-3$, L.M. 573-121-4.

K. Effect of Freeze/Thaw on the Use of Liquid Membranes

The effect of freeze/ thaw stress on the performance of liquid membranes to take up solutes was investigated. Approximately $100 \mathrm{ml}$ 
of the following liquid membranes were frozen for at least 24 hours, thawed, and stored at room temperature for at least 24 hours: L.M. 573-120-1, L.M. 573-120-2, L.M. 573-120-3. These membranes were used for the uptake of salicylic acid $1.0 \mathrm{~g} / 1$ in $\mathrm{pH} 2$ buffer. The membranes were observed for cracking after freezing.

L. Formulations

1. Using the HLB Approach

Table $V$ describes the emulsions prepared by the procedure described in Section III, C-4a. These emulsions were analyzed as described in Section III, C-5.

2. Using the David Approach

Table VI lists the emulsions prepared as described in Section III, C-4b. These emulsions were analyzed as described in Section III C-5. 
TABLE V

PRELIMINARY FORMULATIONS AND FORMULATIONS OF EMULSIONS PREPARED USING THE HLB APPROACH

\begin{tabular}{|c|c|c|c|}
\hline Emulsion & $\begin{array}{l}\text { Surfactant Blend } \\
\text { ( } \% \text { weight of total } \\
\text { emulsifier in blend) }\end{array}$ & $\begin{array}{l}\% \text { Weight of Total } \\
\text { Emulsifying Agent } \\
\text { in 0il Phase*** }\end{array}$ & $\begin{array}{c}\text { Additives } \\
\text { (\% Weight of Total } \\
\text { in 0il Phase) })^{\star * *}\end{array}$ \\
\hline 1 & $\begin{array}{l}\text { Span } 80(50 \\
\text { Tween } 80(50)\end{array}$ & 20 & $\begin{array}{l}\text { - (Comment: Distilled } \\
\text { water, not pH } 10 \text { buffer } \\
\text { used as internal phase) }\end{array}$ \\
\hline 2 & $\begin{array}{l}\text { Span } 80(66) \\
\text { Tween } 80(33)\end{array}$ & 15 & - \\
\hline 3 & $\begin{array}{l}\text { Span } 80(83) \\
\text { Tween } 80(17)\end{array}$ & 12 & Cetyl Alcohol (20) \\
\hline 4 & $\begin{array}{l}\text { Span } 80(83) \\
\text { Tween } 80(17)\end{array}$ & 12 & - \\
\hline 5 & $\begin{array}{l}\text { Span } 60(66) \\
\text { Tween } 60(33)\end{array}$ & 15 & - \\
\hline 6 & $\begin{array}{l}\text { Span } 60(71) \\
\text { Tween } 60(29)\end{array}$ & 7 & - \\
\hline$* * 7$ & $\begin{array}{l}\text { Span } 60(87) \\
\text { Tween } 60 \text { (13) }\end{array}$ & 5 & - \\
\hline 8 & $\begin{array}{l}\text { Span } 80(84) \\
\text { Tween } 80(16)\end{array}$ & 5 & - \\
\hline 9 & $\begin{array}{l}\text { Span } 80(84) \\
\text { Tween } 80(16)\end{array}$ & 10 & - \\
\hline
\end{tabular}


TABLE V (Continued)

\begin{tabular}{|c|c|c|c|}
\hline Emulsion & $\begin{array}{l}\text { Surfactant Blend } \\
\text { (\% Weight of total } \\
\text { emulsifier in blend) }\end{array}$ & $\begin{array}{l}\% \text { Weight of Total } \\
\text { Emulsifying Agent } \\
\text { in 0il Phase }\end{array}$ & $\begin{array}{l}\text { Additives } \\
\text { (\% Weight of Total } \\
\text { in 0il Phase)*** }\end{array}$ \\
\hline 10 & $\begin{array}{l}\text { Span } 80(84) \\
\text { Tween } 80(16)\end{array}$ & 15 & - \\
\hline 11 & $\begin{array}{l}\text { Span } 60(87) \\
\text { Tween } 80(13)\end{array}$ & 5 & - \\
\hline 12 & $\begin{array}{l}\text { Span } 60(87) \\
\text { Tween } 80(13)\end{array}$ & 10 & - \\
\hline 13 & $\begin{array}{l}\text { Span } 60(87) \\
\text { Tween } 80(13)\end{array}$ & 7.5 & - \\
\hline 14 & $\begin{array}{l}\text { Span } 80(84) \\
\text { Tween } 80(16)\end{array}$ & 10 & Cetyl Alcohol (1) \\
\hline 15 & $\begin{array}{l}\text { Span } 60(87) \\
\text { Tween } 80(13)\end{array}$ & 6.25 & - \\
\hline 16 & $\begin{array}{l}\text { Span } 60(87) \\
\text { Tween } 80(13)\end{array}$ & 6 & - \\
\hline 17 & $\begin{array}{l}\text { Span } 60(87) \\
\text { Tween } 80(13)\end{array}$ & 5.75 & - \\
\hline 18 & $\begin{array}{l}\text { Span } 60(87) \\
\text { Tween } 80(13)\end{array}$ & 5.5 & - \\
\hline 19 & $\begin{array}{l}\text { Span } 60(87) \\
\text { Tween } 80(13)\end{array}$ & 5.25 & - \\
\hline
\end{tabular}




\begin{tabular}{|c|c|c|c|}
\hline Emulsion & $\begin{array}{l}\text { Surfactant Blend } \\
\text { (\% Weight of total } \\
\text { emulsifier in blend) }\end{array}$ & $\begin{array}{l}\% \text { Weight of Total } \\
\text { Emulsifying Agent } \\
\text { in 0il Phase } \star \star \star\end{array}$ & $\begin{array}{c}\text { Additives } \\
\text { (\% Weight of Total } \\
\text { in 0il Phase)*** }\end{array}$ \\
\hline $\begin{array}{r}20 a \\
b\end{array}$ & $\begin{array}{l}\text { Span } 80(86.5) \\
\text { Myrj } 52(13.5)\end{array}$ & 10 & - \\
\hline $\begin{array}{r}21 a \\
b\end{array}$ & $\begin{array}{l}\text { Span } 80 \\
\text { Myrj } 52(86.5) \\
(13.5)\end{array}$ & 15 & - \\
\hline
\end{tabular}

* Preliminary emulsions not using HLB approach.

** Using HLB approach.

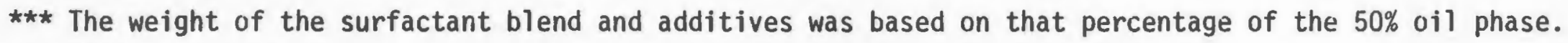

a Hand homogenized.

b Use of homogenizer. 
TABLE VI

EMULSIONS PREPARED AS VARIATIONS OF THE DAVIS

FORMULA (19)

\begin{tabular}{ll}
\hline Emulsion & Variation \\
\hline $101-105$ & Decreased percent cetyl alcohol \\
$106-109$ & Changed percent methocel in aqueous phase \\
\hline
\end{tabular}




\section{RESULTS AND DISCUSSION}

This section contains an evaluation of the experimental protocol and assay techniques used in this study and reports the results obtained. Also, this section contains a critical discussion of the significance and possible interpretation of the results.

The conclusions to be drawn from this study and suggestions for further investigations are presented in the section, Conclusions.

For ease of reference, the results and discussion are organized into the following main sections:

A. General Considerations

B. Evaluation of Assay Methods and Sampling Technique

C. Effect of Initial Donor Phase Concentration on the Rate of Solute Uptake

D. Effect of Liquid Membrane 0i1/Water Ratio on the Rate of Salicylic Acid Uptake

E. Effect of Donor Phase pH on the Rate of Solute Uptake

F. Effect of Viscosity on the Rate of Salicylic Acid Uptake

G. Effect of Temperature on the Rate of Solute Uptake

H. Effect of Viscosity on the Rate of Phenobarbital Uptake at a Critical Temperature

1. Evaluation of Liquid Membrane Reuse

J. Evaluation of Co-Uptake of Solutes From One Donor Phase

K. Effect of Freeze/Thaw on the Use of Liquid Membrane

L. Evaluation of Some Formulation Aspects of Liquid Membranes 
A. General Considerations

1. Autoan Analysis of the Data

In the Autoan (61) analysis of the data, the best apparent compartment model fit chosen to describe the uptake of drug from the donor phase was in many instances a one compartment model. This differs somewhat from the two compartment approach proposed by Yang and Rhodes (17) as referred to in Section III of this thesis. The difference can be explained through characterization of the a phase of the process. The a phase may be described as a rapid initial decline of drug concentration from a particular compartment which is followed by a slower decline or $\beta$ phase (62). Applying this, as Yang and Rhodes did for some systems, to the uptake of solute by a liquid membrane, the $\alpha$ phase is the distributive portion of the process in which the drug leaves the external donor phase and distributes into the oil or liquid membrane phase. Measurement of the a rate constant controlling this process is rather restrictive. The $\alpha$ phase is often very short-term; thus in many liquid membrane experiments the "feathering" technique used to define the $\alpha$ phase results in the accumulation of only three which could be legitimately used to estimate the $\alpha$ rate. It is noteworthy that in the paper by Yang and Rhodes (see Tables I and II of their work (17)), in many instances only two points were available for estimation of $\alpha$; however, there were some instances where as many as 11 points could be used for that purpose.

In their work, Yang and Rhodes also reported that their data showed that the simple model yielding the equation which describes a two 
compartment model (Equation 13 of this thesis), is ". . . suitable for the definition of the kinetics of transport across a liquid membrane." They further state that in a previous paper by Chang, et al. (16), ". . . it was reported that the uptake of drugs by liquid membranes obeyed simple first-order kinetics. For those systems in which the a phase is very short, the description will essentialiy be valid for all practical purposes. However, for other systems, the $\beta$ phase will be of greater magnitude than $\alpha$ and thus the apparent simple monoexponential kinetics will be obeyed." (17).

Variation in the $\alpha$ values is greater than that observed for the \& values. The method of sampling prohibits the acquisition of more data points in the early a stages of the experiment. As Yang and Rhodes have points out, ". . errors in sampling times are relatively greater at the start of experiments than at later times "(17). Thus, those data points acquired for the $\alpha$ phase of a process are subject to more error than those points of the $\beta$ phase. Although the $\beta$ rate constants may be determined from actual experimental points, the a rate constant is calculated indirectly by a "feathering" technique (62).

Although Autoan was used to indicate the best mathematical fit of the data (i.e. one or two compartment model), the simplest model that adequately described the data was chosen when differences between the two models were not sufficient to justify the use of the more complex two compartment model. In the two cases in which this procedure was adopted, the difference in the value assigned to the apparent $B$ rate constant by use of the one or two compartment model was very small, as illustrated in Table VII. 
TABLE VII

COMPARISCN OF APPARENT $\beta$ VALUES FROM ONE AND TWO COMPARTMENT MODEL FITS

\begin{tabular}{|c|c|c|c|}
\hline System & Apparent Best Fit & $\begin{array}{r}\text { Apparent } \\
\times 10 \\
\text { Compar } \\
\underline{1}\end{array}$ & $\begin{array}{l}\text { Constants } \\
\text { in-1) } \\
\text { Model } \\
\underline{2}\end{array}$ \\
\hline $\begin{array}{l}\text { Salicylic Acid } 1.0 \mathrm{~g} / 1 \\
\text { at } \mathrm{pH} 6\end{array}$ & two compartment & $\beta_{1}=0.50$ & $\beta_{1}=0.43$ \\
\hline $\begin{array}{l}\text { Salicylic Acid } 1.0 \mathrm{~g} / 1 \\
\text { LM } 21.6 \mathrm{cps}\end{array}$ & two compartment & $B_{1}=8.4$ & $\beta_{1}=7.3$ \\
\hline
\end{tabular}

2. Significance of the Results

The application of significance to the results has been viewed in three ways.

The first is data which appears to be different by inspection but when tested statistically, the differences were not significant. Although the Student's $T$ test does not show the means to be significantly different, the data may be reviewed for possible trends. Increasing the sample size may help to clarify these cases. Obtaining additional data was hampered by the limited availability of the liquid membrane supplied by Exxon Research and Engineering Company.

Secondly, in some situations the acquisition of more data may prove it to be statistically significant; however, from a practical point of view, were these liquid membranes to be used for the purpose of drug delivery, it may appear that the differences would not be significantly large to be of practical importance.

In the final case, the data was found to be statistically significant and also of likely practical significance. An example of 
this is the situation in which the rate constants between different initial donor phase concentrations were determined to be significant. This finding also has an effect on the efficiency of the liquid membrane to function under varicus conditions. For example, one potential use of liquid membranes is their application as "sinks" for trapping drug in the case of drug overdose. In such a situation it is obviously important that the ability of the liquid membrane to trap drug should be essentially independent of the concentration of the drug in the external aqueous phase (in this case the lumen of the gastro-intestinal tract). The fact that, as determined by this investigation, increasing the external aqueous phase concentration of solute tends to reduce trapping efficiency is unfortunately an indication of a possible practical limitation in liquid membrane use for the treatment of drug overdose.

B. Evaluation of Assay Methods and Sampling Technique

1. Assay Methods

Beer's plots for acetylsalicylic acid, salicylic acid, and phenobarbital are presented in Appendix I. A linear relationship was found to exist between concentration and absorbance for each drug using both conventional UV spectrophotometry (i.e. without a separation technique) and HPLC with UV detection (automatic and manual dilutions) (see Appendix I).

In the initial stages of this project, conventional UV spectrophotometric assays were used to determine the concentration of drug remaining in the external donor phase over a period of time. Recognizing the limitations of this conventional technique, an HPLC assay 
with UV detection (referred to as HPLC) was selected as a more sensitive and reliable method which would aid in a more thorough explanation of the processes studied.

At very low concentrations unreliable absorbance readings are likely using UV spectrophotometry without HPLC separation. The signal to noise ratio is smaller at low concentrations with imprecise readings resulting. Since the passage of part of the incident radiation through the sample cell may occur more than once due to repeated reflections by the front and back of the cuvette surface, higher than actual absorbance readings may result (63). Absorption of stray light by the sample due to lack of a monochromatic light source or extraneous light entering the sample, particles such as fibers in the analysis solution, or dirty cuvette surfaces may produce inaccurate readings.

HPLC can be used to identify and quantify a compound with a high degree of sensitivity. The sensitivity of the HPLC techniques used in this project was demonstrated in two ways. Firstly, the qualitative sensitivity was determined. For example, it was noted by absorbance readings using the UV spectrophotometer that the complete uptake of salicylic acid had apparently occurred within a period of ten minutes. Using HPLC the presence of drug was detected over the course of 120 minutes. By changing the absorbance units full scale on the detector, sharp, measurable drug peaks were recorded, thereby verifying the presence of drug in the donor phase. A comparative study of detected drug in the donor phase over the period of 120 minutes using each 
TABLE VIII

COMPARISON OF DETECTED DRUG IN THE DONOR PHASE USING TWO ANALYTICAL METHODS

\begin{tabular}{|c|c|c|c|c|c|}
\hline \multicolumn{6}{|c|}{ Method of Assay } \\
\hline \multirow{2}{*}{$\begin{array}{l}\text { Time } \\
(\min )\end{array}$} & \multicolumn{2}{|c|}{ UV } & \multicolumn{3}{|c|}{ HPLC } \\
\hline & Absorbance & $\begin{array}{c}\text { Concentration } \\
(g / 1)\end{array}$ & $\begin{array}{l}\text { Absorbance Units } \\
\text { Full Scale }\end{array}$ & $\begin{array}{l}\text { Peak } \\
\text { Height } \\
\text { (mm) }\end{array}$ & $\begin{array}{c}\text { Concentration } \\
(g / 1)\end{array}$ \\
\hline 0 & 1.215 & 0.983 & 2.0 & 11.6 & 0.950 \\
\hline 1 & 0.489 & 0.396 & 2.0 & 11.3 & 0.462 \\
\hline 2 & 0.358 & 0.290 & 2.0 & 8.7 & 0.350 \\
\hline 3 & 0.319 & 0.259 & 1.0 & 11.1 & 0.214 \\
\hline 4 & 0.247 & 0.200 & 1.0 & 8.6 & 0.160 \\
\hline 5 & 0.179 & 0.145 & 0.5 & 11.2 & 0.096 \\
\hline 6 & 0.130 & 0.106 & 0.5 & 7.9 & 0.060 \\
\hline 7 & 0.105 & 0.085 & 0.2 & 12.0 & 0.027 \\
\hline 8 & 0.092 & 0.075 & 0.2 & 7.1 & 0.006 \\
\hline 9 & -- & -- & 0.1 & 3.7 & $<0.001$ \\
\hline 10 & 0.046 & 0.038 & 0.1 & 1.8 & -- \\
\hline 12 & 0.018 & 0.015 & 0.02 & 0.08 & -- \\
\hline 14 & 0.007 & 0.006 & 0.02 & 7.1 & -- \\
\hline 16 & 0.004 & -- & 0.005 & 6.2 & -- \\
\hline 18 & 0.002 & -- & 0.005 & 5.0 & -- \\
\hline 20 & 0.003 & -- & 0.005 & 5.8 & -- \\
\hline 25 & -- & -- & 0.005 & 4.3 & -- \\
\hline 40 & 0.002 & -- & 0.005 & 3.4 & - \\
\hline 50 & 0.003 & -- & 0.005 & 4.2 & -- \\
\hline 60 & 0.003 & -- & 0.005 & 3.0 & -- \\
\hline
\end{tabular}


method of assay is presented in Table VIII. Although very low absorbance readings were obtained, thus indicating the presence of drug, using UV spectrophotometry, the limitations of the technique suggest in fact that no drug was present in the sample.

Secondly, quantitative sensitivity of the HPLC technique was demonstrated as presented in Table IX. It is generally accepted that absorbance readings of less than 0.200 are not recommended for quantitative use (refer to Table VIII). Levels of acetylsalicylic and salicylic acid as low as $0.1 \mu \mathrm{g} / \mathrm{ml}$ and $1.3 \mu \mathrm{g} / \mathrm{ml}$ for phenobarbital can be accurately detected with the appropriate HPLC system.

TABLE IX

COMPARATIVE SENSITIVITY OF UV SPECTROPHOTOMETRY AND HPLC

\begin{tabular}{|c|c|c|c|}
\hline Drug & $\begin{array}{r}\text { Minimal Quantifiable } \\
\text { Concentration }(\mu \mathrm{g} / \mathrm{ml}) \\
\text { UV Spectrophotometry }\end{array}$ & HPLC & $\begin{array}{l}\text { Sensitivity of } \\
\text { HPLC : UV Spec- } \\
\text { trophotometry }\end{array}$ \\
\hline Acety?salicylic Acid & 4.0 & 0.1 & $40: 1$ \\
\hline Salicylic Acid & 3.0 & 0.1 & $30: 1$ \\
\hline Phenobarbital & 6.0 & 1.3 & $4: 1$ \\
\hline
\end{tabular}

In addition to being sensitive and reliable, HPLC is an accurate, precise and reproducible technique. The technique involved less manipulation of the sample since, unlike UV spectrophotometry, no dilution was required. Using the WISP method of sample injection permitted small, accurate and reproducible injection volumes. The accuracy and precision the HPLC systems employed in this study were evaluated using the three drugs at three concentrations within each 
appropriate system. Five samples of each test solution were analyzed for drug content. In each case the accuracy and precision were good with the exception of salicylic acid, $10 \mu \mathrm{g} / \mathrm{ml}$ and phenobarbital $60 \mu \mathrm{g} / \mathrm{ml}$, as can be seen by the data presented in Table $X$. The technique was reproducible as demonstrated by constancy of retention times and peak heights of standard concentrations over the course of the study.

An advantage of particular importance to this work is the ability of HPLC to be a differential assay, thereby allowing analysis of two or more drugs without interference. This added another dimension to the study of drug transport across liquid membranes - investigation of co-uptake of drugs from one donor phase solution. Figure 5 shows the baseline separation obtained when acetylsalicylic and salicylic acids are in solution together. Figure 6 shows a typical chromatogram obtained for phenobarbital.

The HPLC assays used in this study were similar to those described in the literature $(59,60)$. However, unlike the assay described in the Water's Product Literature (60), in this project detection of phenobarbital was achieved at $254 \mathrm{~nm}$ rather than $195 \mathrm{~nm}$. The assay was adapted for use with a $254 \mathrm{~nm}$ lamp with good accuracy, precision, and sensitivity. Use of this wavelength was necessary since a variable wavelength detector was not available. The fact that the assay could be run with satisfactory results at $254 \mathrm{~nm}$, a generally available wavelength, is of considerable value. 
TABLE $X$

ACCURACY AND PRECISIONN OF HPLC TECHNIQUE

\begin{tabular}{|c|c|c|c|c|c|c|c|}
\hline \multirow[b]{2}{*}{$\begin{array}{l}\text { Concentration } \\
\qquad \dot{\mu g} / \mathrm{ml}\end{array}$} & \multicolumn{2}{|c|}{ Acetylsalicyl ic Acid } & \multicolumn{2}{|c|}{ Salicylic Acid } & \multirow[b]{2}{*}{$\begin{array}{c}\text { Concentration } \\
\mu \mathrm{g} / \mathrm{m} 1\end{array}$} & \multicolumn{2}{|c|}{ Phenobarbital } \\
\hline & $\begin{array}{l}\text { Detected } \\
(\mu g / \mathrm{ml})\end{array}$ & $\begin{array}{c}\text { Difference } \\
(\mu \mathrm{g} / \mathrm{ml})\end{array}$ & $\begin{array}{l}\text { Detected } \\
(1, \mathrm{~g} / \mathrm{ml})\end{array}$ & $\begin{array}{c}\text { Difference } \\
(\mu \mathrm{g} / \mathrm{ml})\end{array}$ & & $\begin{array}{l}\text { Detected } \\
(\mu \mathrm{g} / \mathrm{ml})\end{array}$ & $\begin{array}{c}\text { Difference } \\
(\mu \mathrm{g} / \mathrm{ml})\end{array}$ \\
\hline 5.0 & $\begin{array}{l}5.0 \\
4.5 \\
4.8 \\
4.8 \\
4.9 \\
4.8 \pm 0.1^{\star} \\
3.9 \% \star \star \star\end{array}$ & $\begin{array}{l}0.0 \\
0.5 \\
0.2 \\
0.2 \\
0.1 \\
4.0 \% \star \star \star\end{array}$ & $\begin{array}{l}5.1 \\
5.2 \\
5.0 \\
5.0 \\
4.7 \\
5.0 \pm 0.2 \star \\
3.7 \% \star \star\end{array}$ & 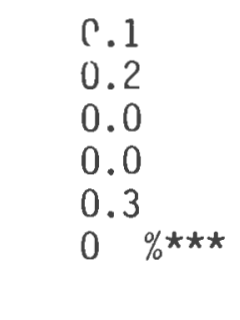 & 15.0 & $\begin{array}{l}14.9 \\
14.8 \\
14.8 \\
14.9 \\
14.8 \\
14.8 \pm 1^{\star} \\
0.4 \% \star \star\end{array}$ & $\begin{array}{l}0.1 \\
0.1 \\
0.2 \\
0.1 \\
0.2 \\
0.9 \% \star \star \star\end{array}$ \\
\hline 10.0 & $\begin{array}{l}10.3 \\
10.1 \\
10.3 \\
10.1 \\
10.2 \pm 0.1 \text { * } \\
1.0 \% \star \star\end{array}$ & $\begin{array}{l}0.3 \\
0.1 \\
0.3 \\
0.3 \\
0.1 \\
2.2 \% \star \star \star\end{array}$ & $\begin{array}{l}11.8 \\
12.1 \\
11.9 \\
12.1 \\
12.1 \\
12.0 \pm 0 . \pm \star \\
1.2^{\star}\end{array}$ & 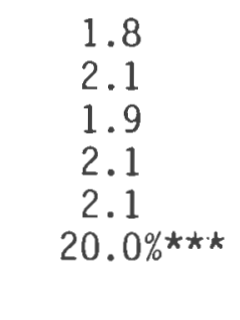 & 30.0 & $\begin{array}{l}30.9 \\
31.3 \\
30.4 \\
31.3 \\
30.9 \\
31.0 \pm 0.4^{\star} \\
1.2 \% \star\end{array}$ & $\begin{array}{l}0.9 \\
1.3 \\
0.4 \\
1.3 \\
0.9 \\
3.2 \% \star \star \star\end{array}$ \\
\hline 25.0 & $\begin{array}{l}25.9 \\
25.9 \\
25.5 \\
25.9 \\
25.9 \\
25.8 \pm 0.2^{\star} \\
1.0 \% \star \star\end{array}$ & $\begin{array}{l}0.9 \\
0.9 \\
0.5 \\
0.9 \\
0.9 \\
2.4 \% \star \star \star\end{array}$ & $\begin{array}{l}27.1 \\
27.7 \\
26.7 \\
28.0 \\
27.8 \\
27.5 \pm 0.5^{\star} \\
2.0 \star \star\end{array}$ & $\begin{array}{l}2.1 \\
2.7 \\
1.7 \\
3.0 \\
2.8 \\
9.8 \% \star \star \star\end{array}$ & 60.0 & $\begin{array}{l}61.0 \\
62.6 \\
63.0 \\
62.6 \\
62.1 \\
62.3 \pm 0.8 * \\
1.2 \% \star \star\end{array}$ & $\begin{array}{l}1.0 \\
2.6 \\
3.0 \\
2.6 \\
2.1 \\
26.5 \% \star \star \star\end{array}$ \\
\hline
\end{tabular}

*Mean \pm SD

** Coefficient of variation

$\star \star \star$ Relative Error 


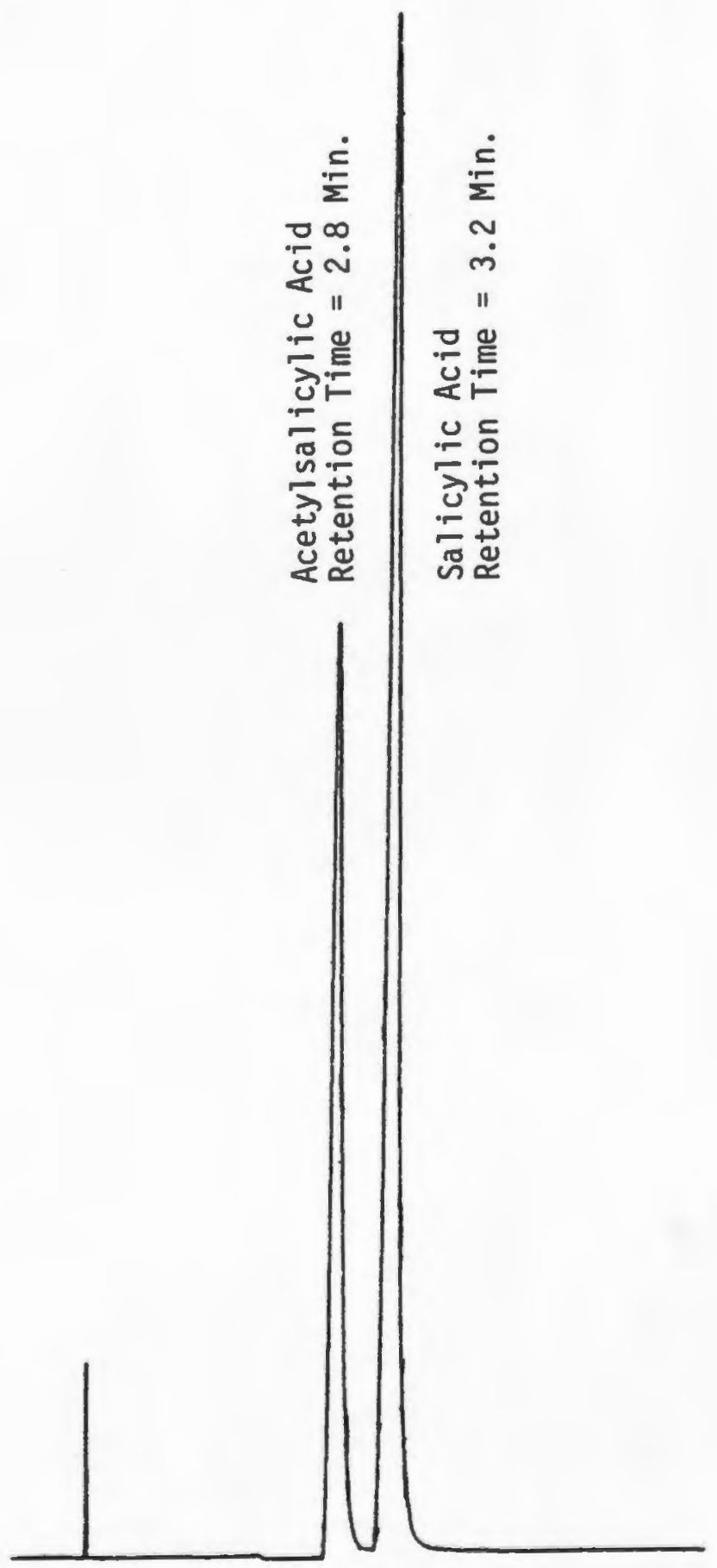

Fig. 5 Typical HPLC Chromatogram for Acetylsalicylic Acid and Salicylic Acid 


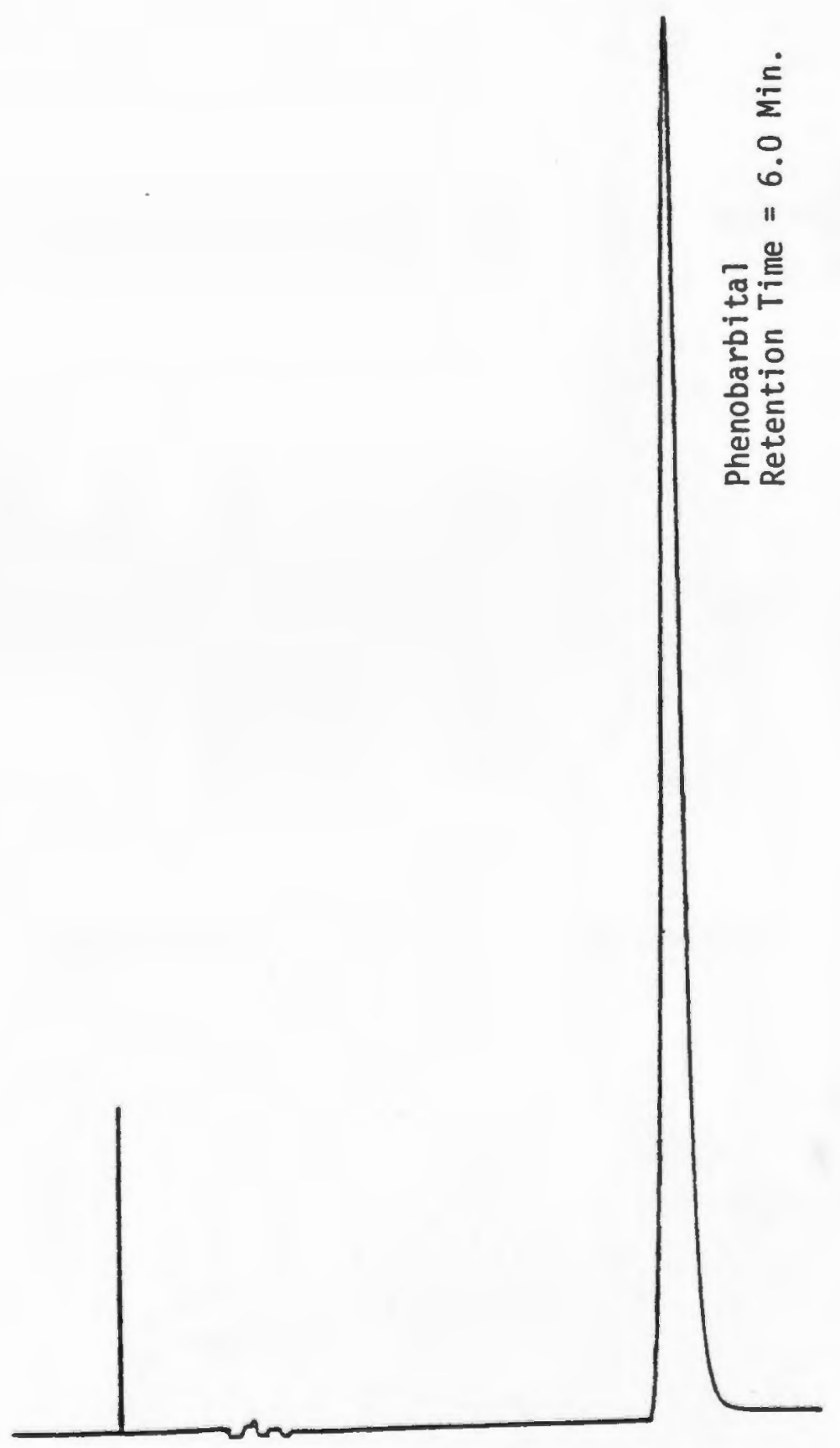

Fig. 6 Typical HPLC Chromatogram for Phenobarbital 


\section{Evaluation of Sampling Technique}

The sampling technique was quite reproducible. Table XI lists the percent of acetylsalicylic acid $1.0 \mathrm{~g} / 1$ remaining in the external donor phase at various times over 60 minutes for six replicate experimental runs. Table XII lists the same data for five replicate runs of the drug at a concentration of $0.5 \mathrm{~g} / 1$. Low standard deviations were noted at each time point throughout the experimental runs. A plot of concentration versus time for the two sets of data can be found in Figures 7 and 8 .

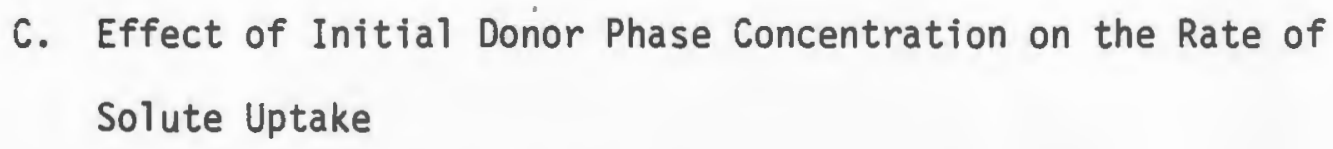

1. Acetylsalicylic Acid

The rate of uptake of acetylsalicylic acid as a function of initial donor phase concentration was investigated (refer to Figures 7 and 8). The apparent $\beta$ rate constants for each replicate run of acetylsalicylic acid $1.0 \mathrm{~g} / 1$ and $0.5 \mathrm{~g} / 1$ and the mean apparent $\beta$ rate constants are listed in Table XIII and XIV. The mean apparent $\beta$ rate constant was higher for the lower concentration of acetylsalicylic acid. This proved to be a statistically significant difference.

Alteration of the properties of the membrane surface may occur at the external donor phase/liquid membrane interface or at the liquid membrane/internal donor phase interface. It is possible that an interaction between the solute and the surfactant causes an alteration in one or both of these surfaces which may alter the transport of drug to allow a modification of diffusion either into or out of the 1 iquid membrane. 
TABLE XI

COMPARISON OF PERCENT ACETYLSALICYLIC ACID $1.0 \mathrm{~g} / 1$ REMAINING

IN EXTERNAL AQUEOUS PHASE AFTER TREATMENT WITH LIQUID MEMBRANE

AT VARIOUS TIMES IN SIX REPLICATED EXPERIMENTS

\begin{tabular}{ccrrrrrl}
\hline \hline $\begin{array}{c}\text { Time } \\
\text { (mins) }\end{array}$ & \multicolumn{1}{c}{1} & \multicolumn{1}{c}{ Replicates } & \multicolumn{1}{c}{ 3 } & \multicolumn{1}{c}{ Mean } \\
\hline 0 & 100.00 & 100.00 & 100.00 & 100.00 & 100.00 & 100.00 & $100 \pm 0$ \\
1 & 95.54 & 92.35 & 91.34 & 90.45 & 90.15 & 92.90 & $92.12 \pm 1.98$ \\
2 & 90.74 & 89.14 & 88.38 & 87.98 & 87.55 & 88.70 & $88.75 \pm 1.12$ \\
3 & 88.57 & 87.58 & 85.42 & 86.29 & 81.28 & 82.35 & $85.25 \pm 2.89$ \\
4 & 79.86 & 78.16 & 80.59 & 81.57 & 79.76 & 77.07 & $79.50 \pm 1.64$ \\
5 & 75.05 & 75.17 & 75.66 & 74.83 & 74.89 & 74.49 & $75.02 \pm 0.39$ \\
6 & 74.06 & 73.61 & 71.49 & 69.44 & 70.77 & 72.34 & $71.95 \pm 1.75$ \\
7 & 67.77 & 68.96 & 67.32 & 70.22 & 66.99 & 68.99 & $68.38 \pm 1.23$ \\
8 & 65.03 & 64.09 & 64.34 & 63.71 & 63.74 & 64.80 & $64.79 \pm 1.37$ \\
9 & 61.71 & 61.09 & 60.09 & 60.56 & 59.52 & 61.36 & $60.72 \pm 0.82$ \\
10 & 53.25 & 60.31 & 57.89 & 54.94 & 58.23 & 58.45 & $57.18 \pm 2.59$ \\
12 &.-- & 54.21 & 53.51 & 49.55 & 51.62 & 52.96 & $52.37 \pm 1.84$ \\
14 & 46.06 & 48.00 & 46.82 & 42.92 & 46.65 & 49.09 & $46.59 \pm 2.10$ \\
16 & 41.60 & 44.90 & 42.76 & 39.66 & 41.02 & 43.16 & $42.18 \pm 1.83$ \\
18 & 38.34 & 39.25 & 38.38 & 33.48 & 37.77 & 39.61 & $37.81 \pm 2.22$ \\
20 & 32.34 & 35.70 & 33.88 & 32.46 & 33.66 & 35.52 & $33.76 \pm 1.68$ \\
25 & 23.39 & 26.72 & 25.33 & 23.03 & 25.87 & 27.99 & $25.38 \pm 1.93$ \\
30 & 15.23 & 19.40 & 16.01 & 17.87 & 19.37 & 21.20 & $18.33 \pm 2.00$ \\
40 & 8.23 & 10.98 & 9.54 & 10.45 & 10.93 & 11.30 & $10.24 \pm 1.16$ \\
50 & 4.69 & 5.66 & 4.93 & 6.07 & 7.68 & 6.35 & $5.90 \pm 1.08$ \\
60 & 3.77 & 3.99 & 2.85 & 2.58 & 4.22 & 3.34 & $3.29 \pm 0.61$ \\
\hline
\end{tabular}


TABLE XII

COMPARISON OF PERCENT ACETYLSALICYLIC ACID $0.5 \mathrm{~g} / 1$ REMAINING IN EXTERNAL AQUEOUS PHASE AFTER TREATMENT WITH LIQUID MEMBRANE AT VARIOUS TIMES IN FIVE REPLICATED EXPERIMENTS

\begin{tabular}{|c|c|c|c|c|c|c|}
\hline $\begin{array}{l}\text { Time } \\
\text { (mins) }\end{array}$ & 1 & 2 & $\begin{array}{c}\text { Replicates } \\
3\end{array}$ & 4 & 5 & $\begin{array}{l}\text { Mean } \\
\pm 1 \text { SD }\end{array}$ \\
\hline 0 & 100.00 & 100.00 & 100.00 & 100.00 & 100.00 & $100.00 \pm 0$ \\
\hline 1 & 88.77 & 93.36 & 86.96 & 91.30 & 90.41 & $90.16 \pm 2.44$ \\
\hline 2 & 85.59 & 89.16 & 82.82 & 81.74 & 83.66 & $84.59 \pm 2.92$ \\
\hline 3 & 78.81 & 80.31 & 79.09 & 76.52 & 79.08 & $78.76 \pm 1.38$ \\
\hline 4 & 74.58 & 76.77 & 69.36 & 73.70 & .72 .77 & $74.05 \pm 2.96$ \\
\hline 5 & 67.58 & 68.14 & 62.11 & 68.04 & 70.15 & $67.20 \pm 3.01$ \\
\hline 6 & 64.41 & 66.15 & 59.00 & 65.57 & 61.00 & $63.23 \pm 3.09$ \\
\hline 7 & 59174 & 60.40 & 55.90 & 57.39 & 57.30 & $58.15 \pm 1.87$ \\
\hline 8 & 56.57 & 56.42 & 50.31 & 53.26 & 53.59 & $54.01 \pm 2.62$ \\
\hline 9 & 52.33 & 51.77 & 48.45 & 49.57 & 50.54 & $50.53 \pm 1.58$ \\
\hline 10 & 48.31 & 48.45 & 44.72 & 46.09 & 47.06 & $46.93 \pm 1.57$ \\
\hline 12 & 42.37 & 38.50 & 38.72 & 41.96 & 39.87 & $40.28 \pm 1.80$ \\
\hline 14 & 36.87 & 32.96 & 31.47 & 36.74 & 34.42 & $34.49 \pm 2.36$ \\
\hline 16 & 31.99 & 31.64 & 26.29 & 28.48 & 28.76 & $29.43 \pm 2.38$ \\
\hline 18 & 27.97 & 24.78 & 21.53 & 25.87 & 23.31 & $24.69 \pm 1.72$ \\
\hline 20 & 23.73 & 21.90 & 19.88 & 24.36 & 20.26 & $22.03 \pm 2.01$ \\
\hline 25 & 15.89 & 14.82 & 13.46 & 13.26 & 12.64 & $14.01 \pm 1.32$ \\
\hline 30 & 11.02 & 12.61 & 8.70 & 7.17 & 7.84 & $9.47 \pm 2.28$ \\
\hline 40 & 6.58 & 3.54 & 4.14 & 2.39 & 1.96 & $3.73 \pm 1.82$ \\
\hline 50 & 2.54 & 1.11 & 1.66 & --- & --- & $1.77^{*} \pm 0.72$ \\
\hline 60 & 1.48 & 3.76 & 1.24 &.-- &.-- & $2.16^{\star} \pm 1.39$ \\
\hline
\end{tabular}

*Based on Runs 1-3 


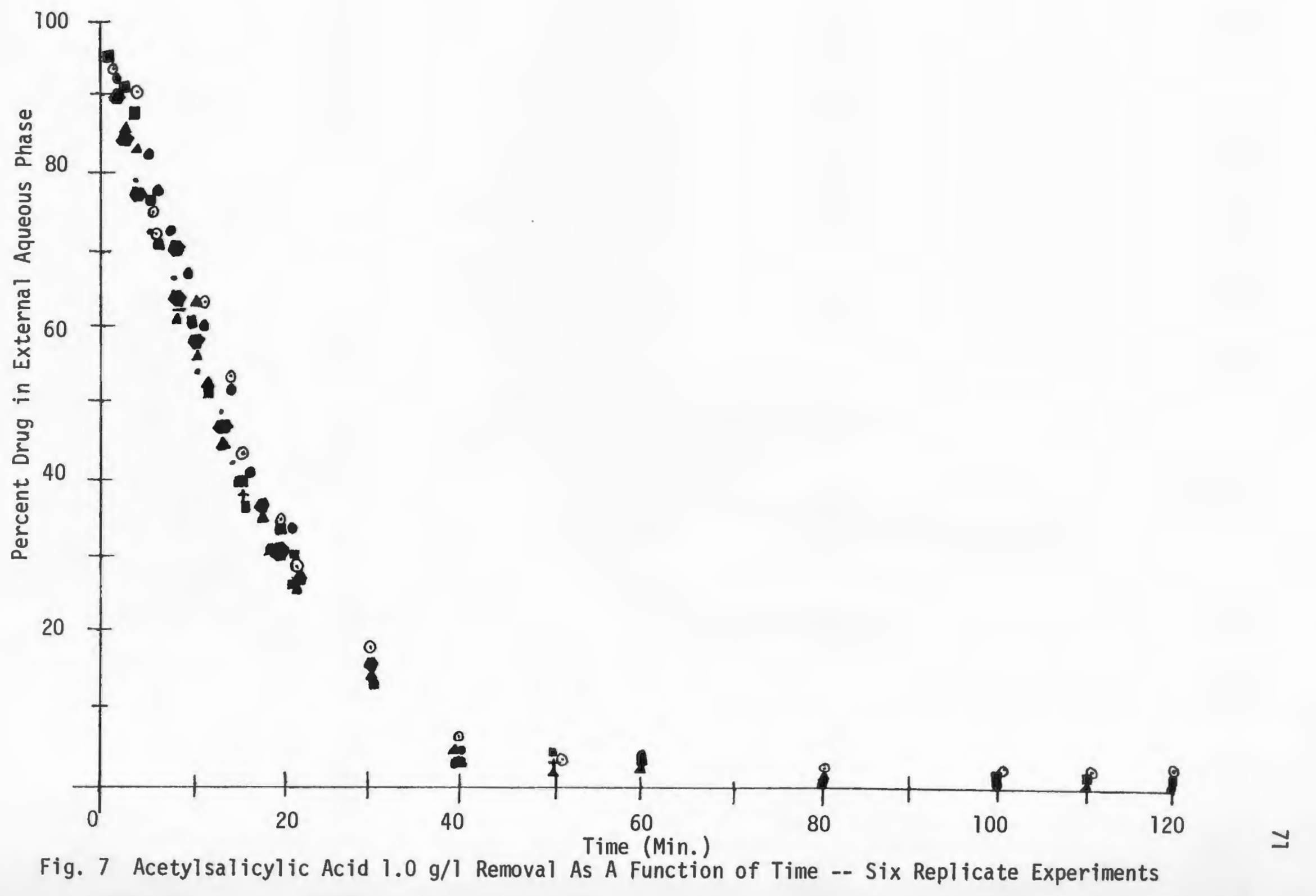




$$
4
$$


Since there is a continual decrease in drug concentration in the external donor phase and no discernable a phase, it seems likely that this phenomena of surface alteration would occur at the liquid membrane/internal aqueous phase interface. It may further be speculated that the micro rate constant of the apparent $B$ phase controlling the transport of solute out of the internal aqueous phase may become greater as the concentration of solute increases, thus resulting in an overall decrease in the apparent $B$ rate. If in fact membrane surface alteration is occurring, surfactant would be displaced from the interface and possibly form micelles. If this were the case, solute may become trapped in the micelle or the transport of solute may be otherwise affected by the presence of micelles.

Another possible reason for displacement of surfactant may be due to the limited capacity of the internal aqueous phase droplets. As more solute tries to eriter these droplets, capacity limitations may be exceeded thereby forcing rearrangement in the packing of the surfactant molecules and an alteration in the permeability of the membrane. However, it will be appreciated that the above discussion is in the realm of reasonable speculation rather than firm conclusions.

2. Salicylic Acid

Four donor solutions, each with a different initial molar concentration of salicylic acid $(2.5 \mathrm{mM} ; 4.1 \mathrm{mM} ; 5.6 \mathrm{mM} ; 7.2 \mathrm{mM})$ were studied for affect of concentration on solute uptake. Figure 9 shows the mean apparent 3 rate constants for each sec of uptake runs as a function of molar concentration. These are listed in Table XV. 
The rate of uptake at $2.5 \mathrm{mM}$ was very rapid with less than one percent of the drug remaining in the external donor phase after three minutes. Sampling every 30 seconds over the three minutes allowed the acquisition of more data points enabling calculation of an apparent $\beta$ rate constant. Although this was a single run and the limitations associated with assigning sampling times were recognized, two additional runs showedapproximately the same percent of drug remaining after one minute in the external donor phase $(21.28 \% ; 22.14 \%, 25.00 \%)$.

The same trend of decreasing apparent $B$ with increased donor concentration over a wider range was observed for the uptake of salicylic acid as was noted for acetysalicylic acid. Thus in summary, the results for these two solutes do indicate that as the initial concentration of the drug in the donor phase increases, the apparent $\beta$ does have a tendency to decrease.

TABLE XIII

APPARENT $\&$ RATE CONSTANTS FOR EACH REPLICATE RUNS OF ACETYLSALICYLIC ACID $1.0 \mathrm{~g} / 1$ UPTAKE.

\begin{tabular}{cc}
\hline Run & Apparent $\beta$ Rate Constant $\times 10^{-2}\left(\mathrm{~min}^{-1}\right)$ \\
\hline 1 & 5.88 \\
2 & 5.75 \\
3 & 5.98 \\
4 & 7.11 \\
5 & 5.22 \\
6 & 5.51 \\
Mean & 5.91 \\
\hline
\end{tabular}


TABLE XIV

APPARENT $\beta$ RATE CONSTANTS FOR EACH REPLICATE RUN

OF ACETYLSALICYLIC ACID $0.5 \mathrm{~g} / 1$ UPTAKE.

\begin{tabular}{cc}
\hline Run & Apparent $\beta$ Rate Constant $\times 10^{-2}\left(\min ^{-1}\right)$ \\
\hline 1 & 7.06 \\
2 & 8.56 \\
3 & 7.97 \\
4 & 8.90 \\
5 & 9.24 \\
Mean & 8.34 \\
\hline
\end{tabular}

TABLE XV

MEAN APPARENT $\beta$ RATE CONSTANTS FOR UPTAKE OF VARIOUS

MOLAR CONCENTRATIONS OF SALICYLIC ACID

\begin{tabular}{cc}
\hline \hline Molar Concentration (mM) & Mean Apparent $\beta$ Rate Constant $\times 10^{-2}(\min -1)$ \\
\hline 2.5 & $96.11(1)^{*}$ \\
4.1 & $74.89(2)$ \\
5.6 & $44.09(1)$ \\
7.2 & $49.67(2)$ \\
\hline
\end{tabular}

* Number of Runs

D. Effect of Liquid Membrane 0il/Water Ratio on the Rate of Salicylic Acid Uptake

Extraction curves in Figure 10 show the effect of liquid membrane $0 i 1 /$ water ratio on the rate of uptake of salicylic acid $1.0 \mathrm{~g} / 1$. The 


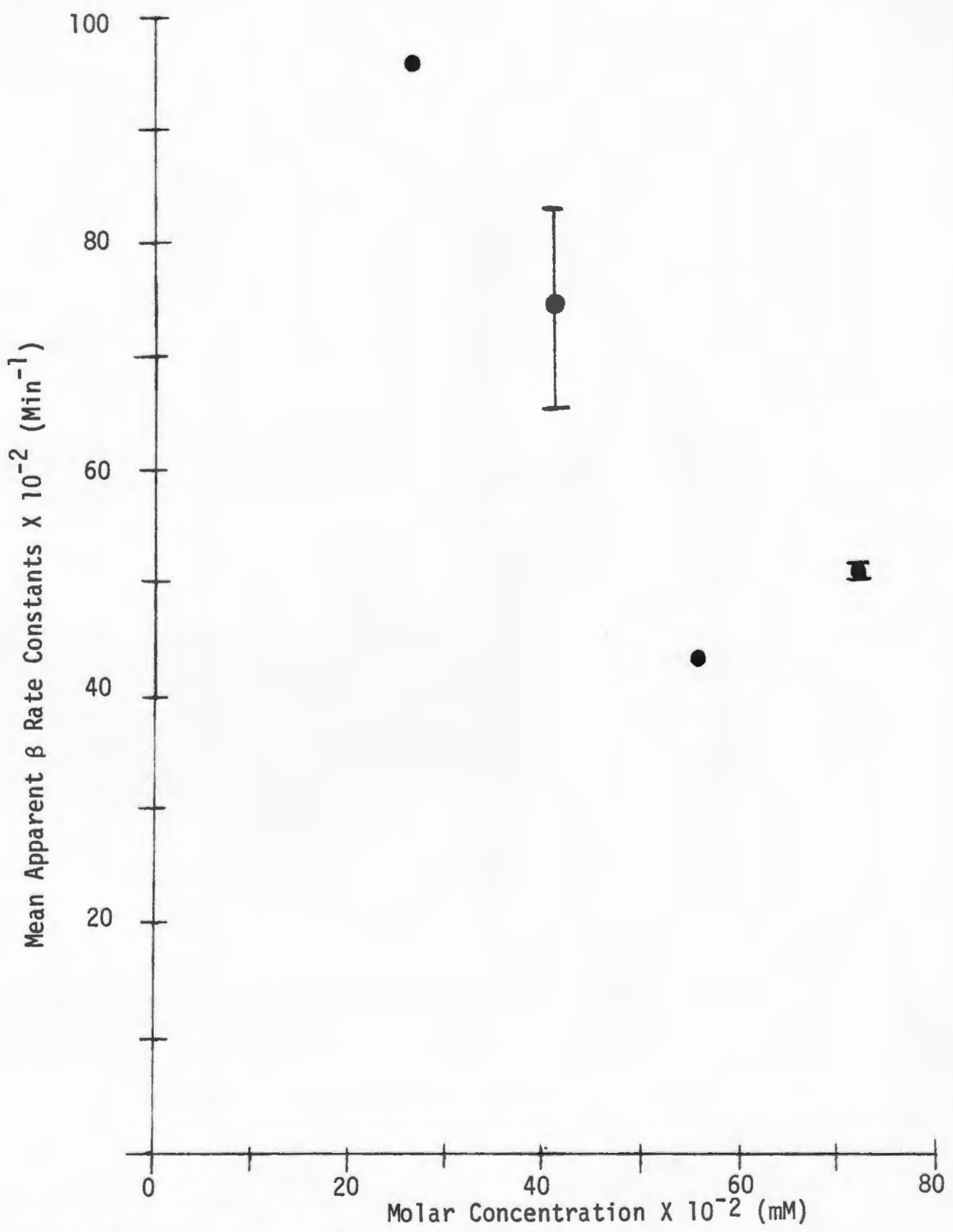

Fig. 9 Mean Apparent $B$ Rate Constants As A Function of Initial Salicylic Acid Concentration 


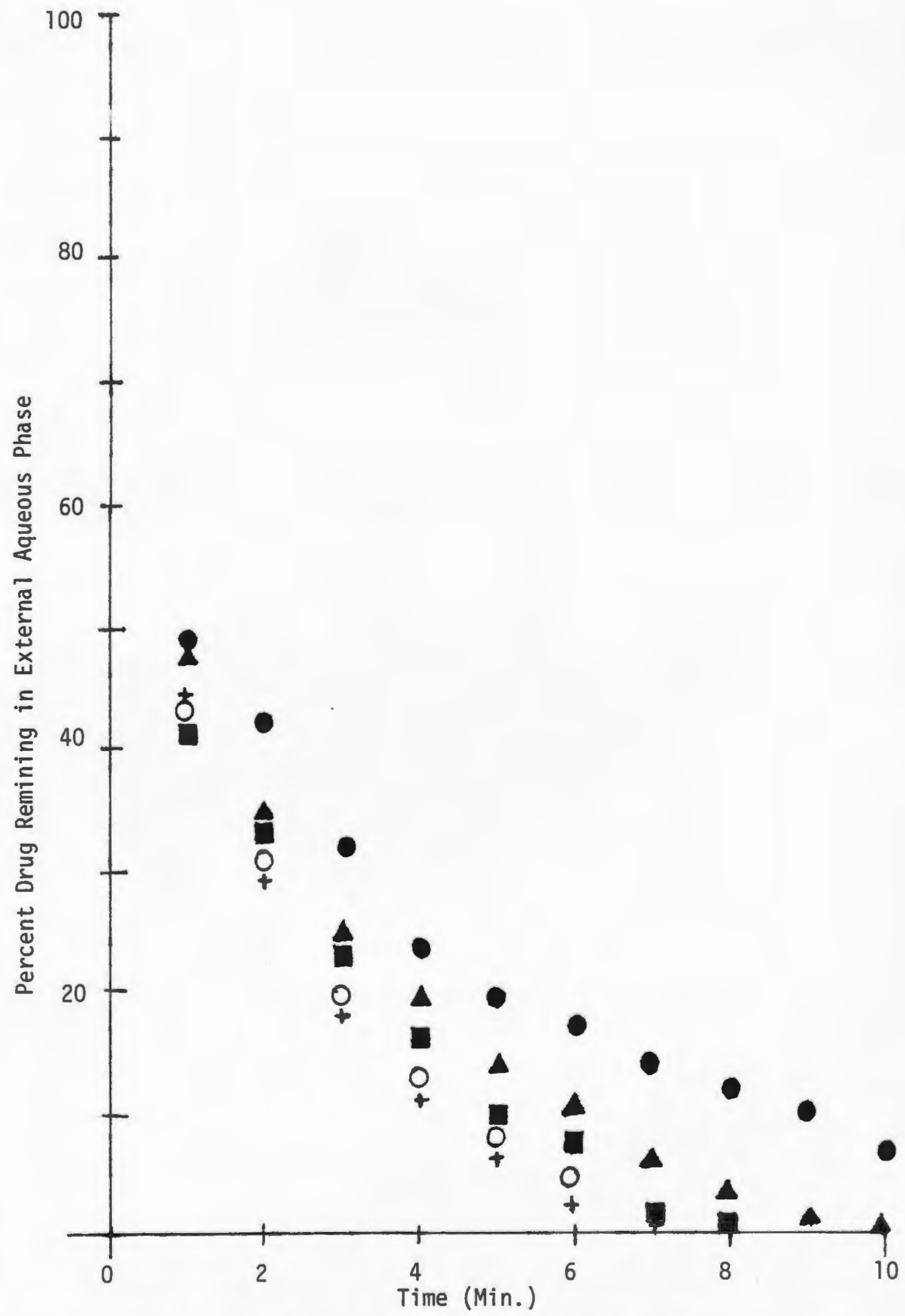

Fig. 10 Salicylic Acid $1.0 \mathrm{~g} / 1$ Removal As A Function Time Using Liquid Membranes with Different 0 il/Water Ratios

○ $0.5 ;+0.67 ; 01.0 ; \Delta 2.0 ; \bigcirc 3.0$ 
mean apparent $\beta$ rate constants for these uptake processes are tabulated in Table XVI. A plot of the mean apparent $\beta$ rate versus liquid membrane oil/water ratio is presented in Figure 11. As the oil/water ratio increased, the drug was extracted less rapidly with the exception of the $3: 1$ liquid membrane. In this case a variation in the apparent $\beta$ rate constant was observed and thisapparent $\beta$ rate was greater than that of the 2:1 liquid membrane.

It is hypothesized that the oil phase acts as "resistance" in the transport process. As the volume or the thickness of the liquid membrane increased, the apparent $\beta$ rate constant consequently reduced, as would be expected from a consideration of Fick's law (Equation (2)). However, it is appreciated that other factors such as variability in the mean droplet size of the internal aqueous phase could conceivably be responsible for the reduced rate constant. It is quite possible that factors which modify the properties of one interface will not alter the properties of the other. Whereas the external aqueous phase was constantly stirred throughout the experimental run, the internal aqueous phase was not. It is possible that the internal aqueous phase had changed with the formation of larger size droplets which were not broken up by agitation. This would result in a decrease in surface area at the liquid membrane/internal aqueous phase interface available for diffusion and thus a reduced apparent $\beta$. 
TABLE XVI

MEAN APPARENT B RATE CONSTANTS FOR THE UPTAKE OF SALICYLIC ACID $1.0 \mathrm{~g} / 1$ BY LIQUID MEMBRANES WITH VARIOUS OIL/WATER RATIOS

\begin{tabular}{cc}
\hline \hline 0 i1/Water Ratio & Mean Apparent $B$ Rate Constant $\times 10^{-2}\left(\mathrm{~min}^{-1}\right)$ \\
\hline 0.5 & $64.98(2) \star$ \\
0.67 & $48.75(2)$ \\
1.0 & $49.67(2)$ \\
2.0 & $18.33(2)$ \\
3.0 & $33.10(2)$ \\
\hline
\end{tabular}

*Number of Runs

E. Effect of Donor Phase pH on the Rate of Solute Uptake

1. Acetylsalicylic Acid

The effect of donor phase $\mathrm{pH}$ on the rate of acetylsalicylic acid uptake was investigated using three different pH donor solutions $(\mathrm{pH} 1, \mathrm{pH} 2, \mathrm{pH} 3)$. Figure 12 shows a plot of mean apparent $\mathrm{B}$ as a function of $\mathrm{pH}$. This mean apparent $\beta$ rate constants are listed in Table XVII. For acetylsalicylic acid, since at low pH more drug exists in its unionized form than at high $\mathrm{pH}$, it was expected that the apparent $\beta$ would decrease with increased $\mathrm{pH}$. In fact, however, the apparent $\beta$ rate constant increased and then decreased with a change in $\mathrm{pH}$ from 1 to 2 differing from that which was expected.

A more extensive study of acetysalicylic acid uptake as a function of $\mathrm{pH}$ is necessary before any definite conclusions may be drawn. 


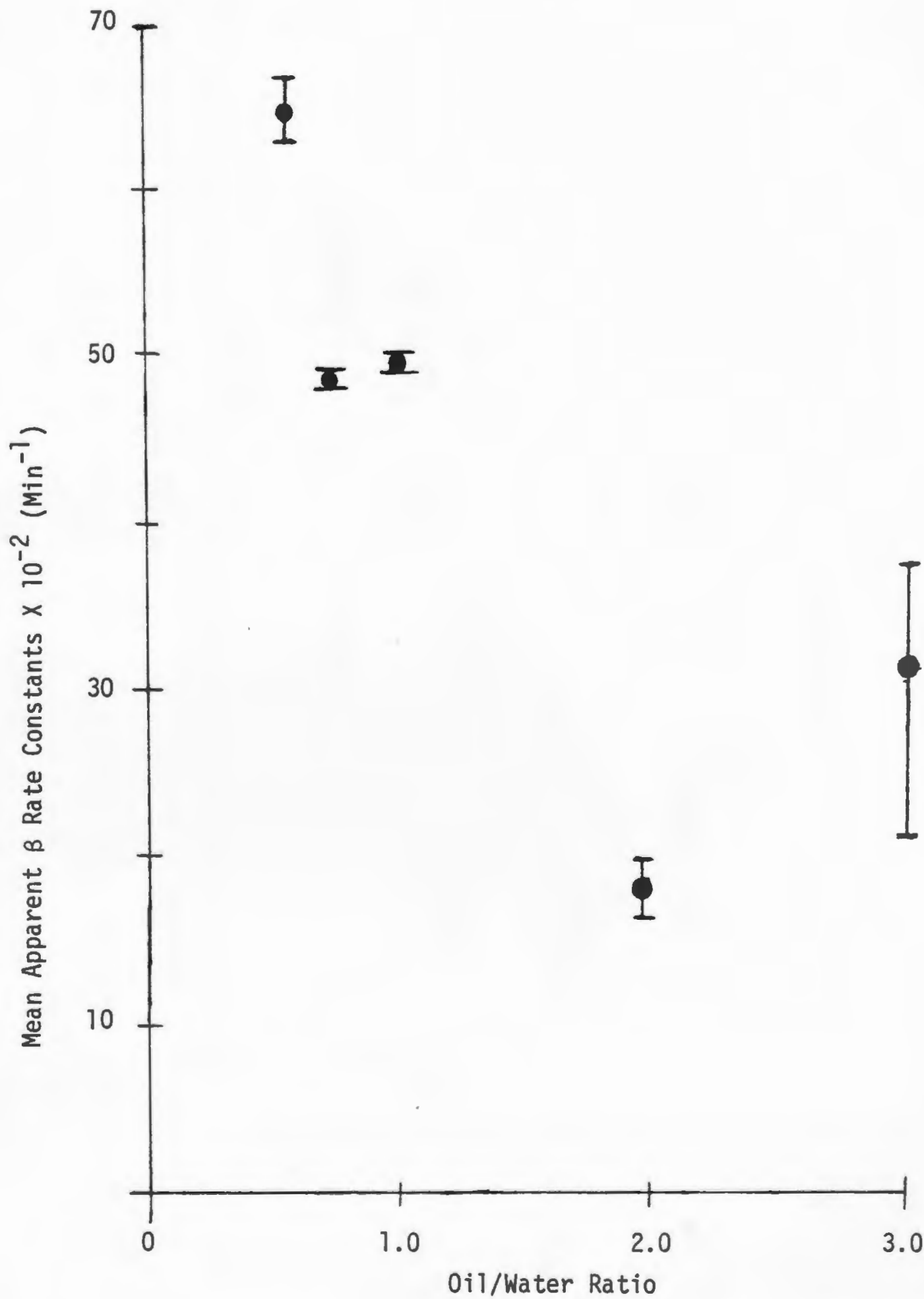

Fig. 11 Mean Apparent $\beta$ Rate Constants for Salicylic Acid Removal As A Function of Liquid Membrane 0i1/Water Ratio 


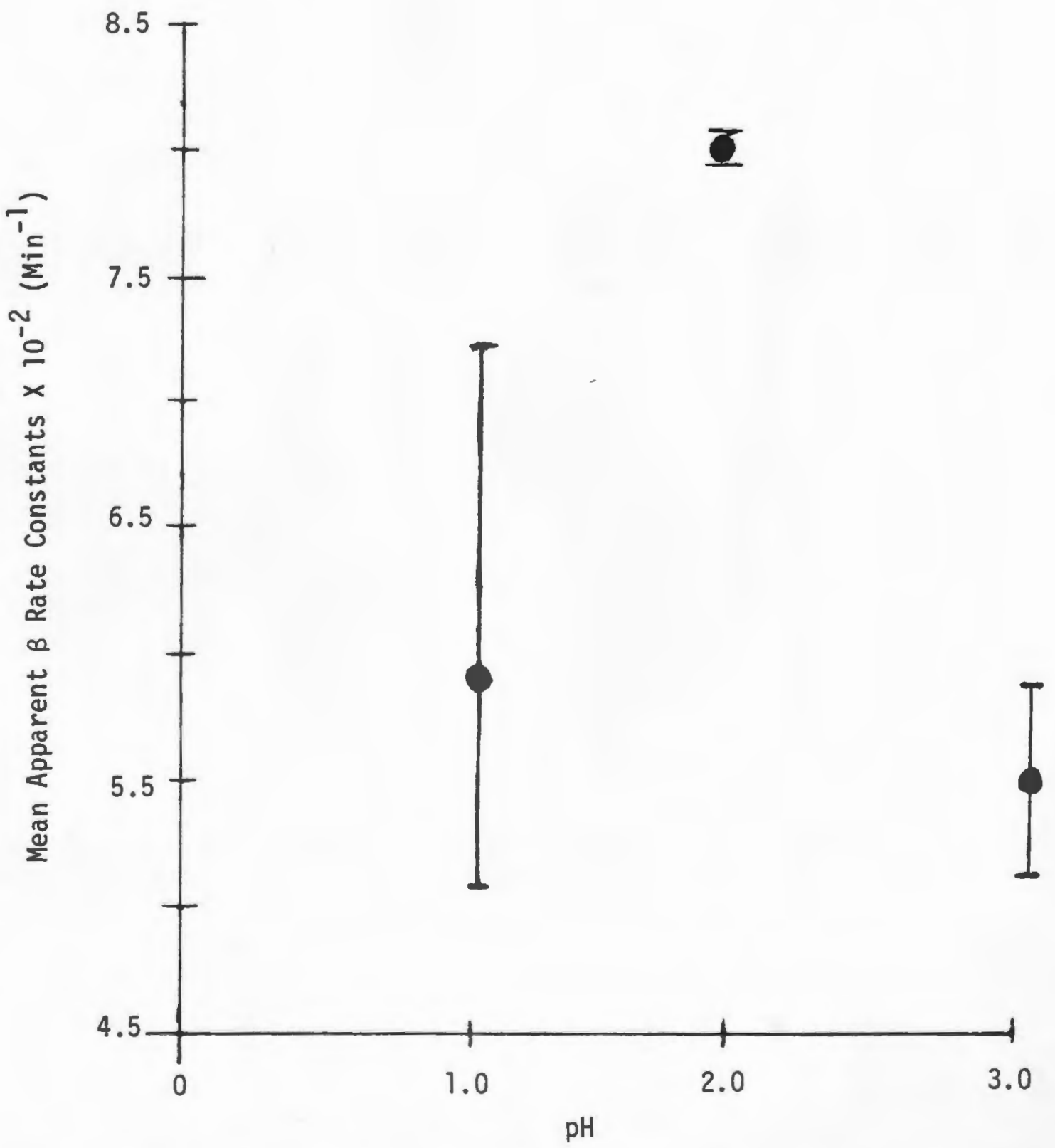

Fig. 12 Mean Apparent $\beta$ Rate Constants for Acetylsalicylic Acid Removal As A Function of External Aqueous Phase pH 
TABLE XVII

MEAN APPARENT B RATE CONSTANTS FOR THE UPTAKE OF A.CETYSALICYLIC

ACID $1.0 \mathrm{~g} / 1$ UPTAKE AS A FUNCTION OF DONOR PHASE $\mathrm{pH}$.

\begin{tabular}{cc}
\hline $\mathrm{pH}$ & Mean Apparent $\beta$ Rate Constant $\times 10-2(\mathrm{~min}-1)$ \\
\hline 1 & $5.91(6)^{*}$ \\
2 & $7.92(2)$ \\
3 & $5.52(2)$ \\
\hline
\end{tabular}

* Number of Runs

2. Salicylic Acid

The effect of donor solution $\mathrm{pH}$ on the rate of salicylic acid $1.0 \mathrm{~g} / 1$ uptake is shown in Figure 13. The mean apparent $\beta$ rate

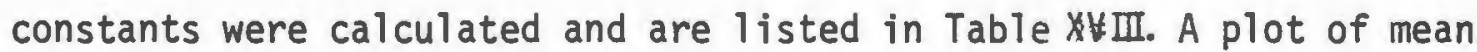
$\beta$ as a function of $\mathrm{pH}$ (Figure 14) shows that as the $\mathrm{pH}$ of the donor phase increased, the rate of drug was extracted at a slower rate. This result was expected since at lower pH (below 2.97, the pKa for salicylic acid), more unionized drug was present in the external donor phase for removal in accordance with the pH-partition theory. Using the Henderson-Hasselbach equation (Equation 4), it was possible to calculate the percent of unionized drug in the donor phase for any $\mathrm{pH}$ at time 0 (see Table XVIII).

An attempt was made to predict the rate of salicylic acid $1.0 \mathrm{~g} / 1$ uptake from donor solutions of various $\mathrm{pH}$ using the HendersoriHasiselbach equation and the S/360 Continuous System Modeling Program (CSMP). CSMP is ". . a problem-oriented program designed to facilitate the digital simulation of a continuous process. . ."(64). 
The simple model used to describe drug uptake anpears to be insufficient when used in conjunction with CSMP to predict drug uptake as a function of $\mathrm{pH}$ in a quantitative manner.

One probable explanation for the failure of the simple model and CSMP to quantitatively predict the rate of drug uptake is the fact that the surfactant used in the preparation of these emulsions contains an amino functional group. At low pH these groups will be largely ionized, whereas at higher $\mathrm{pH}$ they will be predominately unionized. Ionization of the amino functional groups will tend to cause mutual repulsion of the head groups as well as alter the effective HLB of the system. This head group repulsion is likely to reduce the packing density of the surfactant molecules in the condensed film on both interfaces. This difference in the density of the condensed film of surfactant is highly likely to affect the interfacial film permeability and also there will be a change in the total net charge of the interfacial head groups.

Further, for any surfactant system with a finite amount of surfactant present, reduction in the amount of surfactant present at the interfaces must, of necessity, increase the amount of surfactant present in either the oil or water phase as monomeric or micellar species. Although it is interesting to speculate how the above changes could modify the drug membrane transport, there are so many possibilities that at present it would be invalid to draw any conclusions. For example, it has already been established that the bulk diffusion coefficient of drugs can be both increased and decreased 
by the presence of surfactants. It is noteworthy in this respect that certain other workers using liquid membranes have employed "mobile" surfactants as carriers to improve transport across liquid membranes (14). TABLE XVIII

MEAN APPARENT $\beta$ RATE CONSTANTS FOR THE UPTAKE OF SALICYLIC ACID $1.0 \mathrm{~g} / 1$ AS A FUNCTION OF $\mathrm{pH}$.

\begin{tabular}{lcc}
\hline \hline $\mathrm{pH}$ & $\begin{array}{c}\text { Percent Unionized } \\
\text { at Time } 0\end{array}$ & Mean Apparent $\beta$ Rate Constant $\times 10^{-2}\left(\min ^{-1}\right)$ \\
\hline 1 & 98.93 & $81.48(2) *$ \\
2 & 89.28 & $54.64(2)$ \\
3.5 & 13.83 & $13.83(2)$ \\
6 & 0.01 & $0.59(2)$ \\
\hline
\end{tabular}

* Number of Runs

F. Effect of Viscosity on the Rate of Salicylic Acid Uptake As was expected, a slower rate of salicylic acid $1.0 \mathrm{~g} / 1$ uptake was observed as the viscosity of the liquid membrane increased. Mean apparent $\beta$ rate constants were calculated and can be found in Table XIX. A plot of salicylic acid as a function of liquid membrane viscosity is shown in Figure 15. Since the change in viscosity of each liquid membrane results from using oils with different viscosities, it is probable that the change in the apparent $\beta$ rate is directly attributed to the diffusivity ability of the solute. This may be applied to Fick's law (Equation 2). A larger diffusion coefficient will result in a faster rate of transport. 


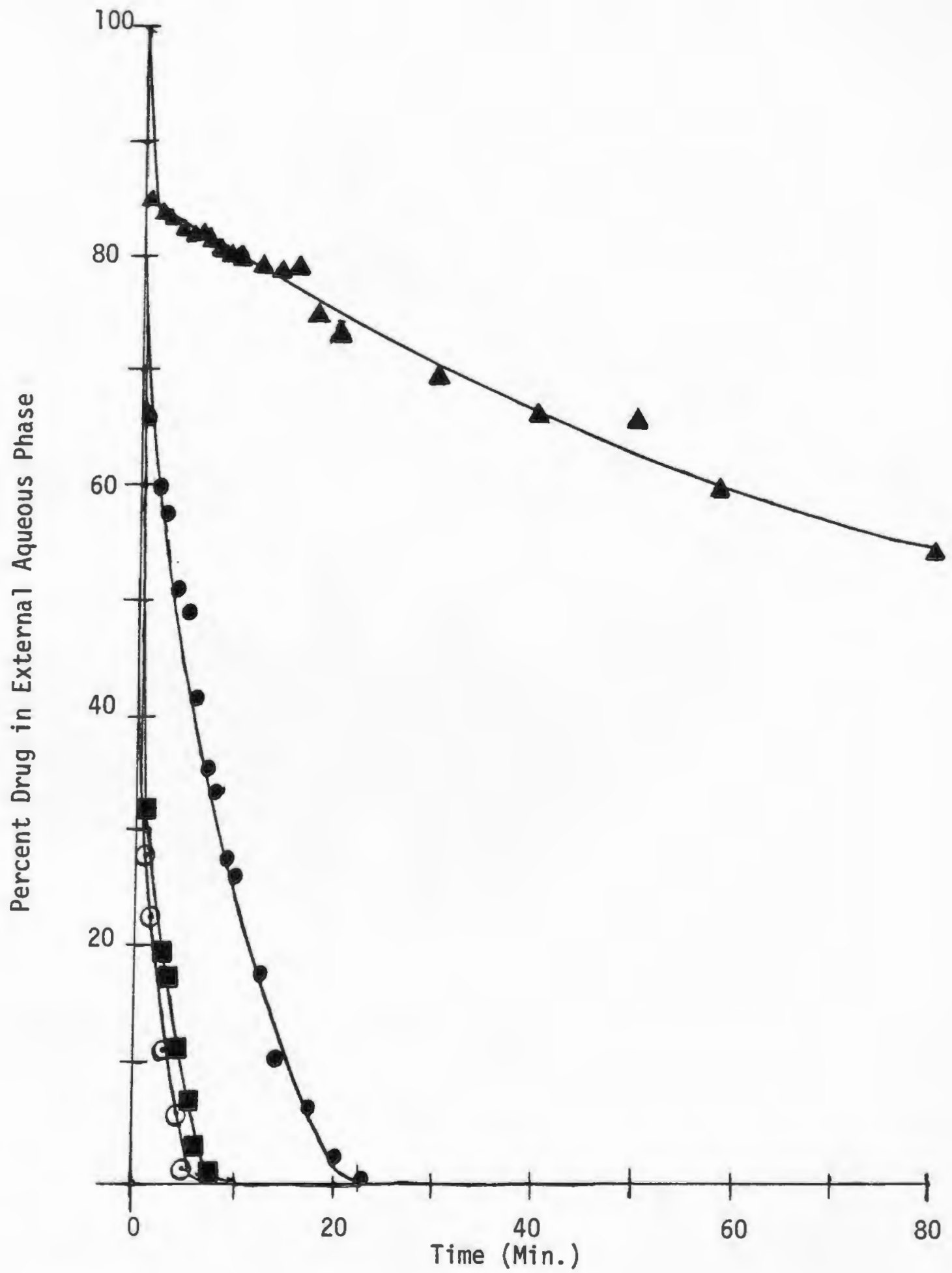

Fig. 13 Salicylic Acid $1.0 \mathrm{~g} / 1$ Removal As A Function of Time Using External Aqueous Phases with Different $\mathrm{pHs}$

○ $\mathrm{pH} 1 ; \square \mathrm{pH} 2 ; \bullet \mathrm{pH} 3.5 ; \Delta \mathrm{pH} 6$ 


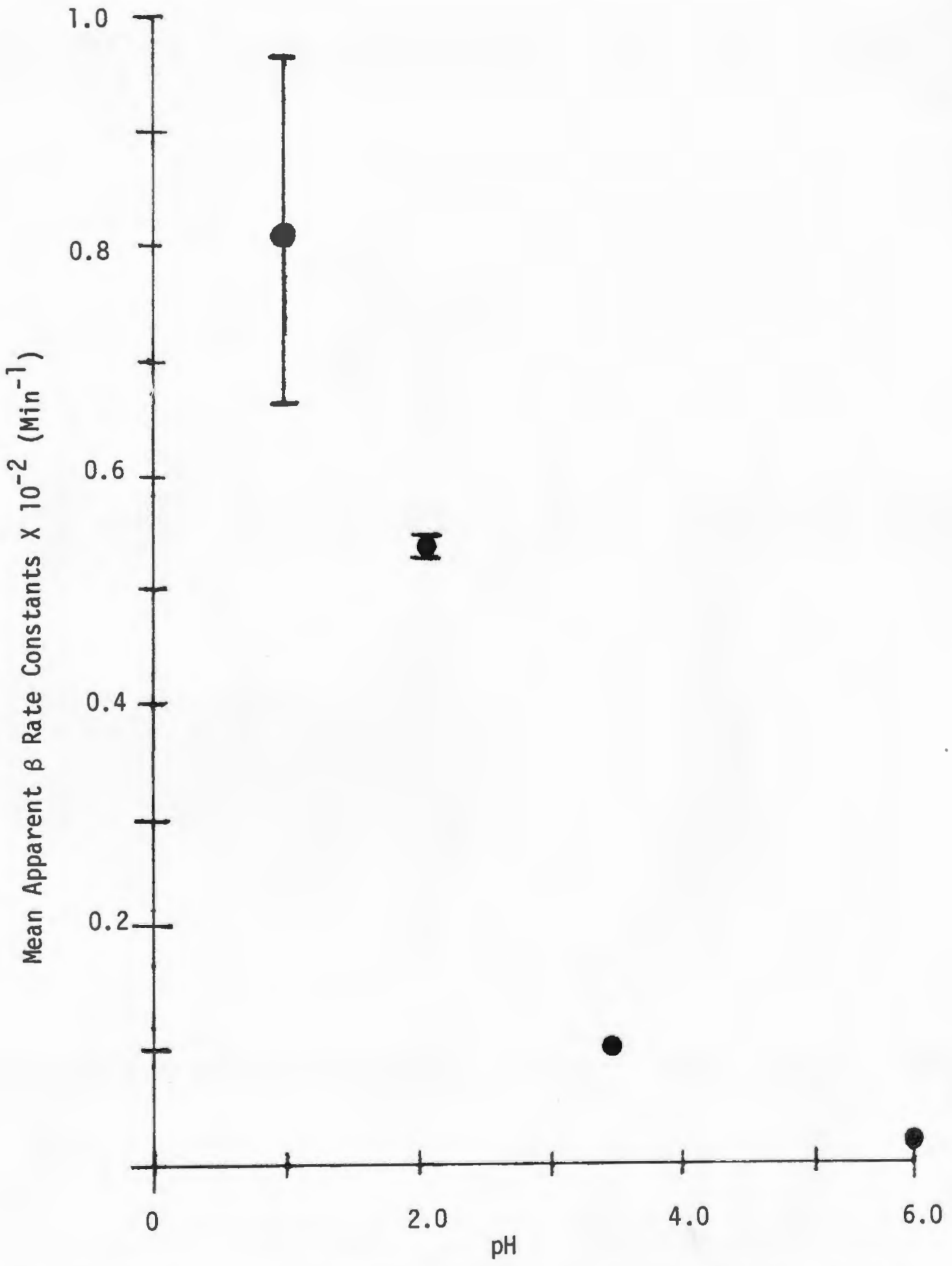

Fig. 14 Mean Apparent $\beta$ Rate Constants for Salicylic Acid 1.0 g/1 Removal As A Function of External Aqueous Phase $\mathrm{pH}$ 
TABLE XIX

MEAN APPARENT $\beta$ RATE CONSTANTS FOR THE UPTAKE OF SALICYLIC ACID $1.0 \mathrm{~g} / 1$ AS A FUINCTION OF LIQUID MEMBRANE VISCOSITY

\begin{tabular}{rl} 
Viscosity (cps) & Mean Apparent $\beta$ Rate Constants $\times 10-2($ min -1$)$ \\
\hline 3.6 & $49.67(2) \star$ \\
9.9 & $46.63(2)$ \\
12.8 & $31.17(2)$ \\
21.6 & $10.00(2)$ \\
\hline
\end{tabular}

* Number of Runs

G. Effect of Temperature on Solute Uptake

1. Salicylic Acid

The effect of temperature on the rate of salicylic acid uptake was studied at $4,16,28,37.5$, and $50^{\circ} \mathrm{C}$. A plot of percent drug uptake versus time is shown in Figure 16. Table XX lists the mean apparent $\beta$ rate constants. As expected, the results show that as the temperature increased, the apparent $\beta$ rate constants for the process increased. Due to the extremely rapid removal of drug at $50^{\circ} \mathrm{C}$ (approximately $94 \%$ of the total drug was removed in one minute), an insufficient number of data points prevented calculation of a rate constant. The high temperature also had an effect on the integrity of the liquid membrane. By extending the time of one run at $50^{\circ} \mathrm{C}$ to five hours, the steady leakage of removed drug back out of the 1iquid membrane into the external aqueous phase was observed (Figure 17). The high temperature had imposed an abnormal stress on the system 


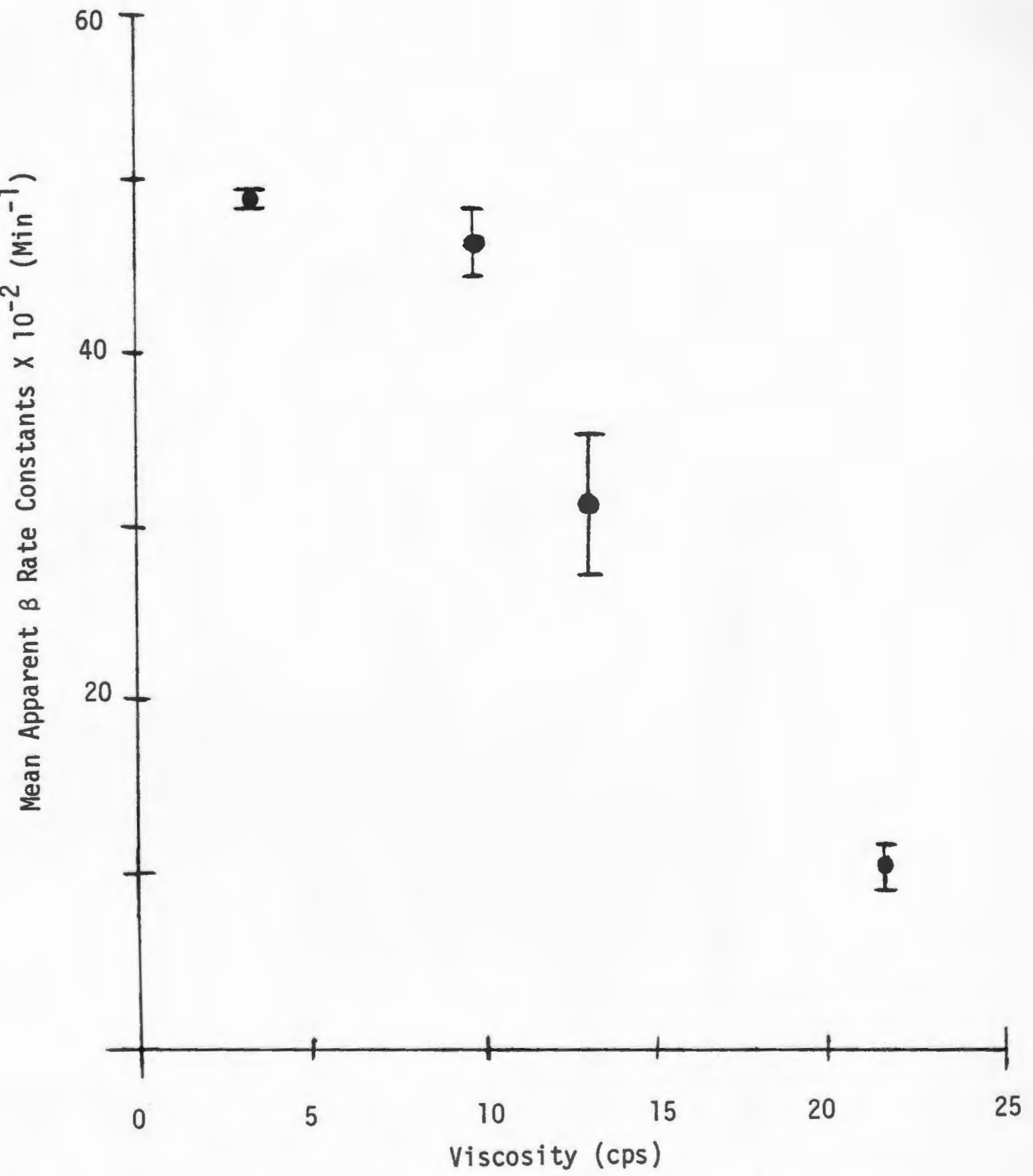

Fig. 15 Mean Apparent $B$ Rate Constants for Salicylic Acid $1.0 \mathrm{~g} / 1$ Removal As A Function of Liquid Membrane Viscosity 
which probably caused an alteration in the physical properties of the emulsion. The interfacial barrier was altered partially thereby permitting removed drug to diffuse out of the internal aqueous phase. More discussion of this will follow in a later section concerning the subsequent uptake of solutes.

A semilog plot of mean apparent $\beta$ rate constant as a function of the reciprocal absolute temperature was generated to characterize the effect of temperature on the uptake of salicylic acid over the range of $4-37^{\circ} \mathrm{C}$ (Figure 18 ). An apparent linear relationship between the log of the mean apparent $\beta$ rate constant and reciprocal temperature was found to exist $\left(r^{2}=0.999,4\right.$ points). The apparent activation energy of $8.95 \mathrm{kcal} / \mathrm{mole}$ or $3.74 \times 10^{4}$ Joules/mole was calculated from the slope of the line obtained. This is a reasonable value for a diffusion controlled process.

The Arrhenius relationship was apparentiy obeyed as indicated, but this does not necessarily mean that the $E_{a}$ calculated was the true $E_{a}$. Since, as previously discussed, alterations in the temperature of the liquid membrane system not only affect the solute per se but also affects the properties of the liquid membrane, it is unlikely that the transport process is occurring between the same standard states. 
TABLE XX

MEAN APPARENT $\beta$ RATE CONSTANTS FOR THE UPTAKE OF

SALICYLIC ACID $1.0 \mathrm{~g} / 1$ AS A FUNCTION OF TEMPERATURE

\begin{tabular}{cl}
\hline Temperature ${ }^{\circ} \mathrm{C}$ & Mean Apparent $\beta$ Rate Constants $\times 10^{-2}\left(\mathrm{~min}^{-1}\right)$ \\
\hline 4 & $10.98(2) \star$ \\
16 & $20.51(2)$ \\
28 & $39.95(2)$ \\
37.5 & $63.45(2)$ \\
50 & $\ldots \star \ldots *$ \\
\hline
\end{tabular}

*Number of Runs

**Approximately $6 \%$ of drug remained in external aqueous phase after 1 minute.

\section{Phenobarbital}

The effect of temperature over the range of $4-45^{\circ} \mathrm{C}$ on the removal of phenobarbital from the external donor phase was investigated. A semilog plot of removal of drug as a function of time over the temperature range is shown in Figure 19. The $\alpha$ and $\beta$ rate constants were calculated and are listed in Table XXI. The effect of temperature on these systems was not as expected. As the temperature was increased, the a rate constant increased over the range of $4-41^{\circ} \mathrm{C}$. After reaching a maximum at $41^{\circ} \mathrm{C}$, the a rate constant was then reduced. Essentially the same phenomena occurred with the \& rate constant. inis rate constant increased with increasing temperature up to $41^{\circ} \mathrm{C}$, but decreased with any rise in temperature thereafter. 


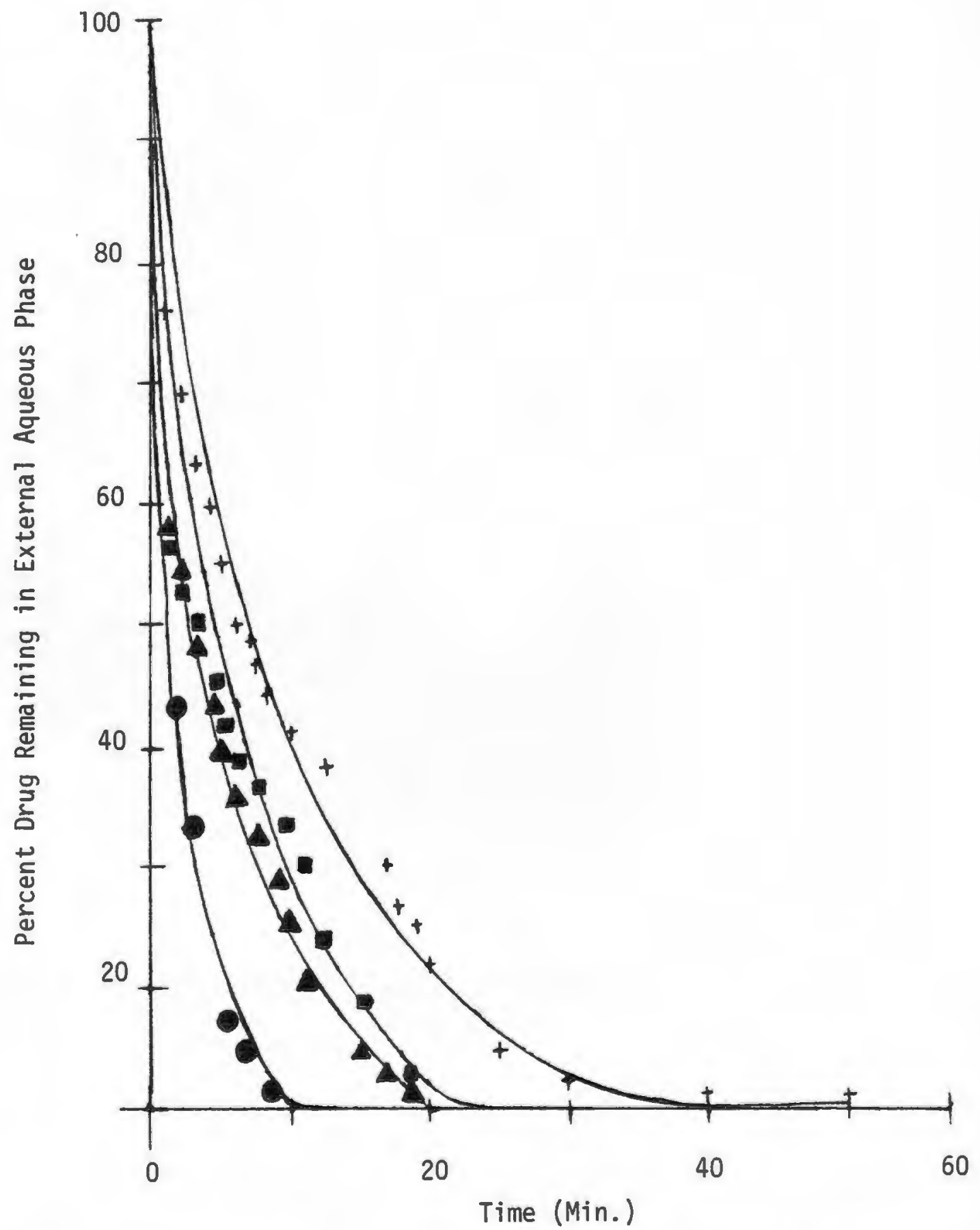

Fig. 16 Salicylic Acid $1.0 \mathrm{~g} / 1$ Removal As A Function of Time at Various Temperatures

$$
+4^{\circ} \mathrm{C} ; 16^{\circ} \mathrm{C} ; \Delta 28^{\circ} \mathrm{C} ;-37.5^{\circ} \mathrm{C}
$$




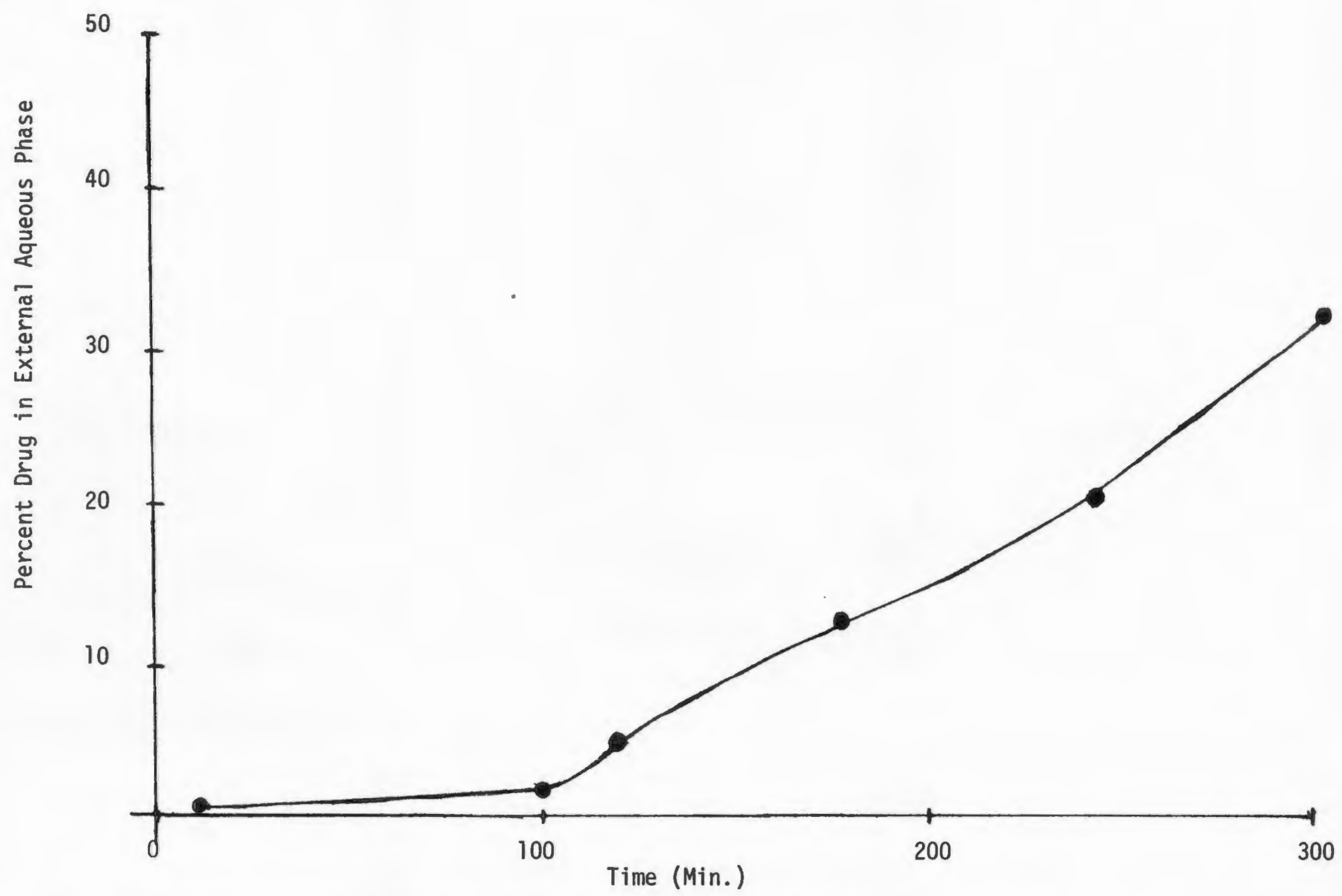

Fig. 17 Percent Salicylic Acid in External Aqueous Phase As A Function of Time at $50^{\circ} \mathrm{C}$ 


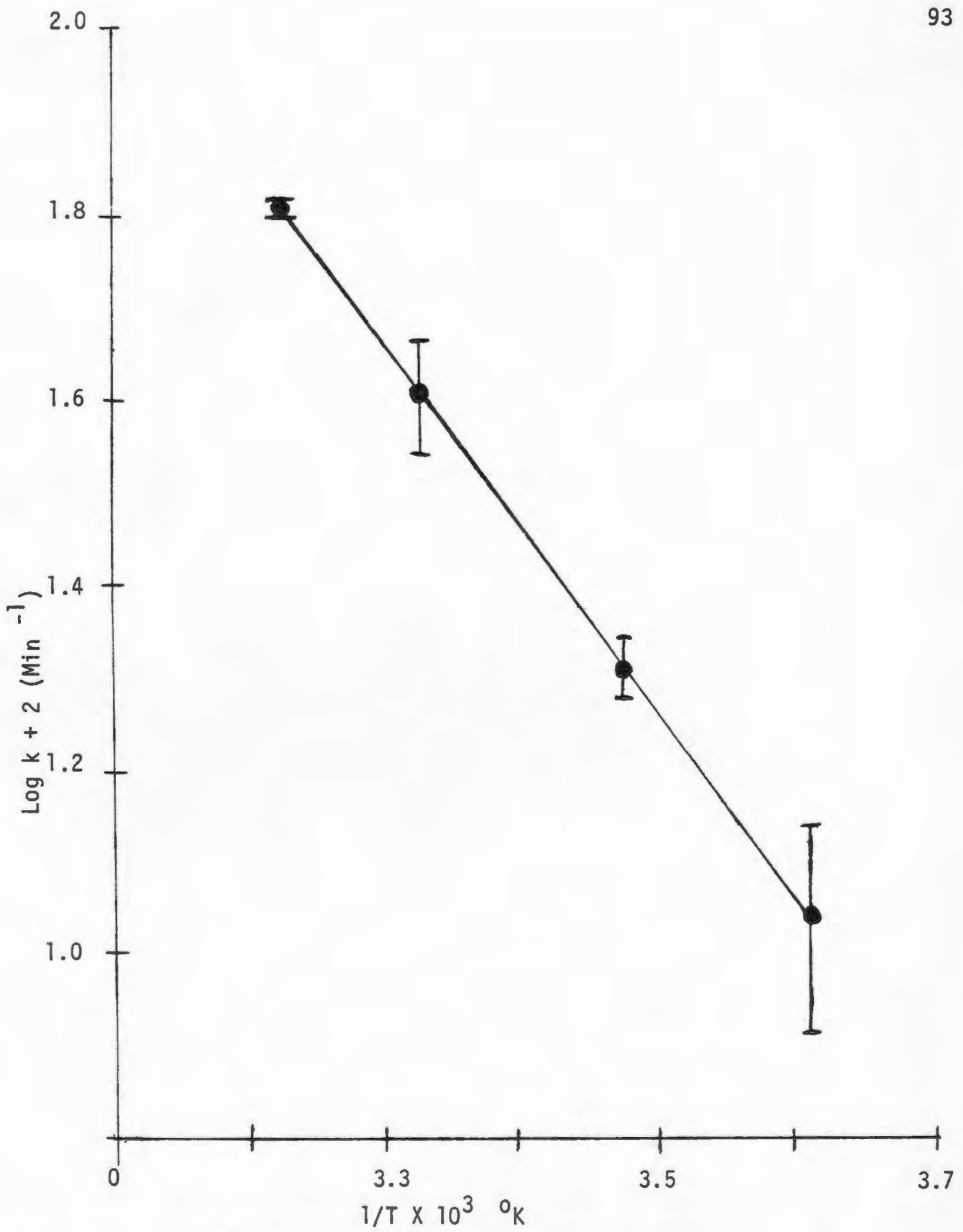

Fig. 18 Log of Mean Apparent $\beta$ Rate Constants for Salicylic Acid Removal As A Function of Reciprocal Absolute Temperature 
The plots of the $\log k$ for both $\alpha$ and $\beta$ versus the reciprocal absolute temperature show that the effect of temperature on the rate constants cannot be described by the Arrhenius equation (Figures 20 and 21).

There are several possible explanations as to why this behavior was observed. As indicated by the uptake of salicylic acid at $50^{\circ} \mathrm{C}$, it appears as though increasing the temperature alters the physical properties of the emulsion in such a way as to change the characteristics of the interfaces. Although, as has been predicted, emulsion properties will change with increasing temperature, the data shows that there is a small temperature change at which there is a radical change in the ability of the liquid membrane to trap drug. It is suspected that this critical temperature $\left(43^{\circ} \mathrm{C}\right)$ reflects a substantial disruption of one or both interfaces. At all temperatures a steady uptake of drug into the liquid membrane was noted. This process occurred at a faster rate than the transport of drug from the liquid membrane into the internal aqueous phase since $\alpha$ was always greater than $\beta$. Therefore, the ability of the liquid membrane to remove solute at any temperature was maintained.

Another consideration may be the formation of a specific complex between phenobarbital and the surfactant depending on the temperature sensitivity of the complexation and membrane transport process. This could possibly be a factor involved in the type of data reported here. 
TABLE XXI

MEAN RATE CONSTANTS FOR THE UPTAKE OF PHENOBARBITAL $0.6 \mathrm{~g} / 1$ AS A FUNCTION OF TEMPERATURE

\begin{tabular}{|c|c|c|c|}
\hline Temperature ${ }^{\circ} \mathrm{C}$ & $\begin{array}{l}\text { Mean Rate Constants } \times \\
\underline{\alpha}\end{array}$ & $\begin{array}{c}10^{-2}\left(\min ^{-1}\right) \\
\underline{B}\end{array}$ & \\
\hline 4 & 0.77 & 8.56 & $(2)^{*}$ \\
\hline 20 & 1.68 & $11.01^{\circ}$ & (2) \\
\hline 37.5 & 5.19 & 12.94 & (2) \\
\hline 41 & 7.19 & 59.95 & (2) \\
\hline 42 & 5.28 & 44.88 & (2) \\
\hline 43 & 4.56 & 15.70 & (4) \\
\hline 45 & 0.99 & 13.42 & (2) \\
\hline
\end{tabular}

*Number of runs

H. Effect of Viscosity on the Rate of Phenobarbital Uptake at a Critical Temperature

At room temperature it is expected that as the viscosity of the liquid membranes increases, there is a decrease in the rate of drug removal from an external aqueous phase. If a faster rate of uptake is desired, a liquid membrane of lower viscosity is selected for drug removal. It has been demonstrated that at elevated temperatures a point was reached in the removal of phenobarbital from the external donor phase where the rate constant dramatically decreased instead of increased. The temperature range at which this occurred has been described as the critical temperature. It was suggested that the 


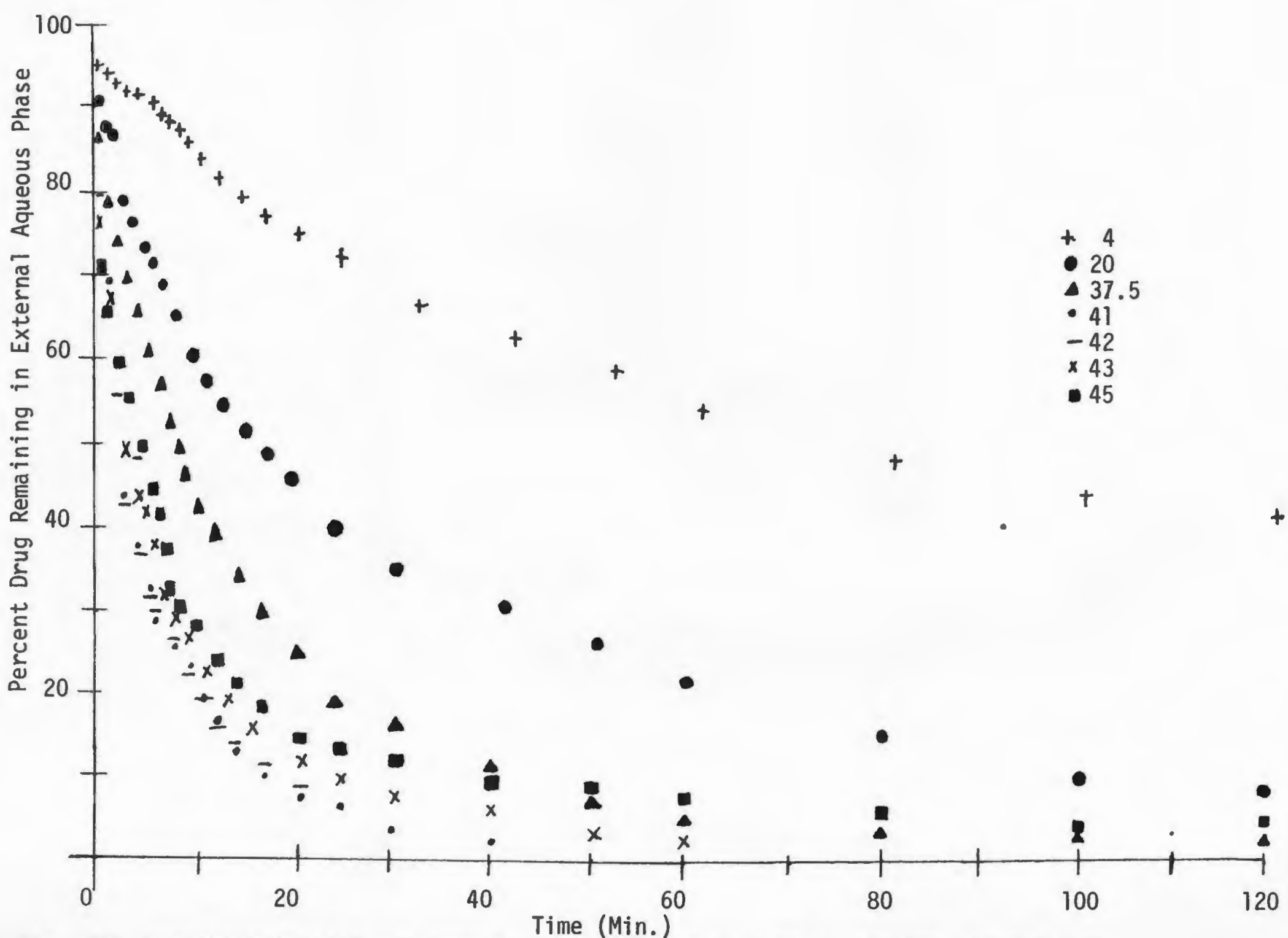

Fig. 19 Phenobarbital $0.6 \mathrm{~g} / 1$ Removal As A Function of Time at Various Temperatures 


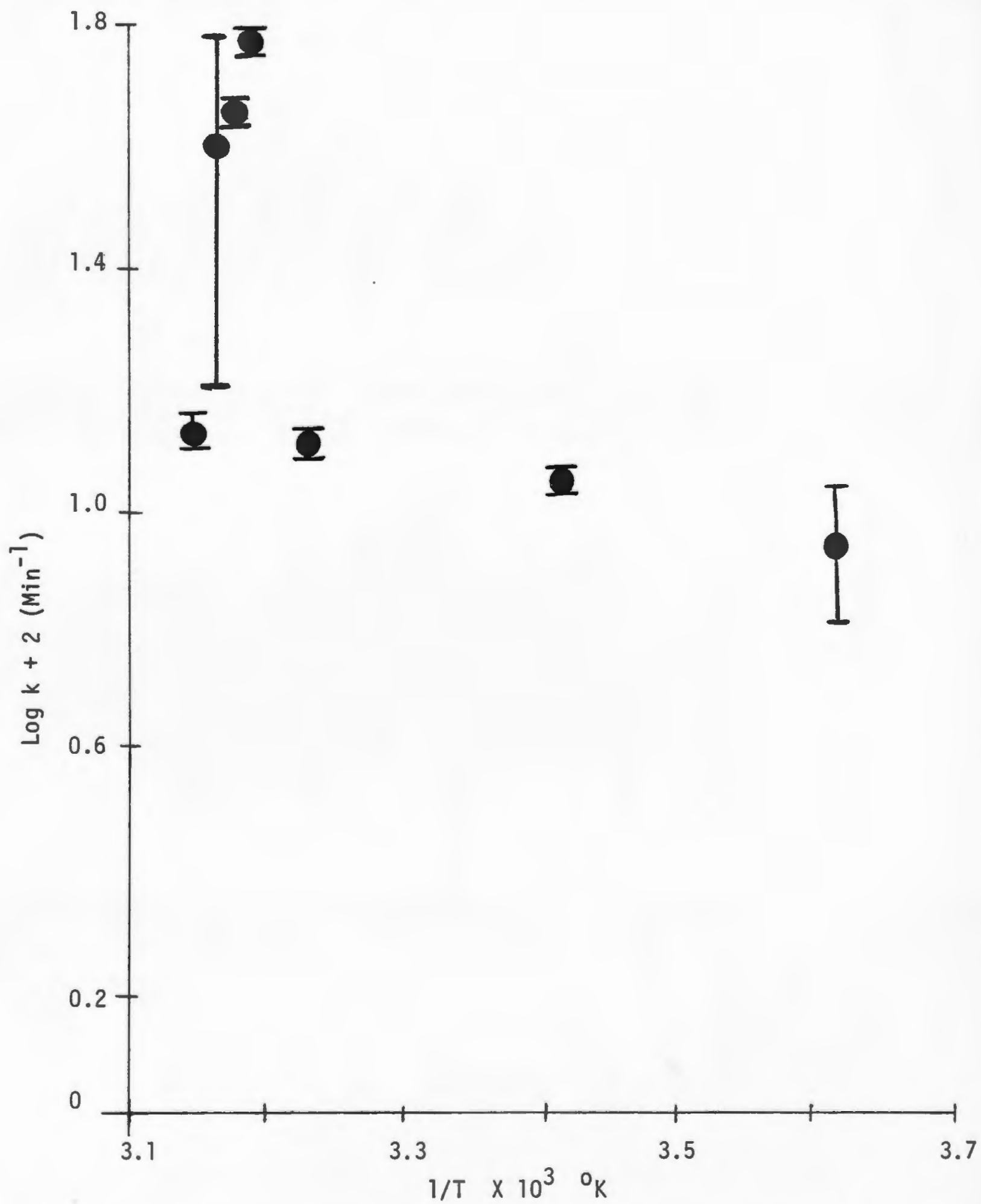

Fig. 20 Log of Mean a Rate Constants for Phenobarbital $0.6 \mathrm{~g} / 1$ As A Function of Reciprocal Absolute Temperature 


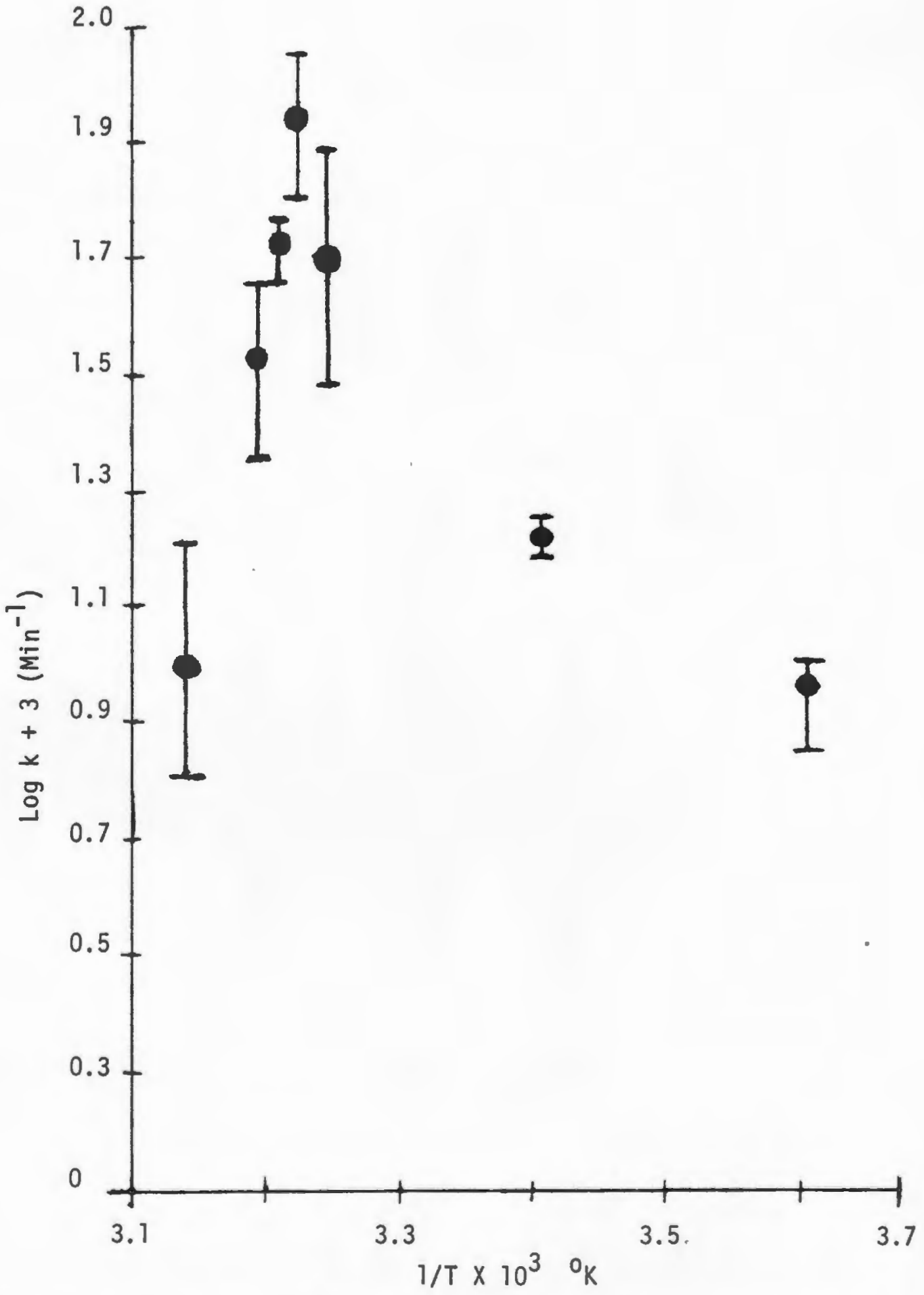

Fig. 21 Log of Mean $\beta$ Rate Constants for Phenobarbital $0.6 \mathrm{~g} / 1$ Removal As A Function of Reciprocal Absolute Temperature 
critical temperature represents a point where temperature stress is such that membrane rupture was beginning or about to occur.

Since increasing the viscosity of the liquid membrane would likely have a stabilizing effect, it seems possible that at the critical temperature it would be advantageous to use a liquid membrane with a greater viscosity. However, the data presented in Table XXII and Figure 22 shows that even at the critical temperature a lower viscosity system had greater $\alpha$ and $B$ rate constants than a higher viscosity system. There was no obvious relationship between viscosity and the rate constants. This is not surprising since viscosity may itself be dependent upon a critical temperature.

TABLE XXII

MEAN RATE CONSTANTS FOR THE UPTAKE OF PHENOBARBITAL $0.6 \mathrm{~g} / 1$ AS A FUNCTION OF VISCOSITY AT A CRITICAL TEMPERATURE

\begin{tabular}{ccc}
\hline \hline Viscosity (cps) & $\begin{array}{c}\text { Mean a Rate Constant } \\
\times 10^{-2}\left(\min ^{-1}\right)\end{array}$ & $\begin{array}{c}\text { Mean } \beta \\
\times 10^{-2}\left(\text { min }^{-1}\right)\end{array}$ \\
\hline 3.0 & 29.56 & $4.56 \quad(2)^{*}$ \\
9.9 & 18.88 & 3.82 \\
12.8 & 11.20 & 1.17 \\
21.6 & 12.46 & 3.04 \\
\hline
\end{tabular}

*Number of Runs

I. Evaluation of Liquid Membrane Reuse

1. Back Transport of Solutes

For most of the experiments in this project the uptake of drug from an external aqueous phase was monitored. In this section the back 


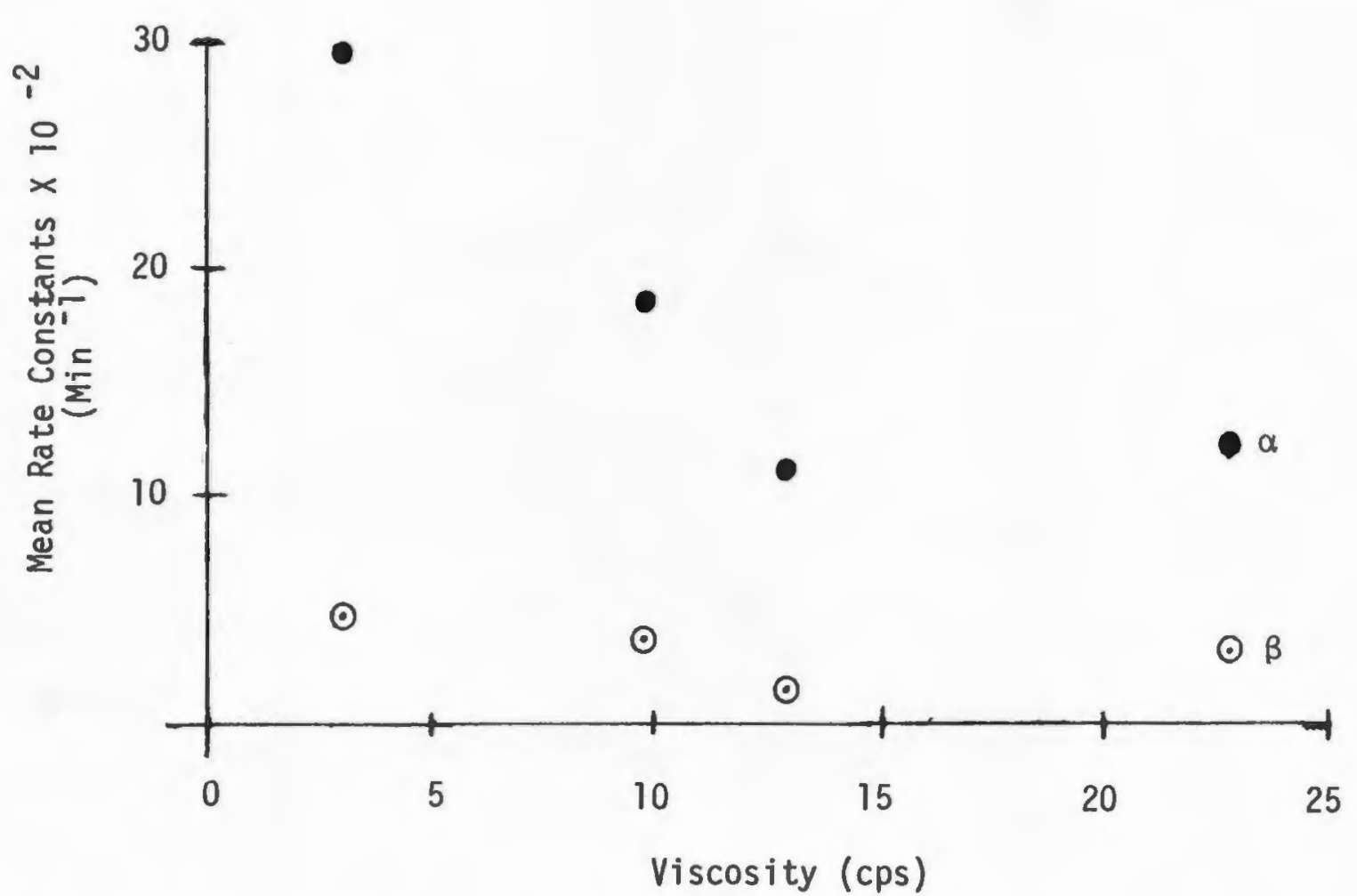

Fig. 22 Mean Rate Constants for Phenobarbital $0.6 \mathrm{~g} / 1$ Removal Using Liquid Membranes with different Viscosities at the Critical Temperature $\left(43^{0} \mathrm{C}\right)$ 
transport or transport of solute from within she liquid membrane to the external aqueous phase was investigated.

Table XXIII lists the estimated as remaining mean percentage of drug in the external aqueous phase following exposure to the liquid membrane for 120 minutes. According to the pH-partition theory, the unionized species transports easily compared to the ionized species. At low pH, salicylic and acetylsalicylic acids are predominately unionized and therefore available for transport across the liquid membrane into the internal aqueous phase. Once inside this internal phase the drug is trapped by conversion to its ionized species. If, as might well be expected, the ionized species of the solute is unable to cross the hydrophobic area of the liquid membrane, then transport will not be possible. The data shown in Table XXIII that with acetylsalicylic and salicyic acids this was the case when the "new" external aqueous phase had a pH of 10 . The experimental data demonstrated no detectable back transport.

In the case of phenobarbital, back transport experiments were conducted with "new" external aqueous phases having a pH of either 2 or 10 . When the $\mathrm{pH}$ was 2 , no back transport was detected. However, when the $\mathrm{pH}$ of the "new" external aqueous phase was 1C, a significant amount of back transport was observed (see Table XXIII). Lack of back transport at $\mathrm{pH} 2$ for phenobarbital can be readily explained by the fact that at $\mathrm{pH} 2$ this drug is predominately unionized and since it is in low competition with the ionized species, the driving force for back transport will be low. At pH 10 phenobarbital is predominately in an 
ionized form. Therefore, there is small but finite quantity of unionized species which could be available for back transport. This seems to be unlikely since the unionized species is present in a very low concentration. It is possible that ionized phenobarbital had undergone back transport.

It is noteworthy that Chilamkurti and Rhodes (18) in their analysis of micro rate constants for liquid membrane transport reached the conclusion that the benzoate ion can cross the liquid membrane whereas the salicylate ion cannot. The data presented here for salicylic acid confirms the findings of Chilamkurti and Rhodes using a different approach (back transport versus analysis of micro rate constants).

TABLE XXIII

ESTIMATED MEAN PERCENT OF DRUG REMAINING IN THE EXTERNAL AQUEOUS PHASE FOLLOWING EXPOSURE TO LIQUID MEMBRANE FOR 120 MINUTES

\begin{tabular}{lcc}
\hline \multicolumn{1}{c}{ Drug } & $\begin{array}{c}\text { Mean Percent Remaining } \\
\text { in pH 10 External } \\
\text { Aqueous Phase }\end{array}$ & $\begin{array}{c}\text { Mean Percent Remaining } \\
\text { in pH 2 External } \\
\text { Aqueous Phase }\end{array}$ \\
\hline Control (no drug) & 0.0 & - \\
Acetylsalicylic acid & 0.0 & - \\
Salicylic Acid & 0.0 & - \\
Phenobarbital & $13: 0$ & 0.0 \\
\hline
\end{tabular}

2. Subsequent Solute Uptake

The ability of liquid membranes to remove one solute from an external aqueous phase following the removal of another solute was 
investigated for three systems. In each case it was observed that the liquid membrane was capable of subsequent uptake of drug to varying degrees. Figures 23,24 , and 25 show the extraction curves for the removal of the second drug.

In the first system the uptake of phenobarbital following the removal of salicylic acid at $50^{\circ} \mathrm{C}$ was slow but steady for one run (Figure 23). When this was repeated, the uptake was slow and variable as a function of time (Figure 23). Variability in this data is somewhat disappointing but not entirely unexpected. As reported in this thesis, the extraction curves for one component system are very reproducible and very much better than might be expected for a complex dispersed system. However, whenever ore tries to study the extraction of a second solute when the system has al ready been perturbed by the extraction of a compound, nonreproducible results may be obtained. It is very easy to postulate that such factors as mean liquid membrane thickness or interfacial area may be substantially modified. Based on the previous findings regarding saficylic acid in single component uptake at $50^{\circ} \mathrm{C}$, it is possible that the diffusion of salicylic acid into the external aqueous phase may be the result of some alteration in the permeability of the liquid membrane due to the high temperature (Figure 26). This indicates membrane rupture and not transport of ionized solute. Moreover it is also noteworthy that whereas salicylic acid trapped in the internal aqueous phase did not diffuse out when the $\mathrm{pH}$ of a "new" external aqueous phase was increased, in the present system salicylic acid diffused into the external aqueous phase when the 


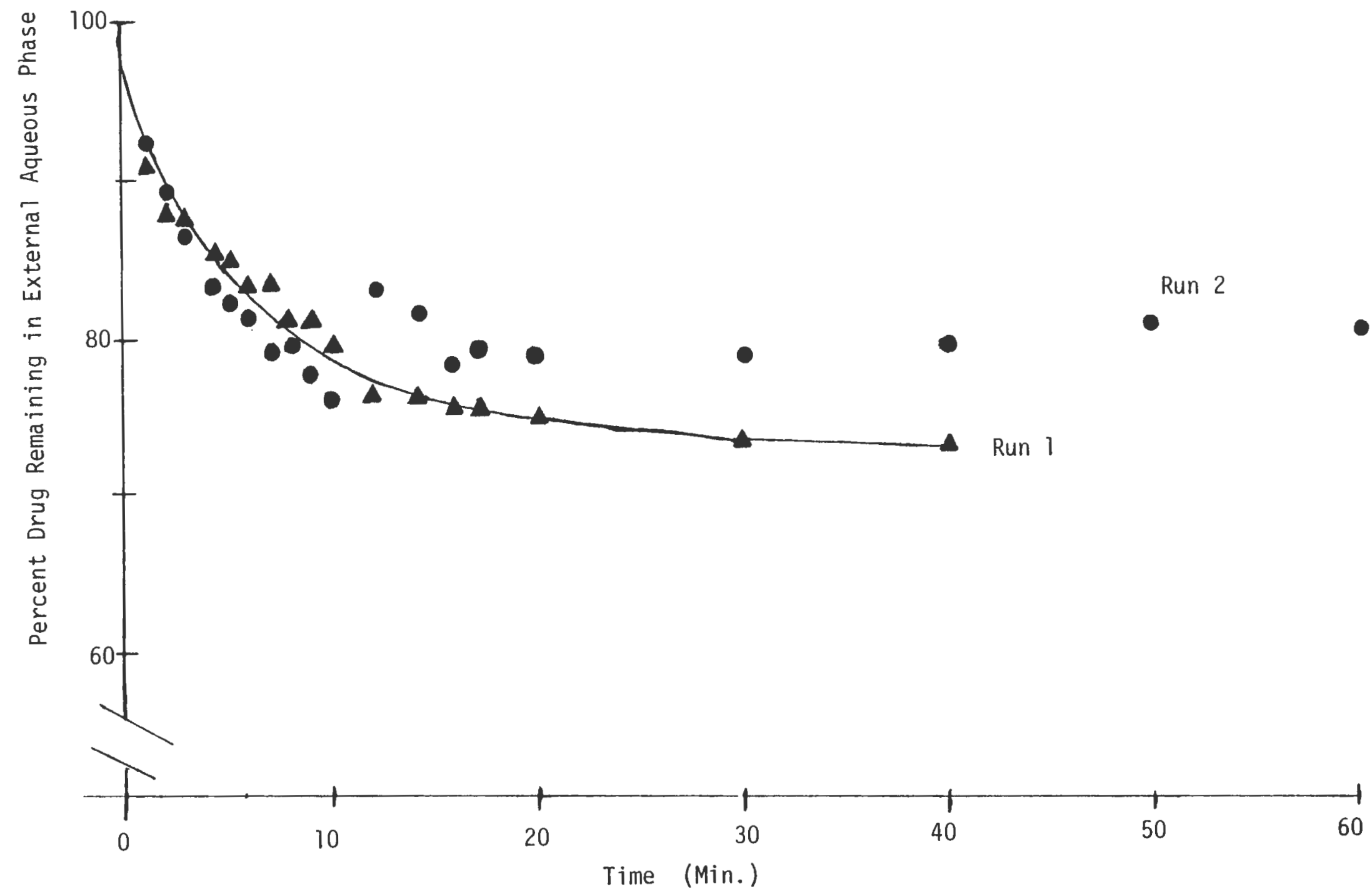

Fig. 23 Subsequent Uptake of Phenobarbital $0.6 \mathrm{~g} / 1$ As A Function of Time Following Salicylic Acid $1.0 \mathrm{~g} / \mathrm{l}$ Removal at $50^{\circ} \mathrm{C}$ 


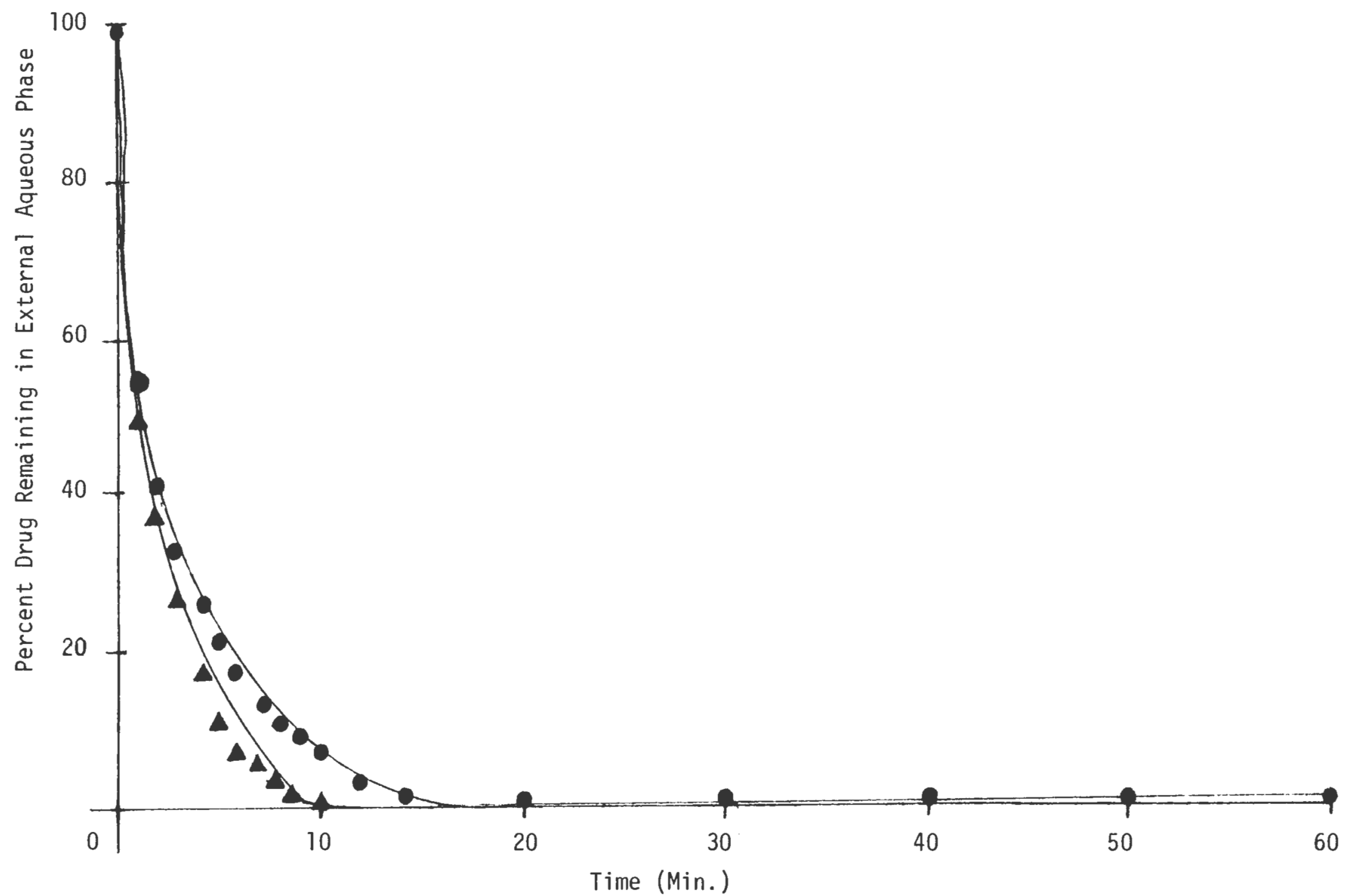

Fig. 24 Subsequent Uptake of Salicylic Acid $1.0 \mathrm{~g} / 1$ As A Function of Time Following Phenobarbital $0.6 \mathrm{~g} / 1$ Removal at $37.5^{\circ} \mathrm{C}$ 


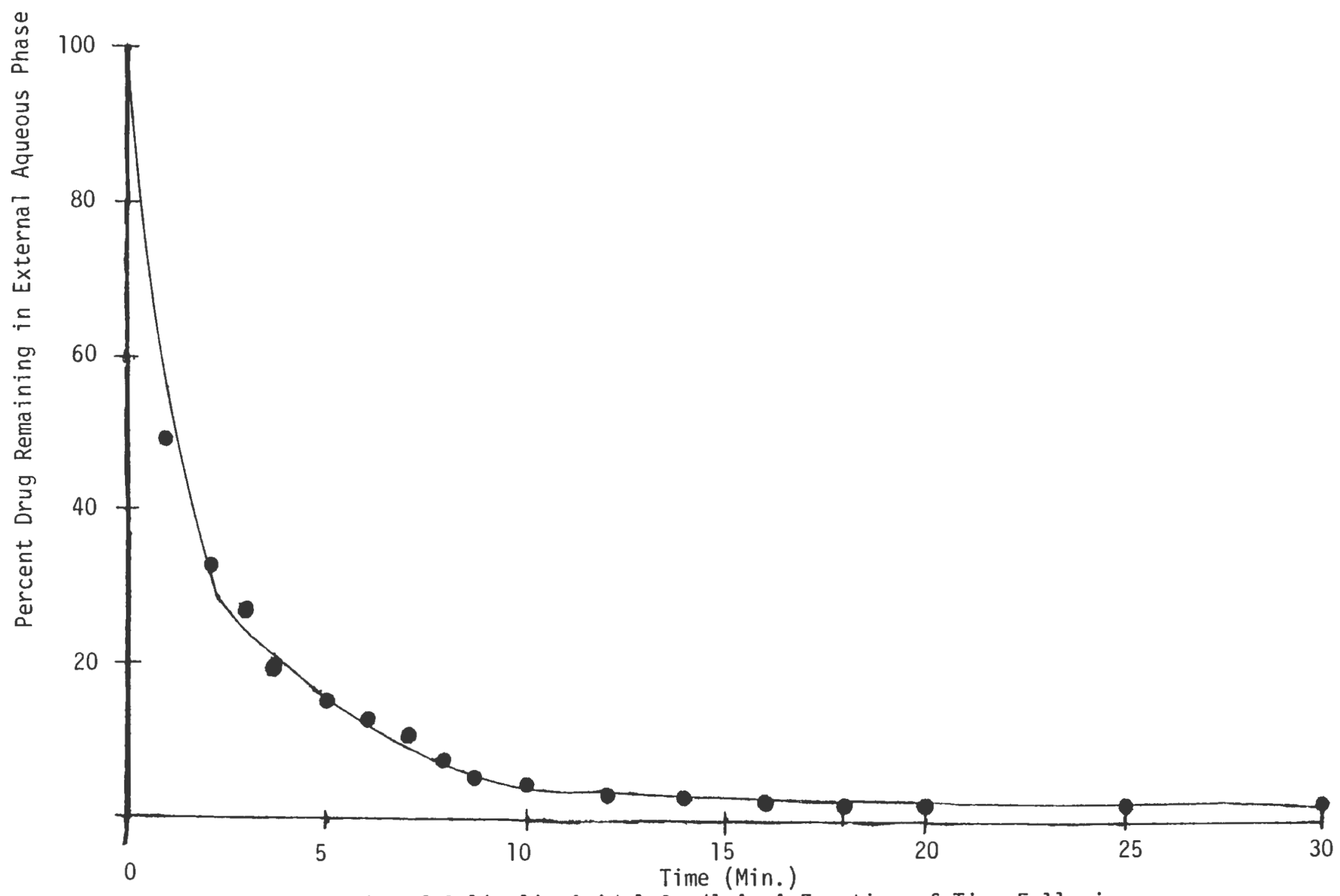

Fig. 25 Subsequent Uptake of Salicylic Acid $1.0 \mathrm{~g} / 1$ As A Function of Time Following Phenobarbital $0.6 \mathrm{~g} / 1$ Removal at $45^{\circ} \mathrm{C}$

$\overrightarrow{8}$ 


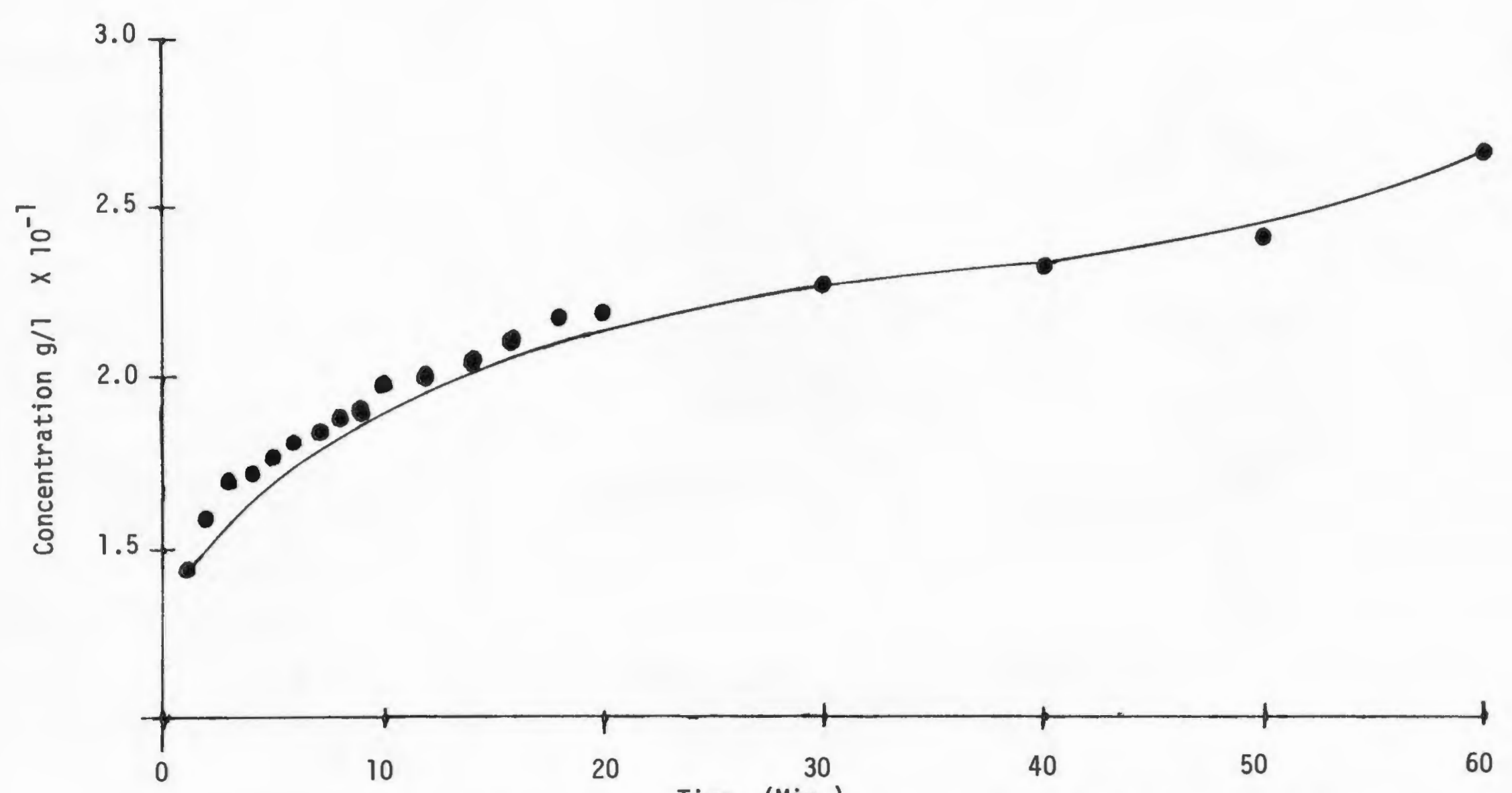

Fig. 26 Concentration of Salicylic Acid in External Aqueous Phase As A Function of Time During Subsequent Uptake of Phenobarbital $0.6 \mathrm{~g} / 1$ at $37.5^{\circ} \mathrm{C}$ 
$\mathrm{pH}$ was low. This further indicates membrane rupte:re had occurred and not transport of the ionized species.

TABLE XXIV

MEAN APPARENT $\beta$ RATE CONSTANTS FOR THE UPTAKE OF

SALICYLIC ACID $1.0 \mathrm{~g} / 1$ FOLLOWING PHENOBARBITAL UPTAKE

\begin{tabular}{lc}
\hline \hline System & Mean Apparent $\beta$ Rate Constant $\times 10^{-2}\left(\min ^{-1}\right)$ \\
\hline I $37.5^{\circ} \mathrm{C}$ & $41.48(2)^{*}$ \\
II $45^{\circ} \mathrm{C}$ & $40.24(1)$ \\
\hline
\end{tabular}

* Number of Runs.

A similar trend was observed for the second and third systems studied. In these systems the removal of salicylic acid from the external aqueous phase subsequent to phenobarbital remova? was investigated at 37.5 and $45^{\circ} \mathrm{C}$. Under both conditions the removal of salicylic acid was steady and essentially complete (Figures 24 and 25 ). The mean apparent $\beta$ rate constant calculated for these systems are listed in Table XXIV. As can be seen, the range of $\beta$ values varied widely for uptake at $37.5^{\circ} \mathrm{C}\left(22.64 \times 10^{-2}\left(\mathrm{~min}^{-1}\right)\right.$ and $50.18 \times 10^{-2}$ $\left.\left(\min ^{-1}\right)\right)$. These $\beta$ values were also less than the apparent mean $\beta$ rate constant calculated for the uptake of salicylic acid in a single component system $\left(22.64 \times 10^{-2}\left(\mathrm{~min}^{-1}\right)\right.$ and $50.18 \times 10^{-2}\left(\mathrm{~min}^{-1}\right)$ versus $63.45 \times 10^{-2}\left(\min ^{-1}\right)$. Figure 27 shows the appearance of phenobarbital in the external aqueous phase as a function of time for one run at $37.5^{\circ} \mathrm{C}$. 


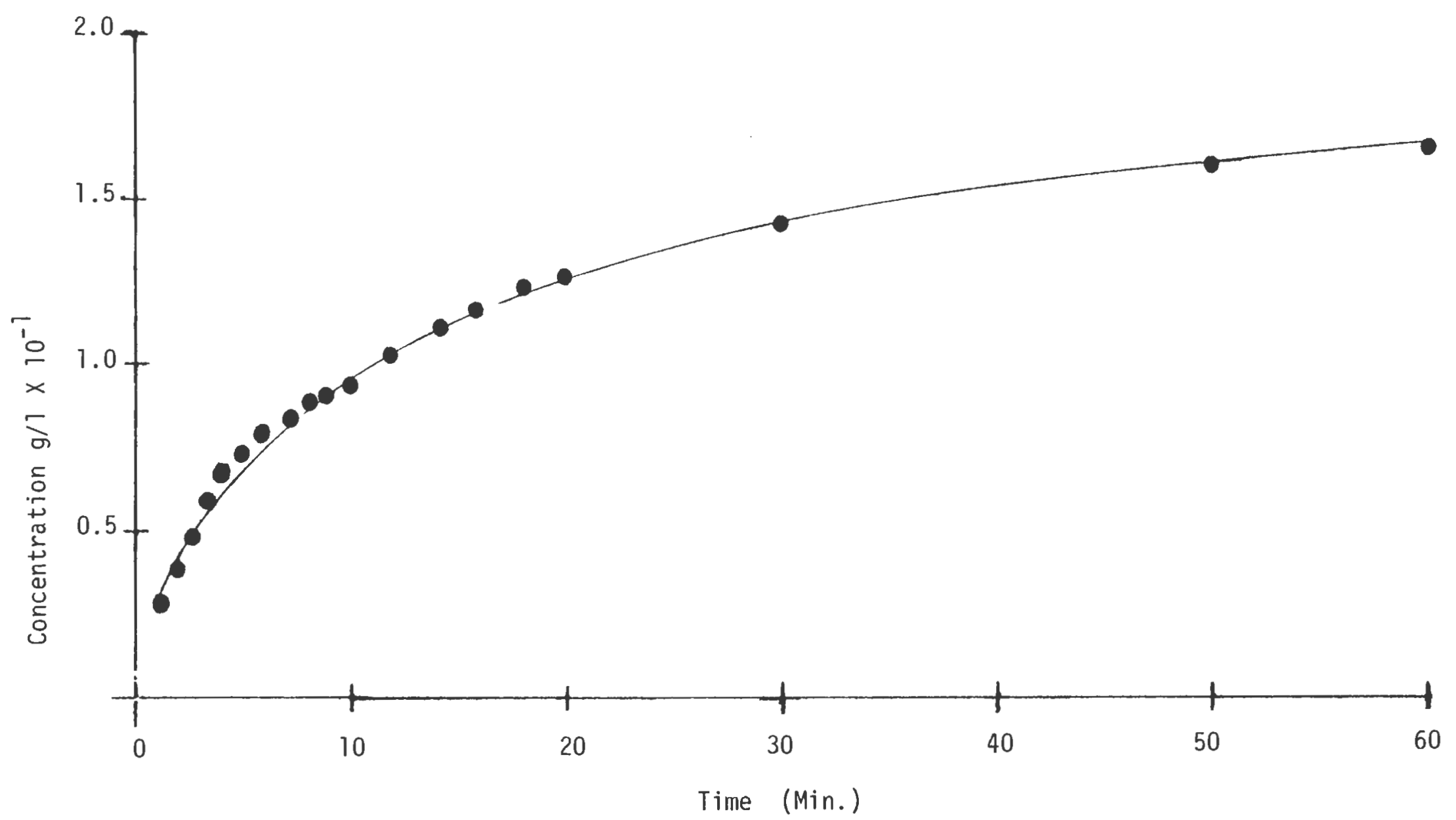

Fig. 27 Concentration of Phenobarbital in External Aqueous Phase As A Function of Time During Subsequent Uptake of Salicylic Acid $1.0 \mathrm{~g} / 1$ at $37.5^{\circ} \mathrm{C}$ 
J. Evaluation of Co-Uptake of Solutes from One Donor Solution

1. Co-Uptake of Solutes with Different Initial Molar Concentrations

Table XXV lists the mean apparent rate constants for the co-uptake of two drugs from one donor phase when their initial molar concentrations were different. As can be seen from these results, the liquid membrane was capable of the simultaneous uptake of drugs. The apparent rate constants and extent of drug uptake differed for each drug in solution with another drug. The mean percent of each drug remaining in the external aqueous phase at 120 minutes can be found in Table XXVI.

From Table XXVI it can be shown that essentially complete uptake had occurred by the end of the experimental run for acetylsalicylic and salicylic acid in a donor phase containing both solutes. However, $25.24 \%$ and $33.78 \%$ of the initial total of phenobarbital remained in the external aqueous phase when this drug was removed from a solvent which also contained acetylsalicylic and salicylic acids respectively.

The highest apparent rate constants were calculated for salicylic acid in a solvent which contained either acetysalicylic acid or phenobarbital. Although the mean apparent $\beta$ rate constant describing the uptake of salicylic acid from a multicomponent external aqueous phase containing acetylsalicylic acid was less than that for salicylic acid in a single component system $\left(32.27 \times 10^{-2}\left(\mathrm{~min}^{-1}\right)\right.$ versus $\left.49.67 \times 10^{-2}\left(\min ^{-1}\right)\right)$, the mean apparent $\beta$ rate constant for salicylic acid in an external aqueous phase with phenobarbital was greater 
$\left(59.79 \times 10^{-2}\left(\mathrm{~min}^{-1}\right)\right.$ versus $\left.49.67 \times 10^{-2}\left(\mathrm{~min}^{-1}\right)\right)$. Additional data would be useful in deterinining the statistical significance of the differences in these rate constants. Although these differences appear to be small, they may be statistically as well as therapeutically significant.

A possible explanation for former case described above may be based on the similarity in chemical structure of acetysalicylic and salicylic acids. As previously observed for both of the drugs in single component systems, increasing the initial concentration of drug in the external aqueous phase resulted in a decreased apparent $\beta$ rate constant. It was speculated that increasing the initial concentration resulted in an alteration of the surfactant properties at the liquid membrane/internal aqueous phase interface. It was further speculated the internal aqueous phase droplets became larger with decreased surface area resuiting.

In the case of co-uptake of acetysalicylic and salicylic acids, this mixture of drugs in one donor phase may have had the same effect as increasing the concentration of one of these drugs alone in the external donor phase. Thus, the decrease in the apparent $\beta$ rate constant was observed for salicylic acid.

The increased mean apparent $\beta$ rate constant for salicylic acid in the presence of phenobarbital may possibly be a result of an interaction between phenobarbital and the surfactant at both interfaces to produce an alteration in the properties of the liquid membrane. This could favor the transport of salicylic acid into both the liquid 
membrane and the internal donor phase. In addition this alteration may increase the micro rate constant controlling the transport of salicylic acid into the liquid membrane with an increase in the apparent $\beta$ rate constant for the system resulting.

It is interesting to note that essentially the same phenomena occurred with the co-uptake of acetylsalicylic acid and phenobarbital. The mean apparent $\beta$ rate constant for acetylsalicylic acid was less when it was in a multicomponent donor phase with salicylic acid than with phenobarbital $\left(6.74 \times 10^{-2}\left(\min ^{-1}\right)\right.$ verus $\left.11.41 \times 10^{-2}\left(\min ^{-1}\right)\right)$. The apparent $\beta$ rate constant for phenobarbital in a multicomponent system with acetylsalicylic acid was similar to that obtained for phenobarbital in a co-uptake situation with salicylic acid (1.24 $\mathrm{x}$ $10^{-2}\left(\min ^{-1}\right)$ versus $\left.1.25 \times 10^{-2}\left(\min ^{-1}\right)\right)$.

TABLE XXV

MEAN APPARENT RATE CONSTANTS FOR THE CO-UPTAKE OF DRUG I IN A MULTICOMPONENT SYSTEM WITH DRUG II WHEN INITIAL MOLAR CONCENTRATIONS ARE DIFFERENT

\begin{tabular}{lccc}
\hline \hline \multicolumn{1}{c}{ Drug I } & $\begin{array}{l}\text { Drug II } \\
\text { Acetylsalicylic } \\
\text { Acid } 5: 6: \mathrm{mM}\end{array}$ & $\begin{array}{c}\text { Salicylic } \\
\text { Acid } 7.2 \mathrm{mM}\end{array}$ & $\begin{array}{c}\text { Phenobarbital } \\
2.5 \mathrm{mM}\end{array}$ \\
\hline $\begin{array}{l}\text { Acetylsalicylic } \\
\text { Acid } 5.6 \mathrm{mM}\end{array}$ & -- & $6.75(\beta)$ & $11.41(\beta)$ \\
$\begin{array}{l}\text { Salicylic Acid } \\
7.2 \mathrm{mM}\end{array}$ & $32.27(\beta)$ & -- & $59.79(\beta)$ \\
$\begin{array}{l}\text { Phenobarbital } \\
2.5 \mathrm{mM}\end{array}$ & $\begin{array}{l}6.65(\alpha) \\
1.24(\beta)\end{array}$ & $1.25(\beta)$ & -- \\
\hline
\end{tabular}


TABLE XXVI

MEAN PERCENT OF DRUG I REMAINING IN THE EXTERNAL AQUEOUS

PHASE AT 120 MINUTES AFTER CO-UPTAKE WITH DRUG II

\begin{tabular}{lll}
\hline Drug I & Drug II & $\begin{array}{c}\text { Mean Percent } \\
\text { Drug I }\end{array}$ \\
\hline Acetylsalicylic Acid & $\begin{array}{l}\text { 1. Phenobarbital } \\
\text { 2. Salicylic Acid }\end{array}$ & $\begin{array}{l}\text { 1. }<1.00 \\
\text { 2. }<1.00\end{array}$ \\
Salicylic Acid & $\begin{array}{l}\text { 1. Phenobarbital } \\
\text { 2. Acetylsalicylic }\end{array}$ & $\begin{array}{l}1 .<1.00 \\
\text { Acid }\end{array}$ \\
Phenobarbital & 1. Salicylic Acid & $\begin{array}{l}1.00 \\
\text { 2. Acetylsalicylic } 3.78 \\
\text { Acid }\end{array}$ \\
\hline
\end{tabular}

*One Run.

2. Co-Uptake of Solutes with Equimolar Initial Concentrations

The effect of concentration on co-uptake was further studied by exposing liquid membrane to an external donor phase containing equimolar concentrations of two solutes. System I consisted of equimolar concentrations of salicylic and acetylsalicylic acids (5.6 mM) while System II contained salicylic acid and phenobarbital at $2.5 \mathrm{mM}$ concentrations. Table XXVII lists the mean apparent $\beta$ rate constants for each drug and the mean percent of drug remaining in the external aqueous phase after 120 minutes.

In System I both acetylsalicylic and salicylic acid were essentially completely removed from the external donor phase after 120 minutes. The mean apparent $\beta$ rate constant for salicylic acid in this system was approximately equal to the rate constant for this drug when alone in the external donor phase $\left(49.10 \times 10^{-2}\left(\right.\right.$ min $\left.^{-1}\right)$ versus 
TABLE XXVII

MEAN APPARENT $\beta$ RATE CONSTANTS FOR THE CO-UPTAKE OF SOLUTES IN EQUIMOLAR

INITIAL CONCENTRATIONS IN A MULTICOMPONENT SYSTEM AND MEAN PERCENT

REMAINING IN THE EXTERNAL. AQUEOUS PHASE AT 120 MINUTES

\begin{tabular}{|c|c|c|c|c|}
\hline \multirow{2}{*}{$\begin{array}{c}\text { System } \\
\mathrm{I}\end{array}$} & \multicolumn{2}{|c|}{$\begin{array}{l}\text { Solutes and Molar } \\
\text { Concentration (mM) }\end{array}$} & \multirow{2}{*}{$\frac{\begin{array}{c}\text { Mean Apparent } \\
\text { Constant } \times 10^{-2}\left(\text { min }^{-1}\right)\end{array}}{49.10(2)^{*}}$} & \multirow{2}{*}{$\begin{array}{l}\text { Mean Percent Remaining } \\
\text { in External Aquecus } \\
\text { Phase at } 120 \text { Minutes } \\
<1.00\end{array}$} \\
\hline & Salicylic Acid & 5.6 & & \\
\hline & Acetylsalicylic & 5.6 & $6.95(2)$ & $<1.00$ \\
\hline \multirow[t]{2}{*}{ II } & Salicylic Acid & 2.5 & $-\ldots \star \star \star t$ & $<1.00$ \\
\hline & Phenobarbital & 2.5 & $3.41(2)$ & 9.48 \\
\hline
\end{tabular}

*Number of Runs.

**Too rapid to calculate. 
$\left.49.67 \times 10^{-2}\left(\min ^{-1}\right)\right)$. This rate constant was greater than that for salicylic acid in a non-equimolar multicomponent system with acetylsalicylic acid $\left(49.10 \times 10^{-2}\left(\min ^{-1}\right)\right.$ versus $\left.32.27 \times 10^{-2}\left(\min ^{-1}\right)\right)$. Moreover the mean apparent $\beta$ rate constant for acetylsalicylic acid in System I was approximately the same as that calculated for this drug in a non-equimolar multicomponent system with salicylic acid (6.95 $\mathrm{x}$ $10^{-2}\left(\min ^{-1}\right)$ versus $\left.6.74 \times 10^{-2}\left(\min ^{-1}\right)\right)$.

The total molar concentration of solute in the external donor phase with these two drugs in equimclar concentrations was less than the total molar concentration of solute in the previous co-uptake system of these two drugs (11.2 $\mathrm{mM}$ versus $12.8 \mathrm{mM}$ of solute). As previously observed for these two solutes as single component systems, a decrease in concentration resulted in increased mean apparent $\beta$ rate constants. The mean apparent $\beta$ rate constants obtained for the present system seem to support the proposed speculations of membrane surface property alterations and changes in the size of the internal aqueous phase droplets. At this lower concentration alterations in the properties of the membrane are not as great as the more concentrated system and the internal aqueous phase droplets were not exposed to as much solute. This resulted in increased apparent $\beta$ rate constants.

For System II the rate of salicylic acid uptake was too rapid to calculate a rate constant for the process. After two minutes less than one percent of the drug remained in the external donor phase. This rapid removal of salicylic acid was similar to both the removal of this drug from a single component $2.5 \mathrm{mM}$ system and from the previous 
salicylic acid/phenobarbital co-uptake system. The percent of phenobarbital remaining in the external aqueous phase after 120 minutes decreased as compared with the percent remaining in the previous salicylic acid/phenobarbital co-uptake system (9.48 versus 33.78 ).

In a co-uptake system, the rate constant and percent of phenobarbital remaining in the external aqueous phase appears to be affected by the total solute concentration in the donor phase. Speculation regarding the mechanisms involved as discussed previously with phenobarbital/salicylate uptake may be applied to this system. The effect of phenobarbital appears to be insignificant to the uptake of salicylic acid at these lower solute concentrations of the external aqueous phase. It is also possible that the lower concentration of solute in the external aqueous phase enhanced the phenobarbital uptake in the same manner.

Because of a short supply of liquid membrane, the combinations of solutes for co-uptake was limited. For this reason the interpretation of the data described above must of necessity be somewhat speculative. Although differences were noted through the comparison of some apparent $\beta$ rate constants, additional data would aid in determining if these differences were significant. From a practical point of view these changes in the apparent $\beta$ rate constants may not be of such a magnitude as to be significant.

3. Effect of Liquid Membrane 0il/Water Ratio on the Co-Uptake of Solutes

In general, the effect of liquid membrane oil/water ratio on the co-uptake of phenobarbital (2.5 miM) and salicylic acid $(7.2 \mathrm{mM})$ was as 
expected. As the ratio of oil/water increased, the uptake of drug by the system was slower. For this situation two parameters must be considered--the $0 i 1 /$ water ratio of the membrane and the presence of two drugs in the external aqueous phase.

Figure 28 shows that the mean apparent $\beta$ rate constant decreased as a function of increasing oil/water ratio for the uptake of phenobarbital as expected. Table XXVIII lists the mean apparent $\beta$ rate constants for this process. As discussed in a previous section, membrane thickness would be expected to decrease the rate of drug transport.

\section{TABLE XXVIII}

MEAN APPARENT B RATE CONSTANTS FOR THE CO-UPTAKE OF DRUGS AS A FUNCTION OF LIQUID MEMBRANE OIL/WATER RATIO

\begin{tabular}{|c|c|c|c|}
\hline \multirow{2}{*}{$\frac{\text { Drug }}{\text { Salicylic Acid }}$} & \multirow{2}{*}{$\begin{array}{c}\begin{array}{c}0 \text { il/Water } \\
\text { Ratio }\end{array} \\
0.5\end{array}$} & \multicolumn{2}{|c|}{$\begin{array}{l}\text { Mean Apparent } \beta \text { Rate Constant } \\
\times 10^{-2}\left(\min ^{-1}\right) \text { and Range }\end{array}$} \\
\hline & & $48.86(2)^{*}$ & $44.56-53.16$ \\
\hline & 0.67 & $54.89(2)$ & $49.82-59.95$ \\
\hline & 1.0 & $59.79(2)$ & $55.19-64.38$ \\
\hline & 2.0 & $32.98(2)$ & $30.85-35.10$ \\
\hline & 3.0 & $26.99(2)$ & $26.98-27.01$ \\
\hline \multirow[t]{5}{*}{ Phenobarbital } & 0.5 & $2.28(2)$ & $2.14-2.41$ \\
\hline & 0.67 & $1.95(2)$ & $1.92-1.98$ \\
\hline & 1.0 & $1.25(2)$ & $1.03-1.48$ \\
\hline & 2.0 & $1.01(2)$ & $0.88-1.13$ \\
\hline & 3.0 & $0.72(2)$ & $0.70-0.74$ \\
\hline
\end{tabular}

*Number of Runs 


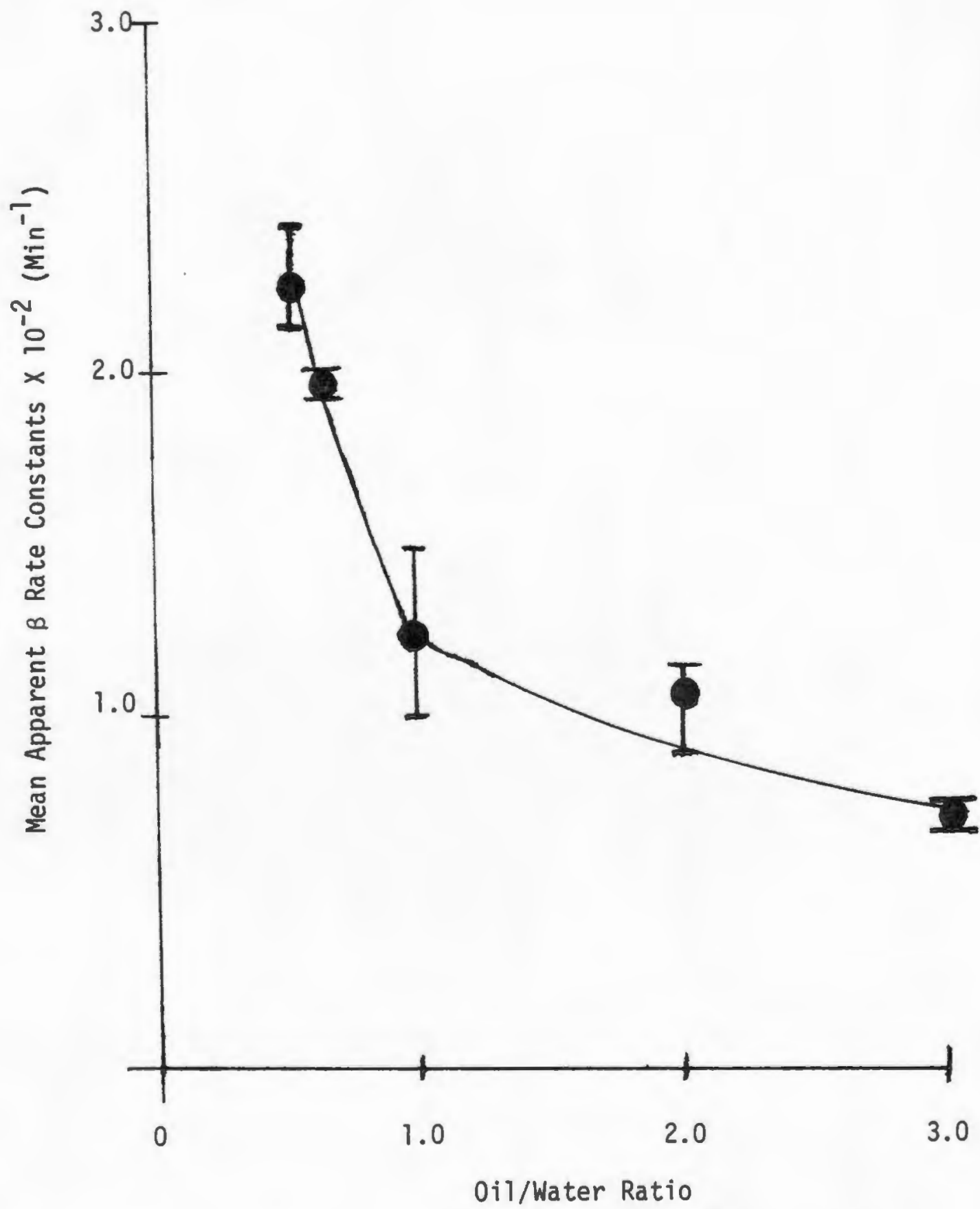

Fig. 28 Mean Apparent $\beta$ Rate Constants for Phenobarbital $0.6 \mathrm{~g} / 1$ Removal in a Multicompartment System As A Function of Liquid Membrane 0il/Water Ratio 
As can be seen from Table XXVIII, there appears to be an optimum $0 i 1 /$ water ratio (1.0) for the uptake of salicylic acid from the multicomponent system. As a general trend, the higher oil/water ratios gave a lower $\beta$ rate constant. However, the range of apparent $\beta$ rate constants varied widely at the lower oil/water ratios. Therefore, it was difficult to designate a specific order of decreasing apparent $\beta$ rate constants for these three liquid membranes $(0.5 ; 0.67 ; 1.0)$. Additional studies at the lower oil/water ratios may help to clarify the order of rate constants in this situation.

Based on the previous results of co-uptake of phenobarbital and salicylic acid at one oil/water ratio (1.0), it was expected salicylic acid would behave similarly when the oil/water ratio was varied. In general this was the case.

K. Effect of Freeze/Thaw on the Use of Liquid Membranes

The integrity of liquid membranes and their capacity to function as sinks was investigated by freezing and thawing three liquid membranes and then exposing them to drug donor solutions. Gross changes were observed after thawing. Nearly total phase separation was noted but the emulsions could be redispersed with vigorous agitation into a homogenous system. Figure 29 shows a plot of percent drug in the external aqueous phase versus time for each of the frozen/thawed systems. The apparent $\beta$ rate constants are listed in Table XXIX. Surprisingly, these rate constants were almost identical to the mean apparent $\beta$ rate constants for salicylic acid using these membranes under ideal conditions (Table $X X I X$ ). It is realized that these rate 


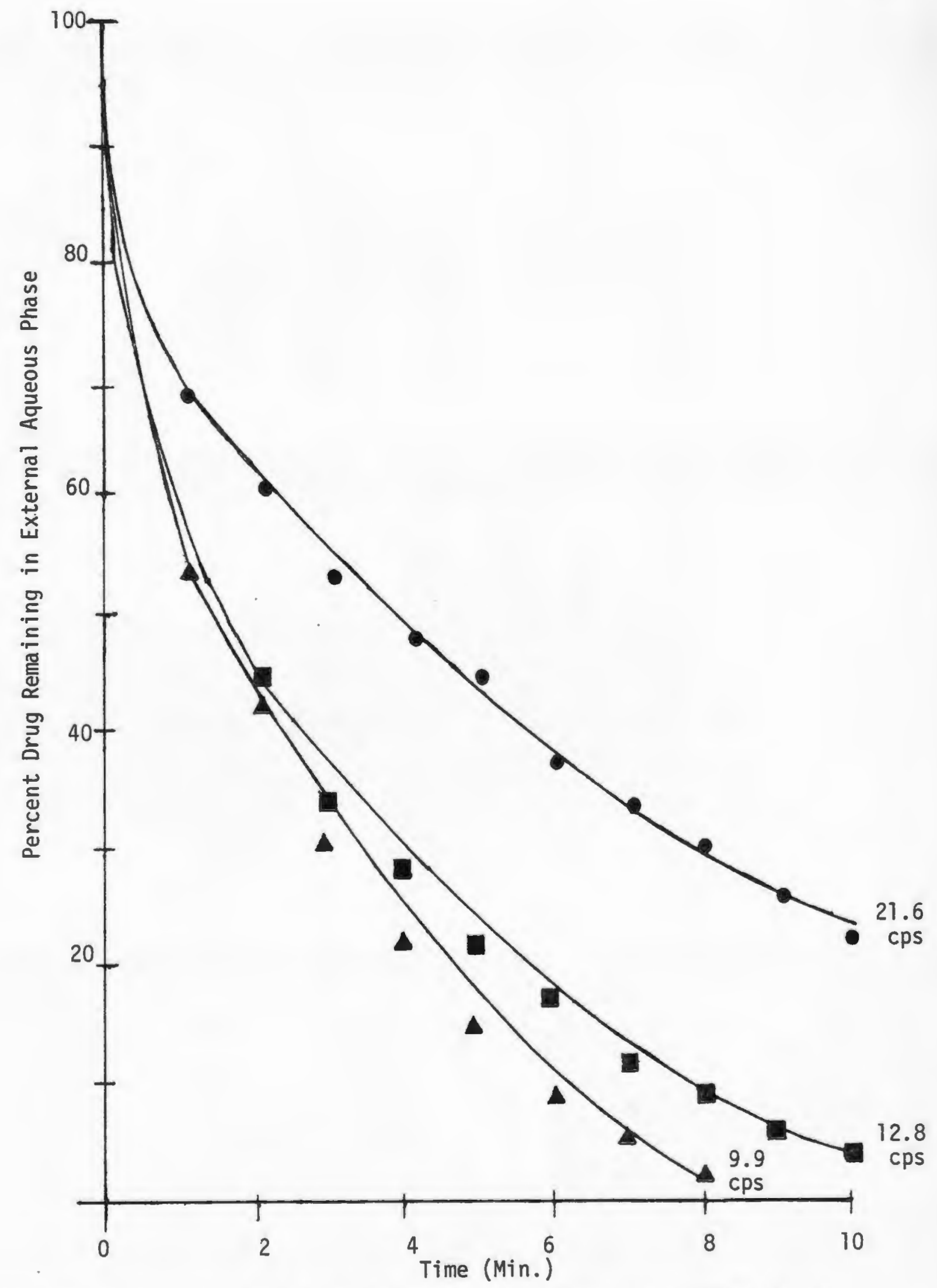

Fig. 29 Salicylic Acid $1.0 \mathrm{~g} / 1$ Removal As A Function of Time Using Frozen/Thawed Liquid Membranes 
the external aqueous phase. Some of the emulsions had good physical properties and readily dispersed as discrete globules when mixed with pH 2 buffer. Their initial flow was average but after standing overnight the emulsions barely flowed or flowed with great difficulty from their containers. These emulsions included 1, 2, 11 and 14 (see Tables XXX and XXXI).

The second major problem, the incomplete dispersion of the emulsion as globules in an external donor phase was observed in a number of formulations which otherwise had good overall properties. In some cases this problem was detected at time 0 ; for other systems this became apparent after overnight storage or when mixed in an appropriate quantity of $\mathrm{pH} 2$ buffer in the reaction flask. The series of emulsions in which this was most prevalent was emulsions 15-19. Slight changes in the total percent of emulsifier blend improved the viscosity and flow characteristics of the emulsions. When these systems were tested for dispersion as globules, they failed to disperse into globules when it was mixed with external aqueous phase.

The formulations which demonstrated the most promise for use in a liquid membrane system were 20a, 20b, 21a, and 21b. Emulsion 20a creamed after storage overnight but was readily dispersed and used in an extraction experiment. The data obtained from an uptake run using salicylic acid $1.0 \mathrm{~g} / 1$ is contained in Table XXXII. Rapid and essentially complete drug removal was observed. Similar results were observed when Emulsion 21b was used in an extraction experiment for salicylic acid $1.0 \mathrm{~g} / \mathrm{l}$. 
constants were obtained from one set of data, yet it is felt that they are indicative of the capacity of the liquid membrane to withstand stress.

TABLE XXIX

A COMPARISON OF THE APPARENT \& RATE CONSTANTS FOR THE UPTAKE OF SALICYLIC ACID $1.0 \mathrm{~g} / 1$ USING A FREEZE/THAW STRESSED LIQUID MEMBRANE VERSUS THE MEAN APPARENT $\&$ RATE CONSTANTS FOR THE UPTAKE OF SALICYLIC ACID $1.0 \mathrm{~g} / 1$ UNDER IDEAL CONDITIONS

\begin{tabular}{rcc}
\hline \hline Viscosity & $\begin{array}{c}\text { Apparent } \beta \text { Rate } \\
\text { Constant } \times 10^{-2}(\text { min-1) } \\
\text { Freeze/Thaw Stress }\end{array}$ & $\begin{array}{c}\text { Mean Apparent } \beta \text { Rate } \\
\text { Constant } \times 10-2(\text { min-1) } \\
\text { Ideal . Conditions }\end{array}$ \\
\hline 9.9 & $49.44(1)^{\star}$ & $46.63(2)$ \\
12.8 & $31.02(1)$ & $31.17(2)$ \\
21.6 & $12.04(1)$ & $10.00(2)$ \\
\hline
\end{tabular}

*Number of Runs.

L. Evaluation of the Formulation Aspects of Liquid Membranes

1. Evaluation of Emulsions Prepared Using the HLB Approach

The results of the evaluation of emulsions prepared using the HLB approach are listed in Tables $X X X$ and $X X X I$. In general good stability was observed for these systems. Most of the emulsions had good white color indicating a small mean particle size. Those emulsions which were the whitest tended to be the most stable as would be expected.

The major problems associated with the use of these emulsions as liquid membranes were their high viscosity (i.e. far too thick) and, in some instances, their incomplete dispersion as discrete globules in 
TABLE $X X X$

VISUAL ANALYSIS, DETERMINATION OF EMULSION TYPE, AND EVALUATION OF POTENTIAL TO FORM

A LIQUID MEMBRANE FOR THOSE EMULSIONS PREPARED USING THE HLB APPROACH

The emulsions listed in this table correspond to those described in Table $V$.

\begin{tabular}{|c|c|c|c|c|c|c|c|c|}
\hline \multirow[t]{2}{*}{ Emulsion } & \multicolumn{4}{|r|}{ Time - } & \multicolumn{4}{|l|}{ Hours } \\
\hline & Color & Separation & Type & $\begin{array}{l}\text { Potential to } \\
\text { Form a Liquid } \\
\text { Membrane }\end{array}$ & Color & Separation & Type & $\begin{array}{l}\text { Potential to } \\
\text { Form a Liquid } \\
\text { Membrane }\end{array}$ \\
\hline 1 & ow & 0 & $w / 0$ & 1 & ow & 0 & $w / 0$ & 1 \\
\hline 2 & gw & +1 & $0 / w$ & 0 & gw & +1 & $0 / w$ & 0 \\
\hline 3 & ow & 0 & $w / 0$ & 1 & ow & 0 & $w / 0$ & 1 \\
\hline 4 & gw & +1 & $0 / w$ & 0 & gw & +1 & $0 / w$ & 0 \\
\hline 5 & ow & 0 & $w / 0$ & 1 & ow & 0 & $w / 0$ & 1 \\
\hline 6 & ow & +1 & $0 / w$ & 0 & OW & +1 & $0 / w$ & 0 \\
\hline 7 & OW & 0 & $w / 0$ & 1 & OW & 0 & $w / 0$ & 1 \\
\hline 8 & $w$ & +1 & $w / 0$ & 0 & $w$ & +1 & $w / 0$ & 0 \\
\hline 9 & $w$ & 0 & $w / 0$ & 1 & $w$ & 0 & $w / 0$ & 1 \\
\hline 10 & $w$ & 0 & $w / 0$ & 1 & $w$ & 0 & $w / 0$ & 1 \\
\hline 11 & gw & +1 & $w / 0$ & 0 & gw & +1 & $w / 0$ & 0 \\
\hline 12 & ow & 0 & $w / 0$ & 1 & gw & 0 & $w / 0$ & 1 \\
\hline 13 & ow & 0 & $w / 0$ & 1 & OW & 0 & $w / 0$ & 0 \\
\hline 14 & ow & 0 & $w / 0$ & 1 & ow & 0 & $w / 0$ & 1 \\
\hline
\end{tabular}


TABLE $X X X$ (Continued)

\begin{tabular}{|c|c|c|c|c|c|c|c|c|}
\hline \multirow[t]{2}{*}{ Emulsion } & \multicolumn{8}{|c|}{ Time - Hours } \\
\hline & Color & Separation & Type & $\begin{array}{l}\text { Potential to } \\
\text { Form a Liquid } \\
\text { Membrane }\end{array}$ & Color & Separation & Type & $\begin{array}{l}\text { Potential to } \\
\text { Form a Liquid } \\
\text { Membrane }\end{array}$ \\
\hline 15 & $w$ & 0 & $w / 0$ & 1 & $w$ & 0 & $w / 0$ & 1 \\
\hline 16 & $w$ & 0 & $w / 0$ & 1 & $w$ & 0 & $w / 0$ & 0 \\
\hline 17 & $w$ & 0 & $w / 0$ & 1 & $w$ & 0 & $w / 0$ & 0 \\
\hline 18 & $w$ & 0 & $w / 0$ & 1 & $w$ & 0 & $w / 0$ & 0 \\
\hline 19 & $w$ & 0 & $w / 0$ & 1 & $w$ & 0 & $w / o$ & 0 \\
\hline $20 a^{*}$ & $w$ & 0 & $w / 0$ & 1 & $w$ & +1 & $w / 0$ & 1 \\
\hline$b^{\star}$ & $w$ & 0 & $w / 0$ & 1 & $w$ & 0 & $w / 0$ & 1 \\
\hline $21 a$ & $w$ & 0 & $w / 0$ & 1 & $w$ & 0 & $w / 0$ & 1 \\
\hline b & $w$ & 0 & $w / 0$ & 1 & $w$ & 0 & $w / 0$ & 0 \\
\hline
\end{tabular}

*Reproducibility difficult

Key: $\quad$ w = off white, $g w=$ grayish white, $w=$ white

$0=$ none,$+1=$ separation occurred, 1 = good potential 
TABLE $X X X I$

DETERMINATION OF VISCOSITY AND CHARACTERIZATION OF FLOW FOR THOSE EMULSIONS PREPARED USING THE HLB APPROACH

The emulsions listed in this table correspond to those described in Iabie $y$

\begin{tabular}{|c|c|c|c|c|}
\hline \multirow[t]{2}{*}{ Emulsion } & \multicolumn{4}{|c|}{ Time - Hours } \\
\hline & $\begin{array}{l}\text { Average Viscosity } \\
\text { (cPs) }\end{array}$ & Flow & $\begin{array}{l}\text { Average Viscosity } \\
(\mathrm{CPs})\end{array}$ & Flow \\
\hline 1 & 3.7 & 3 & $-\cdots$ & 5 \\
\hline 2 & 3.5 & 3 & ---- & 3 \\
\hline 3 & 3.27 & 3 & $-\ldots$ & 5 \\
\hline 4 & $\cdots+$ & 3 & ---- & 3 \\
\hline 5 & ---- & 5 & --- & 5 \\
\hline 6 & $-\ldots$ & 3 & --- & 3 \\
\hline 7 & --- & 5 & $-\cdots$ & 5 \\
\hline 8 & -..- & 3 & ---- & 3 \\
\hline 9 & 2.12 & 2 & 2.12 & 2 \\
\hline 10 & ---- & 4 & $\cdots$ & 4 \\
\hline 11 & 3.66 & 3 & -.-- & 4 \\
\hline 12 & ---- & 4 & -... & 4 \\
\hline 13 & 3.45 & 3 & 3.45 & 3 \\
\hline 14 & 3.8 & 3 & -..- & 5 \\
\hline 15 & 1.55 & 2 & 1.55 & 2 \\
\hline 16 & 1.37 & 2 & 1.37 & 2 \\
\hline 17 & 1.34 & 2 & 1.34 & 2 \\
\hline 18 & 1.01 & 1 & 1.03 & 1 \\
\hline 19 & 0.92 & 1 & 0.93 & 1 \\
\hline $20 a$ & 1.68 & 2 & 1.65 & 2 \\
\hline $20 \mathrm{~b}$ & 2.24 & 2 & 2.26 & 2 \\
\hline $21 a$ & 1.92 & 2 & 1.92 & 2 \\
\hline $21 \mathrm{~b}$ & $2: 12$ & 2 & 2.15 & 2 \\
\hline
\end{tabular}

-- Emulsion either too viscous to too unstable to determine viscosity. 
TABLE XXXII

PERCENT SALICYLIC ACID REMAINING IN THE EXTERNAL AQUEOUS

PHASE WITH TIME AFTER EXPOSURE TO EMULSIONS MANUFACTURED USING THE HLB APPROACH

\begin{tabular}{|c|c|c|}
\hline \multirow[b]{2}{*}{ Time (minutes) } & \multicolumn{2}{|c|}{$\begin{array}{c}\text { Percent Salicylic Acid Remaining in the } \\
\text { External Aqueous Phase }\end{array}$} \\
\hline & Einulsion $20 \mathrm{a}$ & Emulsion 21b \\
\hline 0 & 100.00 & 100.00 \\
\hline 1 & 8.38 & 18.79 \\
\hline 2 & 2.87 & 6.70 \\
\hline 3 & 11.09 & 5.47 \\
\hline 4 & 0.93 & 4.90 \\
\hline 5 & -- & -- \\
\hline 6 & 0.54 & 2.12 \\
\hline
\end{tabular}

The major problem with obtaining additional data with these systems was difficulty to manufacture reproducible batches. The characteristics of Emulsion 20a changed when this emulsion was prepared by homogenization. The homogenized version, Emulsion 20b, was too viscous for use in a liquid membrane system. Whereas Emulsion 21a was unacceptable for forming a liquid membrane system, the homogenized version, $21 \mathrm{~b}$, as can be seen from the data reported above, was acceptable as a liquid membrane. In all cases when the batch size was increased, the results were not reproducible.

The Exxon liquid membranes used in this project have remarkable physical stability, as noted by the freeze/thaw stress, but they are 
not GRAS. It is known that other research groups have been attempting to form stable liquid membranes with GRAS ingredients. They have had 1 imited success and are far from being marketable products. GRAS materials are restricted in the number of components meeting these specifications and are subject to aging effects, as was seen in this present study. In the final stages of emulsion manufacture, intuitive rather than scientific aspects of formulation are important.

There are several reasons why the emulsions manufactured in this project were not acceptable for use as liquid membranes. It is believed that the emulsifier blend and method of achieving emulsification are two key concerns. Although the HLB approach worked reasonably well when used in the formulation of a three rather than two phase system, subsequent treatment of these emulsions to create a liquid membrane system had an adverse effect on these products. Dispersing the emulsions in $\mathrm{pH} 2$ buffer with continued and more vigorous agitation seemed to contribute to phase inversion or cracking which rendered the emulsions unacceptable. Achieving the correct delicate balance of stabilizers and surfactants is a necessity for the overall stability of these emulsions if they are to be used successfully as liquid membranes. In this project, al though it was possible to manufacture a stable w/o emulsion, the formation of a stable w/o/w liquid membrane system was difficult. It is possible that the surfactant blend was at a critical concentration and this resulted in instability when the w/o emulsion was treated further. A change in manufacturing technique is a widely accepted reason for changes in emulsion characteristics. 
This was believed to be a problem in this study, particularly during scale-up operations.

2. Evaluation of Emulsions Using the Davis Approach

An attempt was made to reproduce the formula published in the literature by Davis (19). Reproducing emulsions from a published formula is generally known to be difficult; therefore, it was not surprising that this formula could not be reproduced and that the emulsions manufactured in this attempt were extremely poor (65). 


\section{SUPAMARY}

The following are believed to be the salient points of this work as reported and discussed in the previous section.

The initial concentration of solute in the external donor phase appears to have an effect on the rate constants controlling the removal of solutes by liquid membranes. A decreased mean apparent $\beta$ rate constant was observed for both salicylic and acetylsalicylic acids when the intitial concentration of solute in the external donor phase was increased. It was speculated that this may have been the result of alterations to the surface properties of the membrane which changed its permeability to the solute. Increases in the size of the internal aqueous phase droplets resulting in a decrease in surface area at the liquid membrane/internal aqueous phase interface was also considered as a possible explanation for this phenomena. It should be noted here also that decreased apparent $\beta$ rate constants for solutes were observed as the total concentration of solute increased in a multicomponent system (i.e. two drugs in the external aqueous phase).

The $\mathrm{pH}$ of the external donor phase was observed to affect the rate constants describing salicylic acid uptake in the expected manner. At low $\mathrm{pH}$ the apparent $\beta$ rate constants were greater than at higher $\mathrm{pH}$. This was due tomore nonionized drug being available for transport at low pH values. An attempt was made to predict quantitatively salicylic acid uptake as a function of $\mathrm{pH}$ over 60 minutes using a CSMP computer 
program and based on the simple liquid membrane model described previously. Lack of quantitative agreement between predicted and experimental data is attributed to the complexity of the system and insufficiency of the model. Factors such as effect of $\mathrm{pH}$ on the surfactant and changes in the concentration of micelles may have contributed to the complexity of the model.

The study of the effect of temperature on the uptake of solutes by liquid membranes revealed some interesting phenomena. Whereas the apparent $\beta$ rate constant controlling salicylic acid uptake increased with increases in temperature, as expected, and apparently followed the Arrhenius relationship, this was found to be true for phenobarbital until a critical temperature was reached. It was discovered that a critical temperature range existed above which a sharp decrease in the $\alpha$ and $\beta$ rate constants resulted. It is believed that the liquid membrane was beginning or nearly about to collapse. It is speculated that changes in the physical properties at this high and critical temperature were responsible for this or that secondary reactions between the surfactant and phenobarbital resulted in a temperature sensitive formation of a complex. Through this complex, it was thought that changes in the nature of the interfaces resulted in alterations in solute permeability. By increasing the viscosity of the liquid membrane used at this critical temperature, it was thought that solute transport might be improved. This was not found to be the case, in fact, there was no obvious relationship between the rate constants and viscosity at the critical temperature. Viscosity of the membrane 
itself may be dependent upon a critical temperature and further studies in this area may be useful in determining if this is true.

Altering the physical properties of the liquid membranes was found to have the predicted affects on solute uptake. By increasing the oil/water ratio, the rate of solute uptake decreased. This was observed for salicylic acid in both single component and multicomponent systems and for phenobarbital in a multicomponent system. The increased thickness of the oil phase and any possible changes in the amount of surface area from the internal aqueous phase droplets are proposed as possible explanations for this occurrence.

As the viscosity of the liquid membrane increased, the rate of salicylic acid decreased, as would be expected by consideration of Fick's law. It is probable that as the oil was changed to achieve a more viscous membrane, the diffusion coefficient of the drug changed, hence slower transport.

Through evaluation of the reuse of liquid membrane, it was seen that whereas some drugs (acetylsalicylic and salicylic acids) were not capable of back transport (i.e. transport from the liquid membrane to the external aqueous phase), phenobarbital was able to transport from the liquid membrane into the external aqueous phase. This confirmed the findings of Chilamkurti and Rhodes, who through the analysis of the micro rate constants, showed that some ions could indeed transport out of the liquid membrane (i.e. Benzoate, wion) others could not (i.e. salicylate ion).

The liquid membranes demonstrated the ability to subsequently remove one drug following the removal of another. 
The co-uptake of solutes was investigated on two levels-nulticomponents systems in which the solutes were not in equimclar concentrations and those in which they were. In all cases co-uptake was achieved but to varying degrees. In general, faster rates of uptake were obtained in multicomponent systems of lower total solute concentration. This was similar to the effect of increasing salicylic or acetylsalicylic acid concentrations as single component systems on the rate of soiute up. The reasons proposed for this phenomena may well be applied to multicomponent systems.

Freeze/thaw stressing of the liquid memiranes proved that they are very stable systems. The apparent $\beta$ rate constants obtained from experimental runs using these membranes was surprisingly similar to those obtained for uptake under ideal conditions.

Al though the formulation of liquid membranes with GRAS components was difficult, some success was achieved with the production of two systems which used liquid membranes in drug removal runs. Method of manufacture and appropriate surfactant blends were determined to be key factors in the development of these systems for use as liquid membranes. The HLB approach to emulsion formulation was found to be a useful tool in the development of these systems.

In summary, the major impact of the data reported here on the theoretical aspects of liquid membrane transport will be on the development of amodel which will describe this complex process. Although in many instances the data obtained could readily be explained by the simple model proposed by Yang and Rhodes and Chilamkurti and 
Rhodes, it was insufficient to rationalize all aspects of liquid membrane transport when additional parameters were defined and included the model. Realizing that this is a complex system, it would be inappropriate at this time to develop a model which would quantitatively predict all aspects of liquid membrane transport. Clearly, further study of the kinetics of more complex liquid membrane systems is a fascinating and challenging area for research.

The results reported in this thesis have relevance for a number of practical pharmaceutical applications of liquid membranes.

Although the attempt to produce liquid membrane formulations using GRAS components was only partially successful and it is fully realized that none of the formulations developed in this study are such that they could be marketed in their present form, it is believed that the data reported overall tends to strongly support the potential development of liquid membranes for pharmaceutical uses. Although many of these systems were highly viscous, this does not preclude their use for the delivery of drug by the vaginal or rectal routes or orally through encapsulation in soft gelatin capsules.

It is generally recognized that pharmaceutical emulsions are complex, thermodynamically unstable systems very much more difficult to manufacture on a larger scale in a reproducible manner than are a number of other dosage forms such as compressed tablets. These difficulties are compounded in the case of complex emulsions such as liquid membrane systems. The successful development of such complex dispersed systems for commercial use is at the present time often intuitive rather than entirely scientific. 
For example, the production of IV fat emulsions which would be able to tolerate sterilization by autoclaving at $115^{\circ} \mathrm{C}$ was a thorny problem which was finally solved by one company at least, by the chance observation that intermittent agitation during the cooling part of the sterilization cycle prevents the occurrence of physical stability problems. It seems likely that because of our present incomplete understanding of all the factors which govern the properties of liquid membrane systems, the commercial development of these products may also depend upon such a chance observation or intuition.

Through the study of the effect of temperature on the uptake of phenobarbital and salicylic acid, it was observed that improved rate constants controlling solute uptake occur at body temperature. It is noteworthy that a critical temperature, $43^{\circ} \mathrm{C}$, was discovered in the uptake of phenobarbital, a temperature significantly above the usual range of body temperature.

The results obtained from the evaluation of liquid membrane reuse demonstrate that under the proper conditions of $\mathrm{pH}$ and solute/ surfactant interaction, these systems have the potential to act as drug delivery systems. More studies on the transport of some ionized species out of a liquid membrane may further expand this area of research.

Reuse of liquid membranes in terms of subsequent drug removal may have application in the multiabsorption of drugs in overdose situations. Another area which has direct application is the use of 1 iquid membranes overdose situations is the co-uptake of solutes. The liquid 
membranes were found to behave well in the presence of multicomponent external aqueous phases. Although changes in the rate of uptake were observed in some cases, these changes are thought to have little effect on the overall ability of these membranes to remove two solutes simultaneously.

In conclusion, it is believed that the data reported in this thesis are likely to prove valuable in the development of a comprehensive, rational theory defining the properties of liquid membrane systems. Also it is appreciated that the data reported in this thesis clearly defines a number of aspects pertinent to the practical application of liquid membranes as drug delivery systems or drug sinks in the emergency treatment of drug overdose. 
VII. CONCLUSIONS

1. High pressure liquid chromatography was a sensitive, reproducible and reliable assay technique for the detection of drug in liquid membrane solute uptake experiments.

2. Viscosity and oil/water ratio of 1 iquid membranes will influence the rate of solute uptake.

3. It appears that optimum environmental conditions are necessary for the efficient removal of solutes by liquid membranes. Whereas increasing the temperature will increase the rate of uptake of a solute, there appears to be a critical temperature for phenobarbital uptake. Increasing the $\mathrm{pH}$ and solute concentration of the external aqueous phase decreases the rate of solute uptake.

4. Computer modeling techniques to describe the uptake of solutes with liquid membranes were of limited value. This was probably due to the complex nature of the system.

5. Liquid membranes show potential for use in co-uptake and multidrug uptake and they appear to be reusable.

6. Freezing liquid membranes does not appear to have any adverse affects on the efficiency of these systems to remove solute from an external aqueous phase.

7. The method of manufacture and anpropriate surfactant blend were determined to be key factors in the development of emulsions for use as liquid membranes. 


\section{REFERENCES}

1. Li, N. N., U. S. Patent 3, 410, 794 (1968).

2. Li, N. N., A.I.Ch.E.J., 17, 459 (1971).

3. Wallace, H. W., Asher, W. J., Zubroro, M. T., Stein, T. P., Brooks, H., J. Thorac. Cardiovas. Surg., 66, 887 (1973).

4. Wallace, H. W., Stein, T. P., Asher, W. J., Fed. Proc., 34, 1506 (1975).

5. Li, N. N., Biochem. Biophys. Res. Commun., 47, 1179 (1972).

6. Mohan, R. R., Li, N. N., Biotechnol. Bioeng., 16, 513 (1974).

7. Li, N. N., Ind. Chem. Proc. Des. Dev., 10, 215 (1971).

8. Asher, W. J., Rovee, K. C., Frankenfeld, J. W., Hamilton, R. W., Henderson, L. W., Hotzapple, P. G., Li, N. N., Kidney Int., I, s-409 (1975).

9. Asher, W. J., Vogler, T. C., Bovee, K. C., Hotzapple, P. G., Hamilton, R. W., Kidney Int., 10, s-254 (1976).

10. Frankenfeld, J.W., Asher, W. J., Li, N. N., "Symposium on Recent Advances in Separation Science," American Chemical Society Centennial Meeting, San Francisco, CA, August, 30, 1976.

11. Matulevicius, E. S., Li, N. N., Sep. Purif. Methods, 4, 73 (1975).

12. Cahn, R. P., Li, N. N., Sep. Sci., 9, 505 (1974).

13. Kitagawa, T., Nishikawa, Y., Frankenfeld, J. W., Li, N. N., Environ. Sci. Technol., 11, 602 (1977). 
14. Frankenfeld, J. W., Cahn, R. P., Li, N. N., Sep. Sci. Technol., 16, 385 (1981).

15. Frankenfeld, J. W., Fuller, G. C., Rhodes, C. T., Drug Dev. Commun., 2. 405 (1976).

16. Chang, C. W., Fuller, G. C., Frankenfeld, J. W., Rhodes, C. T., J. Pharm. Sci., 67, 63 (1978).

17. Yang, T. T., Rhodes, C. T., J. Appl. Biochem., 2, 7 (1980).

18. Chilamkurti, R. N., Rhodes, C. T., J. Appl. Biochem., 2, 17 (1980).

19. Davis, S. S., Chemistry and Industry, $\underline{3}, 683$ (1981).

20. Whitehill, D., Florence, A. T., J. Pharm. Pharmacol., 31, 39 (1979).

21. Brodin, A. F., Kavaliunas, D. R., Frank, S. G., Acta Pharm. Suecica, 15, 1 (1978).

22. Kita, Y., Matsumoto, S., Yonezawa, D., J. Coll. Int. Sci., 62, 87 (1977).

23. Flynn, G. L., Yalkowsky, S. H., Rosman, T. J., J. Pharm. Sci., 63, 479 (1974).

24. Modern Pharmaceutics, Banker, G. S., and Rhodes, C. T., Eds., Marcel Dekker, Inc., NY, 1979.

25. Martin, A. N., Swarbrick, J., Carmarata, A., Physical Pharmacy 2nd Ed., Lea \& Febiger, Philadelphia, PA, 1970.

26. Hogben, C. A. M., Turco, D. J., Brodie, B. B., Schanker, L. S., J. Pharmacol. Exp. Ther., 125, 540 (1957).

27. Shore, P. A., Brodie, B. B., Hogben, C. A. M., J. Pharmacol. Exp. Ther., 119, 361 (1957). 
28. Schanker, L. S., Shore, P. A., Brodie, B. B., Hogben, C. A. M., J. Pharmaco1. Exp. Ther., 120, 528 (1957).

29. Schanker, L. S., Turco, D. J., Brodie, B. B., Hogben, C. A. M., J. Pharmacol. Exp. Ther., 123, 81 (1958).

30. Hogben, C. A. M., Turco, D. J., Brodie, B. B., Schanker, L. S., J. Pharmacol. Exp. Ther., 125, 275 (1959).

31. Product Literature, The H. L. B. System, A Time Saving Guide to Emulsifier Selection, ICI United States, Inc., Wilmington, DE, 1976.

32. Parrott, E. L., Pharmaceutical Technology, Fundamental Pharmaceutics, Burgess Publishing Company, Minneapolis, MN, 1970.

33. Becher, P., Emulsions Theory and Practice, 2nd Ed., Reinhold Publishing Corporation, New York, NY, 1966.

34. Zografi, G., "Emulsions," Chapter 16 of The Theory and Practice of Industrial Pharmacy, Leon Lachman, Herbert A. Lieberman, Joseph L. Kanig, Eds., Lea \& Febiger, Philadelphia, PA, 1970.

35. Martin, A. N., J. Pharm. Sci., 50, 513 (1961).

36. Garrett, E. R., J. Pharm. Sci., 54, 1557 (1965).

37. Tingstad, J. E., J. Pharm. Sci., 53, 955 (1964).

38. Lin, T. J., Kurihara, H., Ohta, H., J. Soc. Cos. Chem., 24, 797 (1973).

39. Lin, T. J., Lambrechts, J. C., J. Soc. Cos. Chem., 20, 185 (1969).

40. Parkinson, C., Sherman, P., J. Coll. Int. Sci., 41, 328 (1972).

41. Lin, T. J., J. Soc. Cos. Chem., 19, 683 (1968).

42. Groves, M. J., Chemistry and Industry, 17, 417 (1978). 
43. Boyd, J., Parkinson, C., Sherman, P., J. Coll. Int. Sci., 41, 359 (1972).

44. Groves, M. J., J. Pharm. Sci., 57, 1273 (1968).

45. Groves, M. J., Analyst, 99, 599 (1974).

46. Groves, M. J., Pestic. Sci., Nov/Dec., 274 (1970).

47. Matthews, B. A., Rhodes, C. T., J. Pharm. Sci., 57, 557 (1968).

48. Samyn, J. C., McGee, J. P., J. Pharm. Sci., 54, 557 (1968).

49. Reichmann, K. W., Petersen, R. V., J. Pharm. Sci., 62, 1850 (1962).

50. Vold, R. D., Mittal, K. L., J. Pharm. Sci., 61, 769 (1972).

51. Singleton, W. S., White, J. L., Benerito, R. R., Talluto, K. F., J. Am. Oil Chemists' Soc., 35, 265 (1958).

52. McQuarrier, E. B., Andersen, H. P., Am. J. Clin. Nutr., 16, 23 (1965).

53. Singleton, W. S., Benerito, R. R., White, J. L., J. Am. 0il Chemists' Soc., 37, 88 (1960).

54. Singleton, W. S., Brown, M. L., J. Am. 0il Chemists' Soc., 42, 312 (1965).

55. Collings, A. J., Schneider, R., Br. J. Pharmacol., 38, 469p (1970).

56. Baker, S. P., Dietze, P. E., "Injury Prevention," in Healthy People, The Surgeon General's Report on Health Promotion and Disease Prevention, 1979.

57. United States Pharmacopeia XX, Mack Publishing Company, Easton, PA, p. 1101,1980 .

58. Clarke, E. G. C., Isolation and Identification of Drugs, The Pharmaceutical Press, London, 1969. 
59. Harrison, L. I., Funk, M. L., Ober, Fi E., 1. Pharm. Sci., 69, 1268 (1980).

60. Product Information, Waters Asscciates, Mitiord, MA, 1979.

61. Autoan Computer Program, Publication Distribution Service, Ann Arbor, MI.

62. Loughnan, P. M., Sitar, D. S., Ogilvie, R. I., Neims, A. H., J. Pediatr., 88,869 (1976).

63. Willard, H. H., Merritt, L. L., Dean, J. A., Instrumental Methods of Analysis, 5th Ed., D. Van Nostrand Company, New York, NY, 1974.

64. System/360 Continuous System Model Program User's Manual, 5th Ed., IBil Corporation, White Plains, NY, 1972.

65. Griffen, W. C., "Emsulficiation," Chapter 44 of Cosmetic Science and Technology, M. S. Balsam and E. Sagarin, Eds., John Wiley \& Sons, New York, NY, 1974. 
APPENDIX I 


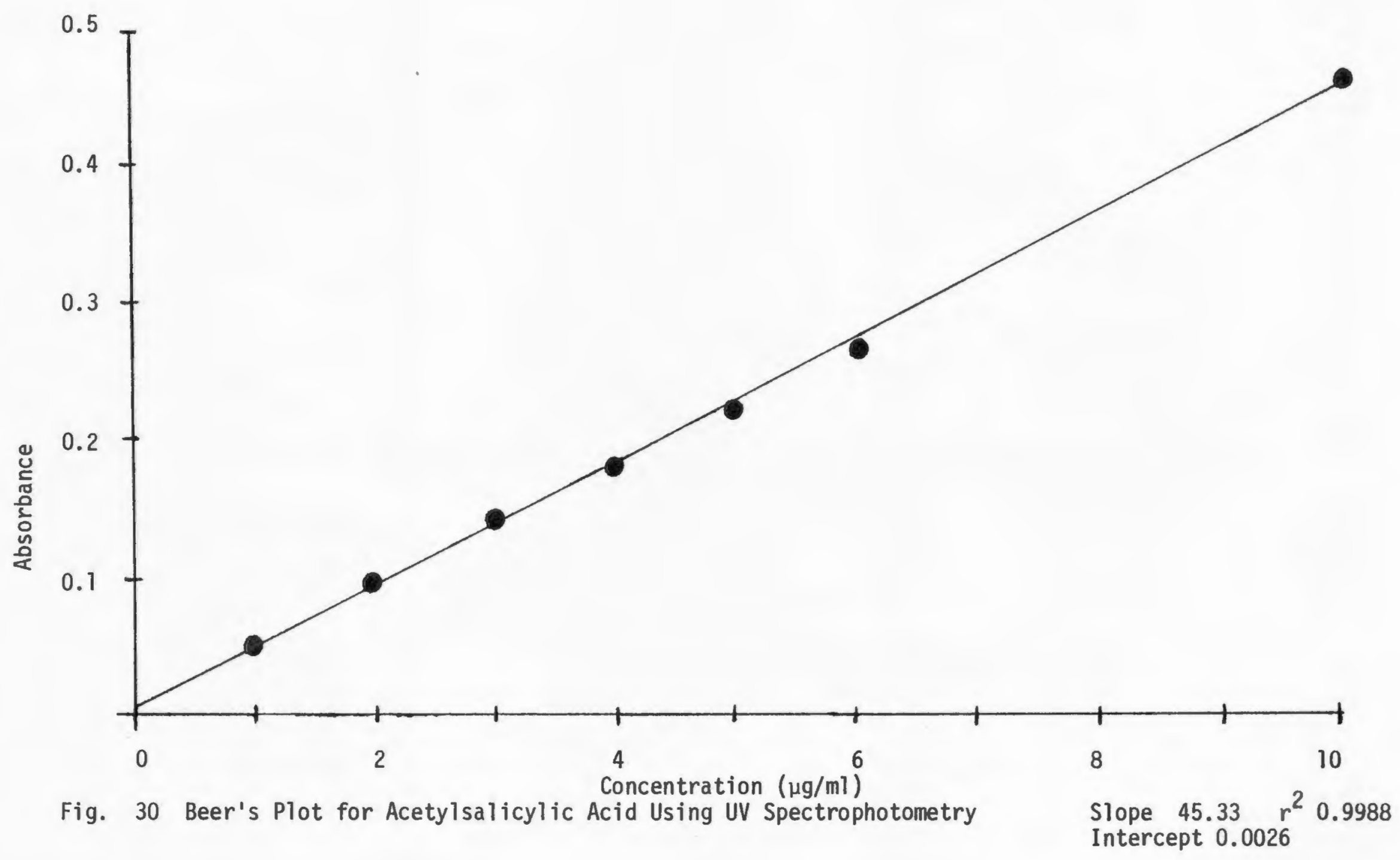




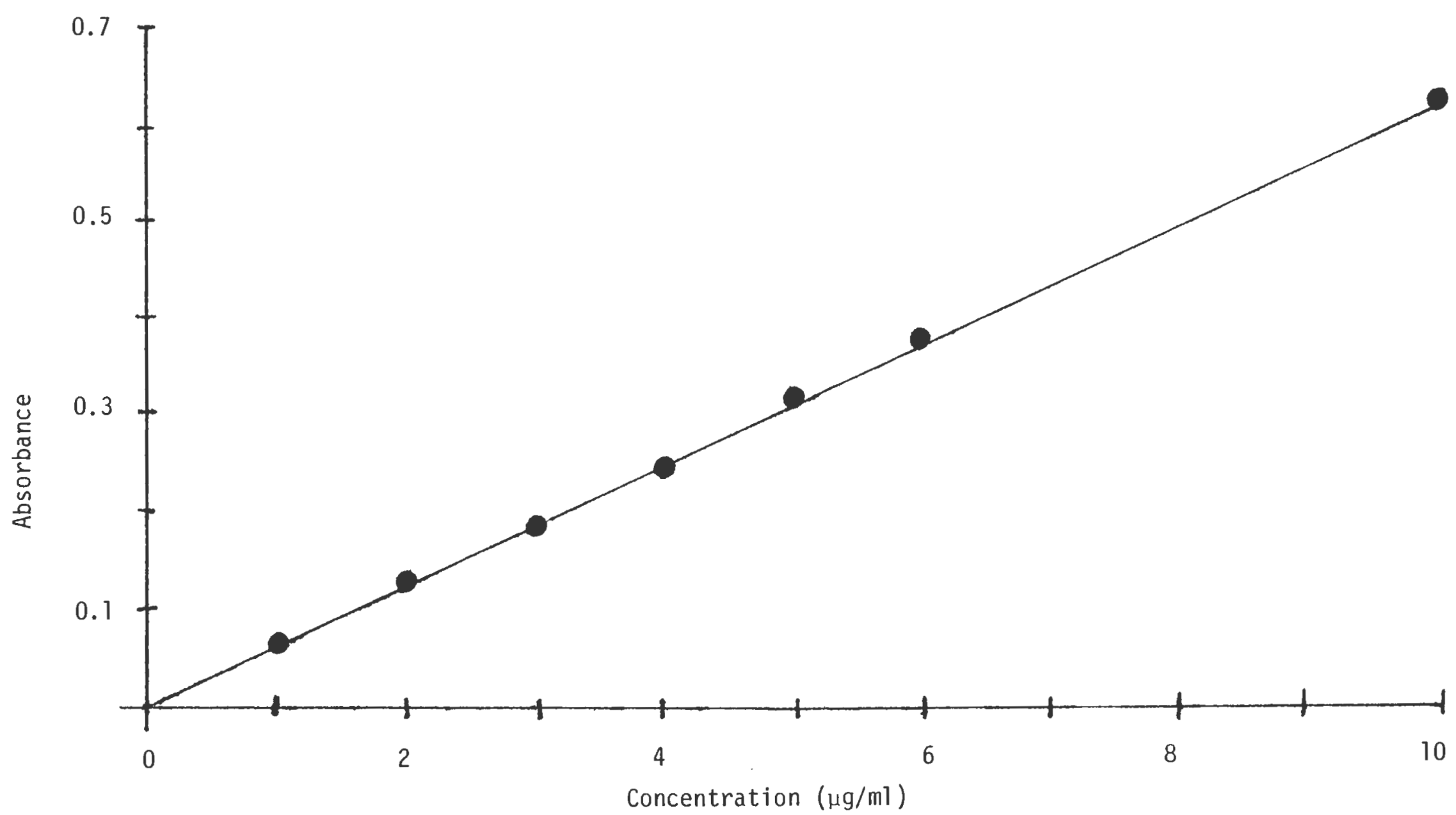

Fig. 31 Beer's Plot for Salicylic Acid Using UV Spectrophotometry

Slope 61.77

Intercept -0.0006

$r^{2} 0.9995$ 


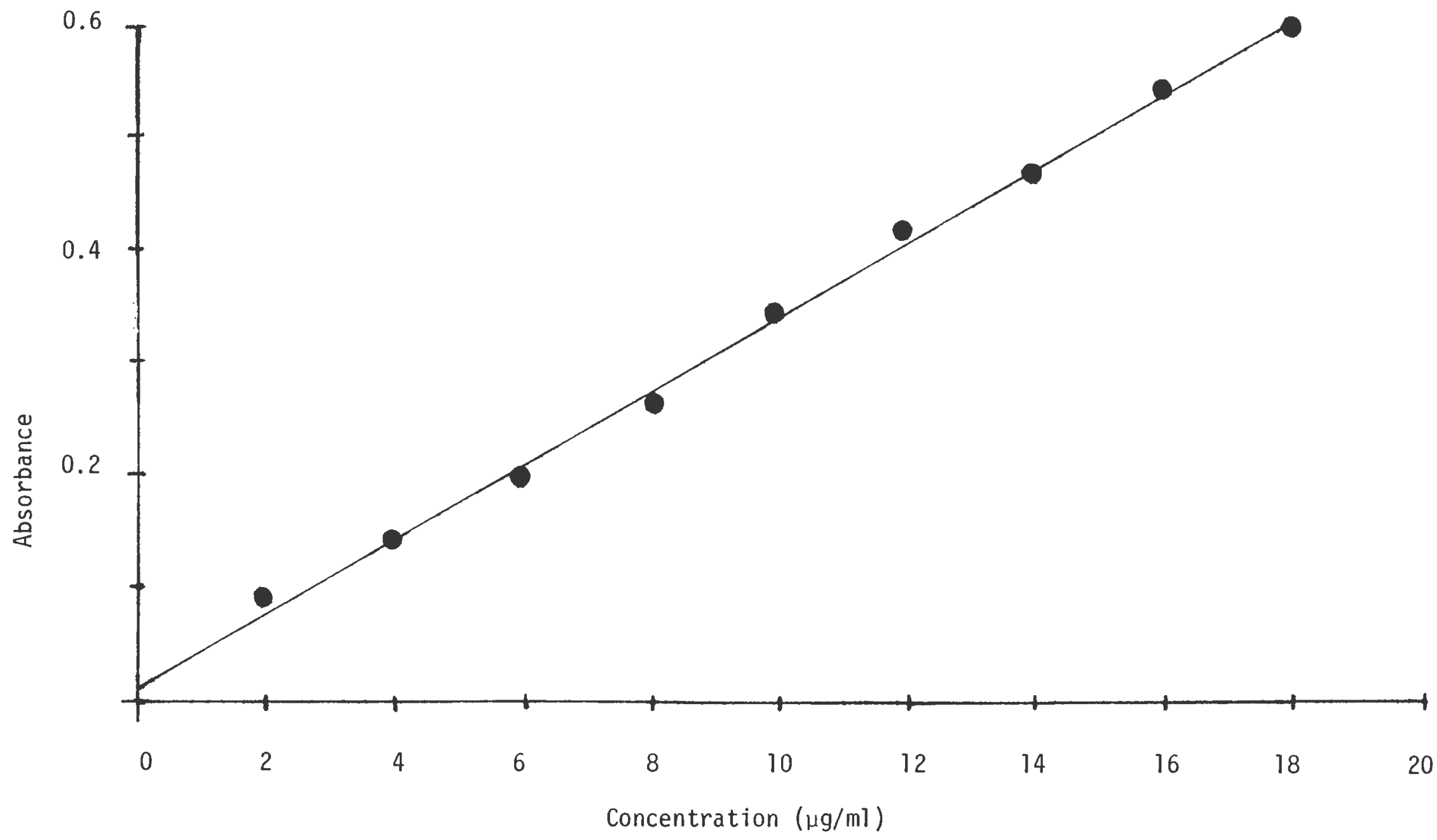

Fig. 32 Beer's Plot for Phenobarbital Using UV Spectrophotometry

Slope 0.0331

Intercept 0.0095

$r^{2} \quad 0.9983$ 


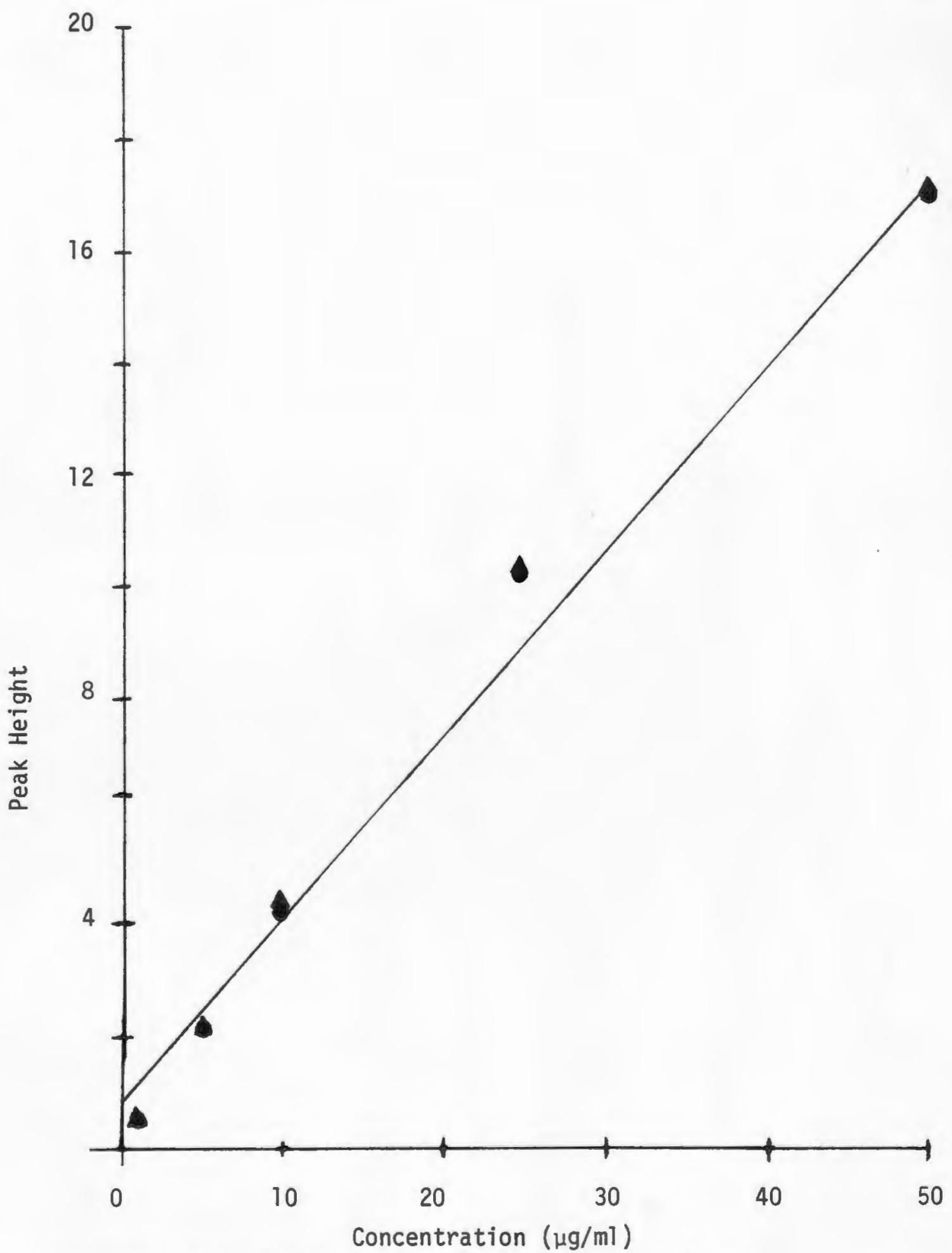

Fig. 33 Beer's Plot for Acetylsalicylic Acid Using HPLC

$\Delta$ Manual Slope 0.3468 ; Intercept $0.5913 ; r^{2} 0.9881 \ldots$

- Automatic Slope 0.3457; Intercept $0.5287 ; r^{2} 0.9827$ 


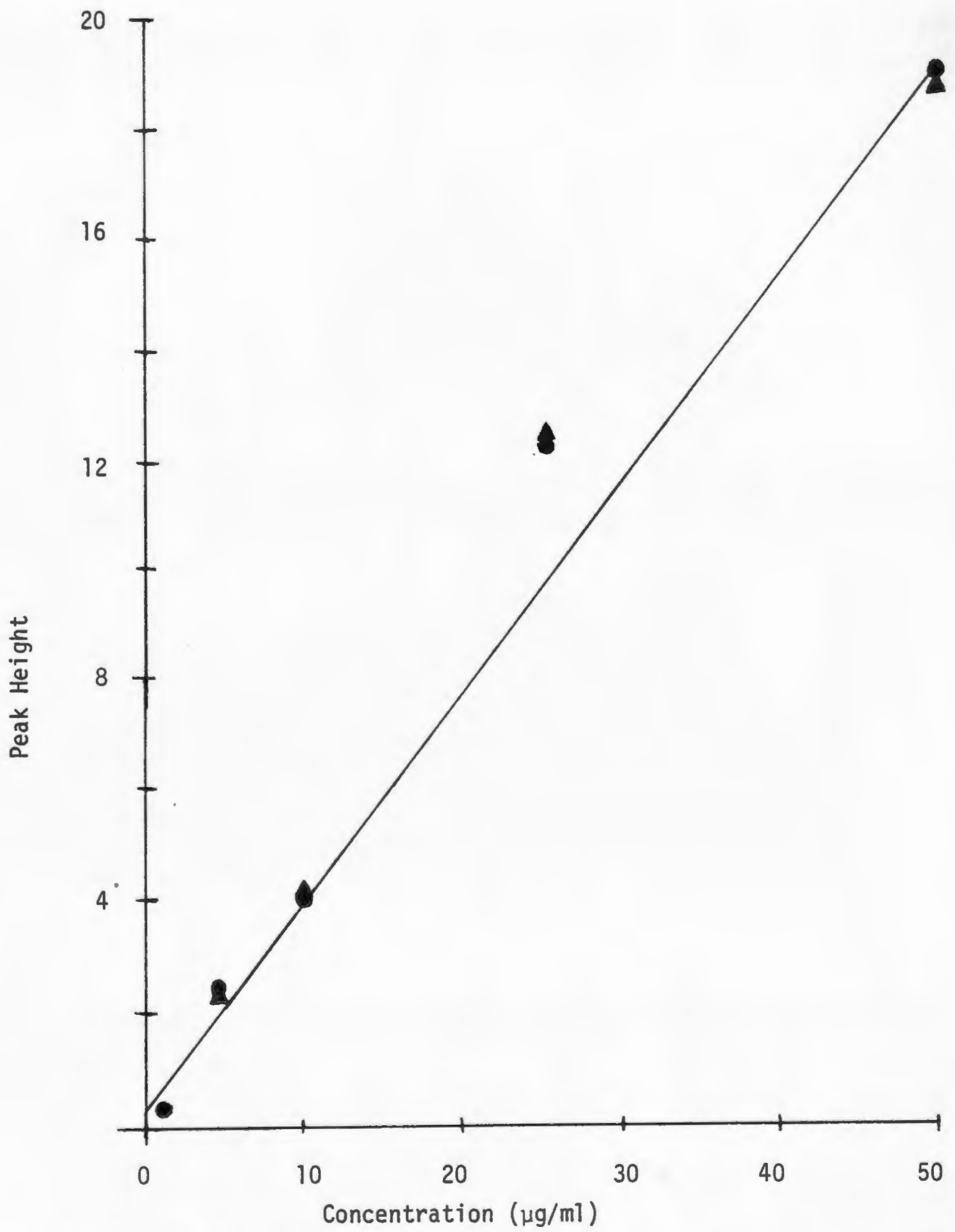

Fig. 34 Beer's Plot for Salicylic Acid Using HPLC

$\Delta$ Manual Slope 0.9384 ; Intercept $1.278 ; r^{2} 0.9727$

- Automatic Slope 0.9282; Intercept 1.164; $r^{2} 0.9785$ 


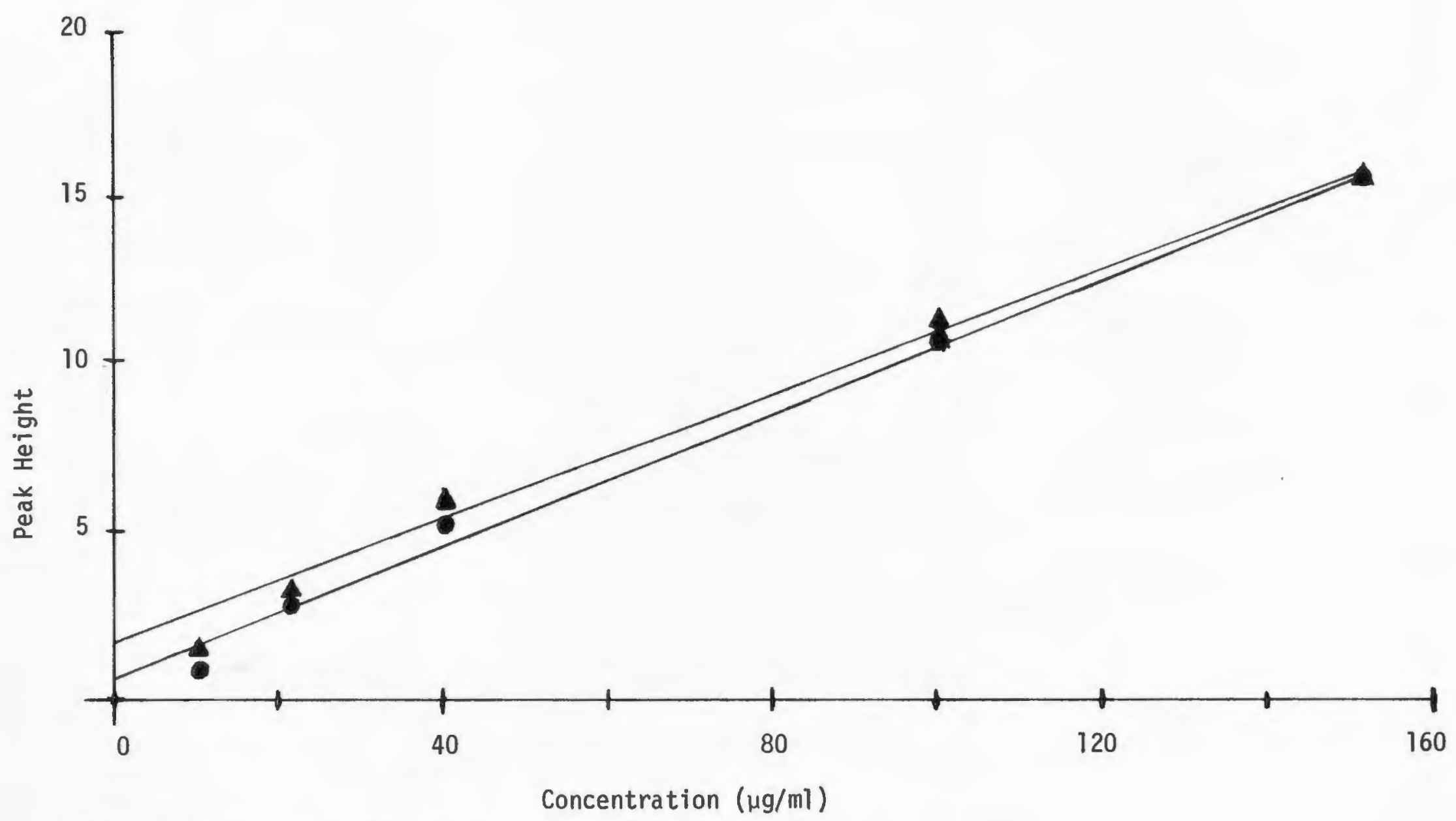

Fig. 35 Beer's Plot for Phenobarbital Using HPLC

$\Delta$ Manual Slope 0.1103 ; Intercept $-0.5075 ; r^{2} 0.9877$

- Automatic Slope 0.1060; Intercept $0.2270 ; r^{2} 0.9943$ 


\section{BIBLIOGRAPHY}

Adams, R. F., Adv. Chromatog., 15, 131 (1977).

Asher, W. J., Bovee, K. C., Frankenfeld, J. W., Hamilton, R. W., Henderson, L. W., Hotzapple, P. G., Li, N. N., Kidney Int., 7, s-409 (1975).

Asher, W. J., Vogler, T. C., Bovee, K. C., Hotzapple, P. G., Hamilton, R. W., Kidney Int., 10, s-254 (1976).

Autoan Computer Program, Publication Distribution Service, Ann Arbor, MI.

Baker, S. P., Dietze, P. E., "Injury Prevention," in Heal thy People, The Surgeon General's Report on Health Promotion and Disease Prevention, 1979.

Becher, P., Emulsions Theory and Practice, 2nd Ed., Reinhold Publishing Corporation, New York, NY, 1966.

Boyd, J., Parkinson, C., Sherman, P., J. Coll. Inst. Sci., 41, 359 (1972).

Brodin, A. F., Kavaliunas, D. R., Frank, S. G., Acta Pharm. Suecica, $15,1(1978)$.

Cahn, R. P., Li, N. N., Sep. Sci., 9, 505 (1974).

Chang, C. W., Fuller, G. C., Frankenfeld, J. W., Rhodes, C. T., J. Pharm. Sci., 67, 63 (1978).

Chilamkurti, R. N., Rhodes, C. T., J. Appl. Biochem., 2, 17 (1980). 
Clarke, E. G. C., Isolation and Identification of Drugs, The

Pharmaceutical Press, London, 1969.

Collings, A. J., Schneider, R., Br. J. Pharmacol., 38, 469p (1970).

Davis, S. S., Chemistry and Industry, 3, 683 (1981).

Flynn, G. L., Yalkowsky, S. H., Rosman, T. J., J. Pharm. Sci., 63, 479 (1974).

Frankenfeld, J. W., Asher, W. J., Li, N. N., "Symposium on Recent

Advances in Separation Science," American Chemical Society

Centennial Meeting, San Francisco, CA, August 30, 1976.

Frankenfeld, J. W., Fuller, G. C., Rhodes, C. T., Drug Dev. Commun., 2., 405 (1976).

Frankenfeld, J. W., Cahn, R. P., Li, N. N., Sep. Sci. Technol., 16, 385 (1981).

Garrett, E. R., J. Pharm. Sci., 54, 1557 (1965).

Groves, M. J., J. Pharm. Sci., 57, 1273 (1968).

Groves, M. J., Pestic. Sci., Nov/Dec., 274 (1970).

Groves, M. J., Analyst, 99, 599 (1974).

Groves, M. J., Chemistry and Industry, 17, 417 (1978).

Harrison, L. I., Funk, M. L., Ober, R. E., J. Pharm. Sci., 69, 1268 (1980).

Hogben, C. A. M., Turco, D. J., Brodie, B. B., Schanker, L. S., J. Pharmacol. Exp. Ther., 125, 540 (1957). Hogben, C. A. M., Turco, D. J., Brodie, B. B., Schanker, L. S., J. Pharmacol. Exp. Ther., 125, 275 (1959).

Kita, Y., Matsumoto, S., Yonezawa, D., J. Coll. Int. Sci., 62, 87 (1977). 
Kitagar'a, T., Nishikawa, Y., Frankenfeld, J. W., Li, N. N., Environ. Sci. Techno1., 11, 602 (1977).

Li, N. N., U. S. Patent 3, 410, 794 (1968).

Li, N. N., A.I.Ch.E.J., 17, 459 (1971).

Li, N. N., Ind. Chem. Proc. Des. Dev., 10, 215 (1971).

Li, N. N., Biochem. Biophys. Res. Commun., 47, 1179 (1972).

Lin, T. J., J. Soc. Cos. Chem., 19, 683 (1968).

Lin, T. J., Lambrechts, J. C., J. Soc. Cos. Chem., 20, 185 (1969).

Lin, T. J., Kurihara, H., Ohta, H., J. Soc. Cos. Chem., 24, 797 (1973). Loughnan, P. M., Sitar, D. S., Ogiivie, R. I., Neims, A. H., J. Pediatr., $88,869(1976)$.

Martin, A. N., J.Pharm. Sci., 50, 513 (1961).

Martin, A. N., Swarbrick, J., Cammarata, A., Physical Pharmacy, 2nd Ed., Lea \& Febiger, Philadelphia, PA, 1970.

Matthews, B. A., Rhodes, C. T., J. Pharm. Sci., 57, 557 (1968).

Matulevicius, E. S., Li, N. N., Sep. Purif. Methods, 4, 73 (1975).

McQuarrier, E. B., Andersen, H. P., Am. J. Clin. Nutr., 16, 23 (1965).

Modern Pharmaceutics, Banker, G. S., and Rhodes, C. T., Eds., Marcel Dekker, Inc., NY, 1979.

Mohan, R. R., Li, N. N., Biotechnol. Bioeng., 16, 513 (1974).

Parkinson, C., Sheman, P., J. Coll. Int. Sci., 41, 328 (1972).

Parrott, E. L., Pharmaceutical Technology, Fundamental Pharmaceutics,

Burgess Publishing Company, Minneapolis, MN, 1970.

Product Information, Waters Associates, Milford, MA, 1979.

Product Literature, The H.L.B. System, A Time Saving Guide to

Emulsifier Selection, ICI United States, Inc., Wilmington, DE., 1976. 
Reichmann, K. W., Petersen, R. V., J. Pharm. Sci., ó2, 1850 (1962).

Samyn, J. C., McGee, J. P., J. Pharm. Sci., 54, 557 (1968).

Schanker, L. S., Shore, P. A., Brodie, B. B., Hogben, C. A. M., J. Pharmacol. Exp. Ther., 120, 528 (1957).

Schanker, L. S., Turco, D. J., Brodie, B. B., Hogben, C. A. M. J. Pharmacol. Exp. Ther., 123, 81 (1958).

Shore, P. A., Brodie, B. B., Hogben, C. A. M., J. Pharmacol. Exp. Ther., 119,361 (1957).

Singleton, W. S., White, J. L., Benerito, R. R., Talluto, K. F., J. Am. $0 i 1$.Chemists' Soc., 35, 265 (1958).

Singleton, W. S., Benerito, R. R., White, J. L., J. Am. Oil Chemists' Soc., $37,88(1960)$.

Singleton, W. S., Brown, M. L., J. Am. 0il Chemists' Soc., 42, 312 (1965) .

System/360 Continuous System Model User's Manua?, 5tr, Ed., IBM Corporation, White Plains, NY, 1972.

Tingstad, J. E., J. Pharm. Sci., 53, 955 (1964). United States Pharmacopeia XX, Mack Publishing Company, Easton, PA, p. $1101,1980$.

Vold, R. D., Mittal, K. L., J. Pharm. Sci., 61, 769 (1972). Wallace, H. W., Asher, W. J., Zubroro, M. T., Stein, T. P., Brooks, H., J. Thorac. Cardiovas. Surg., 66, 887' (1973).

Wallace, H. W., Stein, T. P., Asher, W. J., Fed. Proc., 34, 1506 (1975). Whitehi11, D., Florence, A. T., J. Pharm. Pharmaccl., 31, 39 (1979). Willard, H. H., Merritt, L. L., Dean, J. A., Instrumental Methods of Analysis, 5th Ed., D. Van Nostrand Company, New York, NY, 1974. 
Yang, T. T., Rhodes, C. T., J. Appl. Biochem., 2, 7 (1980).

Zografi, G., "Emulsions," Chapter 16 of The Theory and Practice of

Industrial Pharmacy, Leon Lachman, Herbert A. Lieberman, Joseph L. Kanig, Eds., Lea \& Febiger, Philadelphia, PA, 1970. 